Florida International University FIU Digital Commons

3-29-2004

\title{
Student perceptions of the school physical fitness testing program : the Fitnessgram
}

Jacqueline Becker-Busha

Florida International University

DOI: $10.25148 /$ etd.FI14050467

Follow this and additional works at: https://digitalcommons.fiu.edu/etd

Part of the Curriculum and Instruction Commons

\section{Recommended Citation}

Becker-Busha, Jacqueline, "Student perceptions of the school physical fitness testing program : the Fitnessgram" (2004). FIU Electronic Theses and Dissertations. 1497.

https://digitalcommons.fiu.edu/etd/1497

This work is brought to you for free and open access by the University Graduate School at FIU Digital Commons. It has been accepted for inclusion in FIU Electronic Theses and Dissertations by an authorized administrator of FIU Digital Commons. For more information, please contact dcc@fiu.edu. 
FLORIDA INTERNATIONAL UNIVERSITY

Miami, Florida

\author{
STUDENT PERCEPTIONS \\ OF THE SCHOOL PHYSICAL FITNESS \\ TESTING PROGRAM: THE FITNESSGRAM
}

A dissertation submitted in partial fulfillment of the

requirements for the degree of

DOCTOR OF EDUCATION

in

CURRICULUM AND INSTRUCTION

by

Jacqueline Becker-Busha

2004 
To: Dean Linda Blanton

College of Education

This dissertation, written by Jacqueline Becker-Busha, and entitled Student Perceptions of the School Physical Fitness Testing Program: The Fitnessgram, having been approved in respect to style and intellectual content, is referred to you for judgment.

We have read this dissertation and recommend that it be approved.

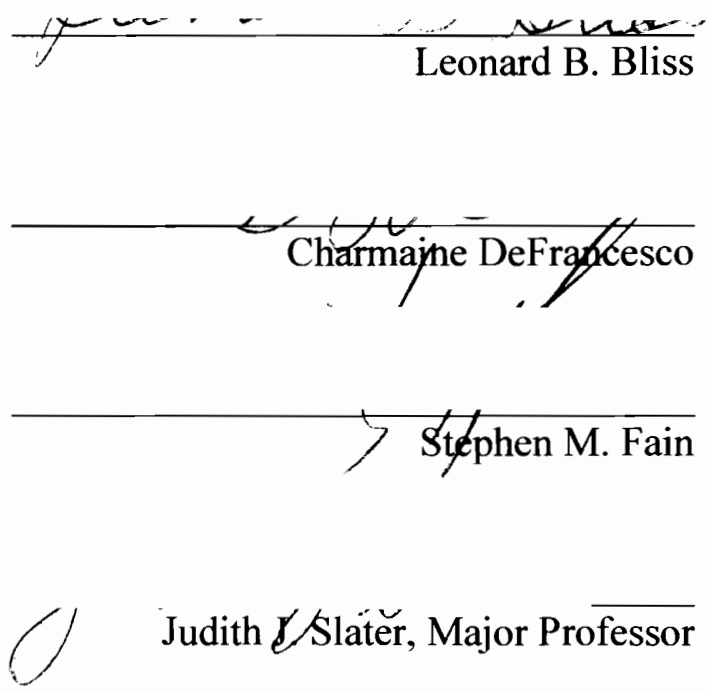

Date of Defense: March 29, 2004

The dissertation of Jacqueline Becker-Busha is approved.

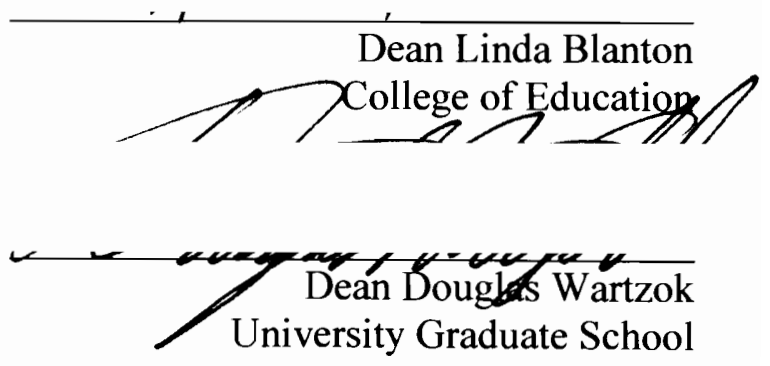

Florida International University, 2004 


\section{DEDICATION}

I dedicate this dissertation to my husband, children, and parents.

Bill, words will never express the admiration, respect and deep gratitude I have for you; my husband and best friend. Without your support, understanding, and help this work would not have been possible.

My wonderful boys Devin, Dylan, and Dawson; my little angels who unknowingly gave up so much of their mommy time: I love you with all my heart and soul always and forever.

My parents who have supported me from the beginning through thick and thin: You never gave up hope, which in turn gave me the confidence to see this journey through. Thanks Mom and Dad. 


\section{ACKNOWLEDGMENTS}

This long and laborious journey was possible only with the support and guidance of several individuals. Dr. Fain was always friendly, understanding, and willing to help. Dr. DeFrancesco's kind words of support such as “just do it!" often gave me the motivation to move to the next step. Dr. Leonard Bliss came on late in the process and offered to take on the extra work of yet another student. Dr. Trigoboff willingly shared a wonderful example, which helped tremendously. Dr. Linda Bliss, with her formatting expertise managed to edit this work in a timely manner. Dr. Slater, my major professor, wielded a firm and tenacious hand and always seemed to know just what to ask for. My brothers and sisters have supported my work; especially my sister Margie who was always there to help and never said no in all my times of desperation. Finally, I appreciate the support I received from the belated Dr. Ida Chadwick, who has been my inspiration for many, many years. 


\section{ABSTRACT OF THE DISSERTATION \\ STUDENT PERCEPTIONS OF THE SCHOOL}

PHYSICAL FITNESS TESTING PROGRAM: THE FITNESSGRAM

by

Jacqueline Becker-Busha

Florida International University, 2004

Miami, Florida

Professor Judith Slater, Major Professor

The purpose of this study was to determine fifth grade students' perceptions of the Fitnessgram physical fitness testing program. This study examined if the Fitnessgram physical fitness testing experience promotes an understanding of the health-related fitness components and examined the relationship between individual fitness test scores and time spent participating in out-of-school physical activity. Lastly, students' thoughts and feelings concerning the Fitnessgram experience were examined.

The primary participant population for the study was 110 fifth grade students at Redland Elementary School a Miami-Dade County Public School (M-DCPS). Data were collected over the course of 5 months. Multiple sources of data allowed for triangulation. Data sources included Fitnessgram test scores, questionnaires, document analysis, and indepth interviews.

Interview data were analyzed qualitatively for common broad themes, which were identified and defined. Document analysis included analyzing student fitness test scores and student questionnaire data. This information was analyzed to determine if the Fitnessgram test scores have an impact on student views about the school fitness-testing 
program. Data were statistically analyzed using analysis of frequency, crosstabulations (Bryman \& Duncan, 1997), and Somers' $d$ Correlation (Bryman \& Duncan, 1997).

The results of the analysis of data on student knowledge of the physical fitness components tested by each Fitnessgram test revealed students do not understand the health-related fitness components.

The results of determining a relationship between individuals' fitness test scores and time spent in out of school physical activity revealed a significant positive relationship for 2 of the 6 Fitnessgram tests.

The results of examining students' thoughts and feelings about each Fitnessgram test focused around 2 broad themes: (a) these children do not mind the physical fitness testing and (b) how they felt about the experience was directly related to how they thought they had performed.

If the goal of physical fitness was only to get children fit, this test may be appropriate. However, the ultimate goal of physical fitness is to encourage students to live active and healthy lifestyles. Findings suggest the Fitnessgram as implemented by M-DCPS may not be the most suitable measurement instrument when assessing attitudinal changes that affect a healthy lifelong lifestyle. 


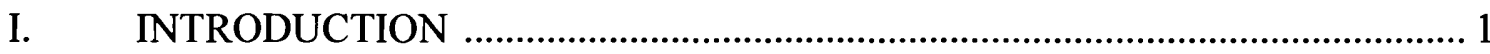

Background of the Problem ...................................................................................... 2

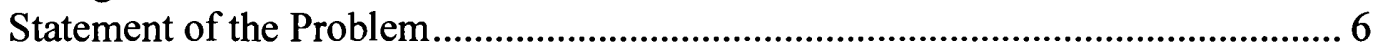

Purpose of the Study .................................................................................................... 6

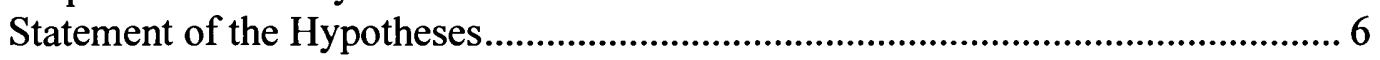

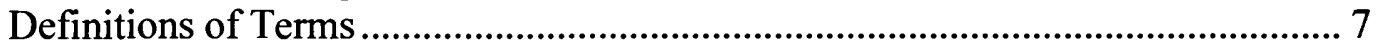

Limitations of the Study............................................................................................ 9

Assumptions............................................................................................................. 9

Organization of the Study ..................................................................................... 10

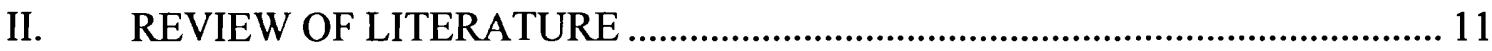

Society as a Source of Curriculum Decisions:

Societal Concerns Become Curriculum Concerns................................................... 11

Sources of Curriculum Development...................................................................... 16

Self-Preservation, Health and Wellness as Curricular Concerns.......................... 26

Recent Societal Health Concerns and Health Curriculum ....................................... 29

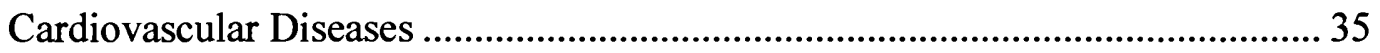

Physical Education Curriculum ............................................................................ 45

Miami-Dade County Public Schools Physical Fitness Testing............................. 49

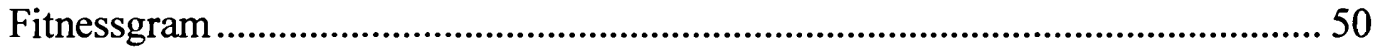

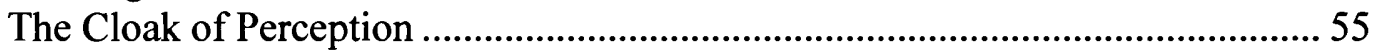

Physical Fitness Final Summary ........................................................................... 59

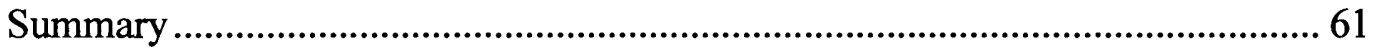

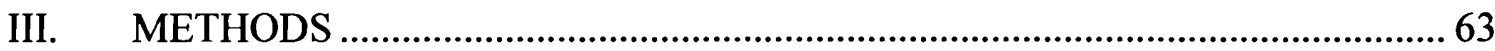

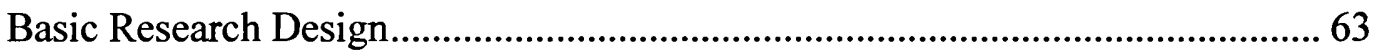

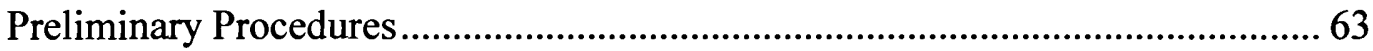

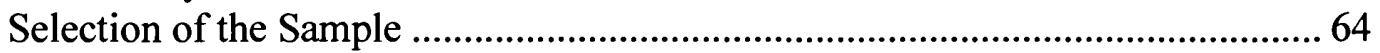

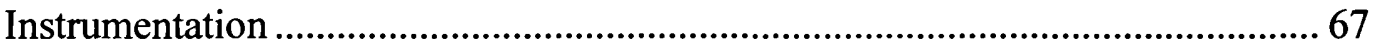

The M-DCPS Fitnessgram Physical Fitness Testing Program ........................... 67

Student Questionnaires Related To Each Fitnessgram Test ................................. 75

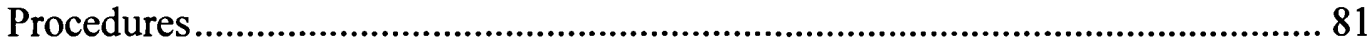

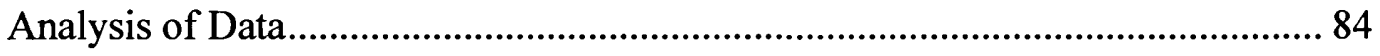

Summary of the Chapter ................................................................................... 86

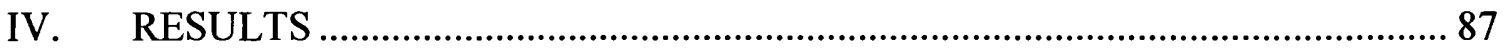

Quantitative Data Analysis ........................................................................... 88

Conclusion Concerning Student Knowledge of the Health-Related

Components of Physical Fitness 
Conclusion of Possible Relationship Between Individual Test

Performance and Time Spent Being Physically Active Outside of School....... 102

Qualitative Data Analysis ................................................................................... 102

Data Analysis ........................................................................................................... 104

Students' Knowledge of and Feelings about Their Fitnessgram Test Scores.... 106

Students' Feelings During the Fitnessgram Experience ........................................ 109

Students' Thoughts About Each Fitnessgram Test............................................... 115

Participants' Favorite and Least Favorite Fitnessgram Test............................... 123

Qualitative Summary ....................................................................................... 124

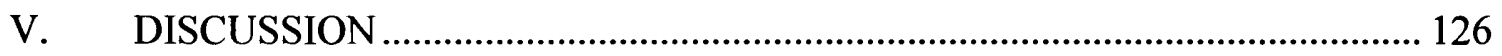

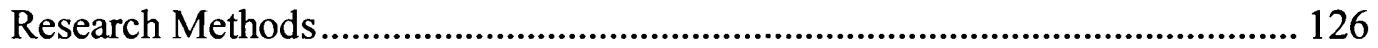

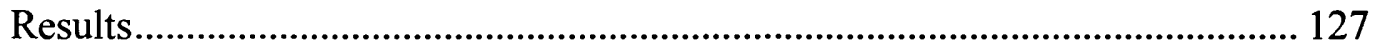

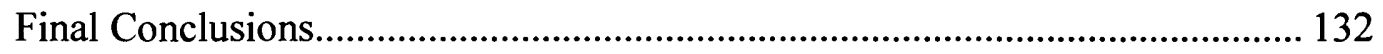

Implications for Miami-Dade County Public Schools........................................... 133

Recommendations for Miami-Dade County Public Schools ............................. 136

Recommendations for Further Research............................................................ 142

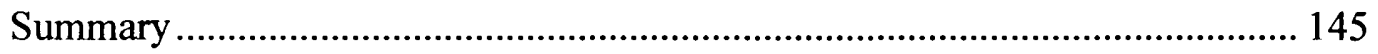

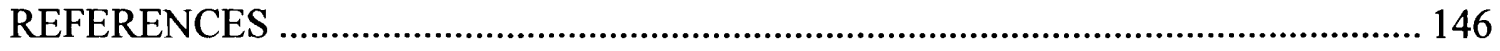

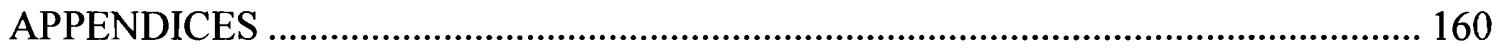

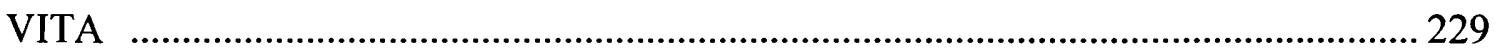




\section{LIST OF TABLES}

TABLE

PAGE

1. Physical Fitness Test Scores for Redland Elementary School.............................. 4

2. Fitnessgram Tests and the Health Related Fitness Component(s) Assessed ........53

3. Fitnessgram Test Results From Redland Elementary School for 1999-2003 ...... 54

4. $\quad$ Fitnessgram Total Award Winners, Gold Card and Silver Card

Award Winners At Redland Elementary School For Years 1999-2003 ................ 54

5. Research Question 1 Correlated to Student Questionnaire.................................... 77

6. Research Question 2 Correlated to Student Questionnaire.................................... 79

7. Physical Fitness Test and Current Fitness Component Answer ............................. 90

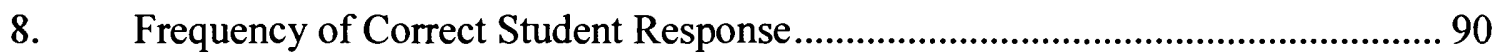

9. Common Themes of Physical Education Activities ......................................... 92

10. Common Themes Related to Health Components .............................................. 93

11. Frequency of Student Participation in Out of School Physical Activities ............ 95

12. Common Themes of Out of School Activities.................................................... 96

13. Crosstabulations Between Test Score and Amount of Time Spent Being Physically Active Outside of School .................................................................... 99

14. Student's Fitnessgram Test Raw Scores and Pass or Fail Status....................... 105

15. Positive (+) / Negative (-) Feelings For Each Test ............................................ 114

16. Favorite $(+)$ and Least Favorite (-) Fitnessgram Test Battery ............................. 123 


\section{LIST OF FIGURES}

FIGURE

PAGE

1. Philosophy of Education Curriculum.............................................................. 12

2. Tyler's Curriculum Rationale (Popham and Baker's Model) ................................. 18

3. Student's Knowledge and Feelings Related to Each Test .................................... 107

4. Feelings During Each Fitnessgram Test ............................................................ 110

5. Thoughts and Feelings During Each Fitnessgram Test .................................... 112

6. Students' Thoughts About the One Mile Walk/Run Test.................................... 117

7. Students' Thoughts About the Body Composition Test ....................................... 118

8. Students' Thoughts About the Curl-Up Test ...................................................... 119

9. Students' Thoughts About the Trunk Lift Test.................................................... 120

10. Students' Thoughts About the Push-Up Test.................................................. 121

11. Students' Thoughts About the Backsaver Sit and Reach Test............................ 122 


\section{CHAPTER I}

\section{INTRODUCTION}

When individuals are asked about childhood physical education experiences many most often recall participating in physical fitness testing. This is of no surprise since physical fitness testing was implemented during the 1960s and since then hundreds of thousands of American youth have participated in a variety of tests (Hopple \& Graham, 1995). These tests were specifically designed to ascertain the level of health-related fitness of students in the following areas: cardiovascular endurance, muscular strength, muscular endurance, flexibility, and body composition (Heyward, 1998). These tests remain one of the most common means of evaluation in physical education.

The necessity for physical fitness evaluation becomes obvious when we are reminded that the steady rise in mortality in the United States is due to chronic degenerative diseases, especially cardiovascular diseases (CVD). Haskell (1988) lists the 10 leading causes of death in the United States; and at the top of the list is heart disease. In 1993 diseases of the heart and blood vessels claimed the lives of over 954,000 individuals in the United States (Heyward, 1998). According to the American Heart Association (1995), 42\% of all deaths in the United States are linked to cardiovascular disease and more than 60 million Americans have some form of cardiovascular disease.

Physical inactivity is a positive risk factor for developing coronary heart disease (CHD). Physical activity and regular exercise can help prevent coronary heart disease. Physically active people have lower incidences of heart attacks and deaths due to CHD, and tend to develop CHD at a much later age when compared to sedentary individuals (Berlin \& Colditz, 1990). 
Concern about our nation's health has led many physical educators to believe that students will embrace the physical fitness testing experience and become motivated into an active lifestyle as adults based upon their fitness scores. Unfortunately, results are often the opposite of those physical educators strive to obtain. One reason for this is due to inappropriate practices when administering physical fitness tests. Some of the most common of these practices are: administering physical fitness tests only once a year for the purpose of qualifying children for school district awards; administering the physical fitness tests without providing children with an understanding why they are performing the test; and requiring children to take physical fitness tests without prior and adequate instruction, practice and conditioning (Graham, Holt/Hale, \& Parker, 1993). These inappropriate practices often cause children to become discouraged and turned off to the idea of fitness as part of their daily lifestyle (Pangrazi, 1998).

\section{Background of the Problem}

Over the past 15 years, Miami-Dade County Public Schools (M-DCPS) has incorporated physical fitness testing and evaluation into their physical education curriculum. Beginning with the 1988-89 school year, the "President's Challenge" was the preferred method of evaluating the fitness levels of children and youth ages 6-17 (MiamiDade County Public Schools, 1988). This test is outcome oriented, emphasizes level of skill, is norm referenced, and has a high failure rate. The President's Council on Physical Fitness and Sports, funded the National School Population Fitness Survey (Reiff et al., 1987), that showed only one-tenth of $1 \%$ of boys and three-tenths of $1 \%$ of girls could pass the six tests at the 85 th percentile, the standard indicated to earn the Presidential fitness award. With this standard obviously set too high, the National fitness award was 
created. The criterion for this award set a passing rate for each of the six tests at the 50th percentile or better. Unfortunately, students most often fail at least one of the tests causing them to earn no award at all and be identified as unfit. "Only $15 \%$ of boys and $19 \%$ of girls were able to pass the 50th percentile standard" (Pangrazi \& Dauer, 1995, p. 265). Miami-Dade County has since abandoned the "President's Challenge" and replaced it with the "Fitnessgram."

The Miami-Dade County Public Schools implemented the Fitnessgram test battery (One Mile Walk/Run, Body Composition, Curl-Up, Trunk Lift, Push-Up, and Backsaver Sit and Reach) into the curriculum beginning with the 1998-99 school year. The change in tests has partly been due to a recent emphasis on assessing a student's level of health rather than the student's level of skill (Miami-Dade County Public Schools, 1997). This test is process oriented, emphasizes the level of health, is criterion referenced, and has a higher passing rate when scores are compared to those of the "President's Challenge." Table 1 displays the fitness test scores for Redland Elementary School for the past 7 years. This table shows the improvement made when the new Fitnessgram assessment was implemented beginning with the 1996-1997 school year. The passing results of the Fitnessgram for this elementary school are higher than those of the "President's Challenge," however many children are still not testing at adequate fitness levels. This may be due in part, to the physical fitness testing protocol. Are evaluators unknowingly setting students up for failure? Or more importantly, does the scope of the physical education curriculum in M-DCPS include appropriate goals and objectives aimed at helping children reach adequate levels of physical fitness? 
Additionally, does this assessment instrument (the Fitnessgram) help children acquire the basic knowledge and understanding of the health-related physical fitness components?

Table 1

Physical Fitness Test Scores for Redland Elementary School.

\begin{tabular}{llccc}
\hline Year & $\begin{array}{c}\text { Fitness Test } \\
\text { Administered }\end{array}$ & $\begin{array}{c}\text { \# of Students } \\
\text { Tested }\end{array}$ & $\begin{array}{c}\text { Total } \\
\text { Winners }\end{array}$ & \% Winners \\
\hline & & & & \\
1997 & President's Challenge & 272 & 69 & $25 \%$ \\
1998 & President's Challenge & 285 & 53 & $19 \%$ \\
1999 & Fitnessgram & 312 & 176 & $56 \%$ \\
2000 & Fitnessgram & 347 & 225 & $65 \%$ \\
2001 & Fitnessgram & 332 & 250 & $75 \%$ \\
2002 & Fitnessgram & 341 & 245 & $72 \%$ \\
2003 & Fitnessgram & 404 & 314 & $78 \%$ \\
\hline
\end{tabular}

The Cooper Institute for Aerobics Research (where the Fitnessgram was created) purports that a short term objective of the Fitnessgram as part of a fitness program should provide students with opportunities to learn the fitness components while participating in fun fitness activities. Additionally, the long-term objectives of the Fitnessgram program is to teach students the skills they need to be active for life. These short and long term objectives are also emphasized by M-DCPS Division of Life Skills as part of their Fitnessgram physical fitness testing program. 
These questions present problems faced by educators and are most compelling because deep in the philosophical roots of education lies the belief that we should foster positive feelings and attitudes about physical education and well being in students (Shephard, 1995). The ultimate goal is to establish a foundation in which physical fitness and physical activity become a part of a daily healthy life. In 1992, the National Association for Sport and Physical Education (NASPE) outlined a universal purpose or ultimate goal of physical education within the "Outcomes Project." In this document, physically educated persons (among other things) regularly participate and select activities that will become a part of their lifestyle and understands the role regular physical activity plays in the pursuit of lifelong health and well-being (National Association for Sport and Physical Education, 1992). This has been identified as the ultimate goal of physical education; however, it is questionable whether or not the Fitnessgram encourages students to attain the goal of lifelong health and well-being. This work is appropriate for a study in Curriculum and Instruction because the Fitnessgram physical fitness testing program is the primary evaluation tool utilized in M-DCPS to measure students' fitness levels and it implies that through this tool, healthy lifestyles will be promoted. As a result, this program encompasses a large portion of the scope of the physical education curriculum. Many hours, days, and weeks are spent preparing students for and administering the Fitnessgram physical fitness tests. With so much instructional time being consumed by the administration of this assessment device it is important to examine whether students gain this insight from this segment of the curriculum. Furthermore, it is beneficial for educators to learn more about this test including whether it does contribute to students' understanding of the health related 
components of fitness and, to learn more about students' perceptions of the testing experience.

\section{Statement of the Problem}

This study was undertaken to investigate whether or not children who participate in the Fitnessgram physical fitness test have acquired a basic knowledge and understanding of its health-related physical fitness components. A secondary problem that was examined was whether there is any relationship between individuals' test scores and the amount of time they spend being physically active outside of the school setting as an indication that they have acquired a health conscience outlook. The final issue that was examined investigated the children's perceptions of the actual testing experience.

Purpose of the Study

The purpose of this study was to determine if the physical fitness test experience promoted an understanding of health-related physical fitness components and examined the relationship between individual test scores and time spent participating in out of school physical activity. Lastly, and just as importantly, an inquiry into students' feelings during the actual testing was conducted. With this information, educators may better understand how the Fitnessgram testing program affects their students' attitudes, knowledge, and participation in regular physical activity.

Statement of the Hypotheses

Upon review of related literature and similar studies, the following hypotheses were prepared:

Hypothesis 1: A significant number of students do not understand the basic health-related components tested with each Fitnessgram test component. 
Hypothesis 2: There is no relationship between whether students pass or fail the Fitnessgram tests and the length of time they spend being physically active outside of school.

Hypothesis 3: Students who scored well on the Fitnessgram tests have more positive attitudes about the fitness testing experience when compared to students who scored poorly.

\section{Definitions of Terms}

To ensure a clear understanding of expression and to provide consistency throughout the study, the following terms have been defined:

Body composition. The amount of fat cells compared to lean cells in the total body mass (Graham, Holt/Hale, \& Parker, 1993).

Cardiovascular disease (CVD). Diseases of the heart and blood vessels which include hypertension, coronary heart disease, congestive heart failure, and stroke (American Heart Association, 1995).

Cardiovascular endurance. The body's ability to undergo vigorous exercise for a long time (Graham, Holt/Hale, \& Parker, 1993).

Coronary heart disease (CHD). A disease of the blood vessels of the heart that causes heart attacks (Sandmaier, 1998).

Criterion-Referenced standards. Standards developed using scientific data relating to what is determined to be healthy or to cause improved health (Hinson, 1995).

Fitnessgram. Comprehensive fitness program which emphasizes knowledge, motivation, and assessment (Cooper Institute for Aerobics Research, 1992).

Flexibility. The range of motion of a joint (Hinson, 1995). 
Health-Related fitness. Fitness related to a person's risk for developing degenerative conditions and includes the following five components: body composition, cardiovascular endurance, muscular endurance, muscular strength, and flexibility (Hinson, 1995).

Skill-Related fitness. Fitness necessary for athletic accomplishment and is strongly influenced by genetics. Skill-Related Fitness components include agility, balance, coordination, power, and speed (Pangrazi, 2001).

Moderate physical activity. Physical activity that uses 150 calories of energy per day (Presidents Council on Physical Fitness and Sports, 1996).

Muscular endurance. A muscle's ability to produce power for a prolonged period of time (Graham, Holt/Hale, \& Parker, 1993).

Muscular strength. The amount of power a muscle can produce (Graham, Holt/Hale, \& Parker, 1993).

Norm-Reference standards. Standards which are determined by a reference group, a sample from the population for which the standards are generalized (Hinson, 1995).

Perception. The awareness or apprehension of the world through the senses (Horner \& Westacott, 2000).

Physical fitness. The condition of the body and its ability to perform activity (Hinson, 1995).

Physically educated person. Twenty major outcomes for a physically educated person are listed under five categories that cover the psychomotor, affective, and cognitive domains (Pangrazi, 1998). 
President's Challenge. Fitness test which measures skill-related fitness (Pangrazi, 2001).

Process evaluation. Related to performance of general movement patterns that emphasize proper form and technique (Pangrazi, 1998).

\section{Limitations of the Study}

The scope of this study was limited to the degree that:

1. Only students from Redland Elementary School in Dade County Florida participated in this study and therefore, the results may not be generalizable to other sites.

2. Only students who returned parental permission forms were allowed to participate in this study.

3. Only fifth grade students participated in this study. These results may not be generalizable to other grade levels.

\section{Assumptions}

The basic assumptions of this study included:

1. Redland Elementary School is representative of other elementary schools in Dade County.

2. The students who returned parental permission forms are representative of students who did not return parental permission forms.

3. The fifth grade students who participated in this study are representative of other fifth grade students. 


\section{Organization of the Study}

This study is presented in five chapters. Chapter I includes an introduction, a statement of the problem, the purpose of the study, the study hypotheses, definitions of relevant terms, and limitations and assumptions of the study. Chapter II is devoted to a review of the related literature including associated research and empirical findings. Chapter III describes the subjects, sampling procedures, treatment procedures, measuring tests and instruments, and the procedure used to conduct this study. Chapter IV consists primarily of the presentation of data along with the statistical analysis employed. Chapter $\mathrm{V}$ presents the summary, discussion, conclusions, and recommendations for future research. 


\section{CHAPTER II \\ REVIEW OF LITERATURE}

This review of literature is divided into three areas: society as a source of curriculum decisions; instances curriculum has been influenced by societal health concerns; and physical education curriculum and physical fitness testing. The first, society as a source of curriculum decisions, focuses on the aims of education, and models of curriculum development, all of which demonstrate the influence of societal needs in curriculum concerns. This is followed by a review of the literature demonstrating several instances in which school-based curriculum has been influenced by societal health concerns. Finally, the third area, physical education curriculum and physical fitness testing will tie together the previous areas of review; focusing on physical fitness tests included as part of the physical education curriculum.

Society as a Source of Curriculum Decisions: Societal Concerns Become

\section{Curriculum Concerns}

For decades, many of the major philosophies that direct and define curriculum have focused on society as a guiding force of curriculum concerns. Of course, the way society is viewed as a force in curriculum questions is quite different when viewed from each philosophical belief. Oliva (1992, p. 193) describes four major philosophies of education, from the most liberal to the most conservative. This continuum is shown in Figure 1.

The Reconstructionists' major premise is to make school a primary agency for social change. Proponents of this philosophy believe society can be improved and made better through education. "In essence, Reconstructionism holds that the school should not 


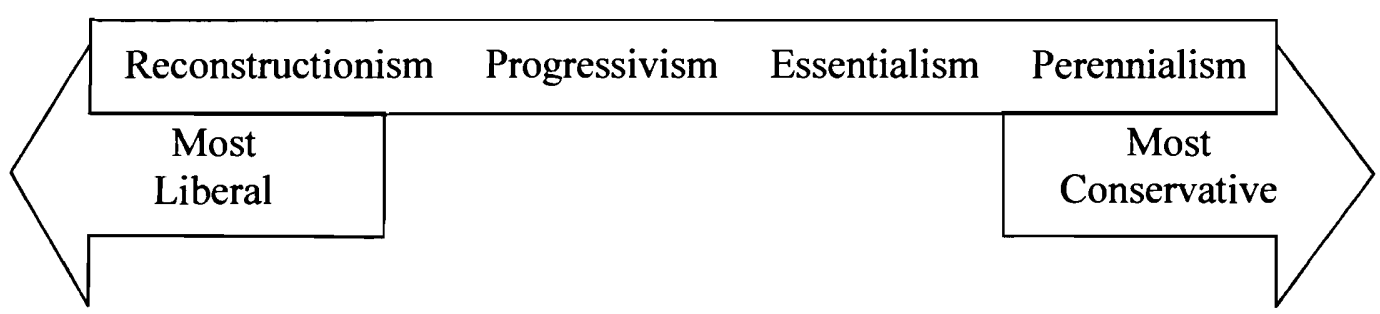

Figure 1. Philosophy of education continuum.

simply transmit the cultural heritage or simply study social problems, but should become an agency for solving political and social problems" (Oliva, 1992, p. 194). Kliebard (1992) describes those of similar beliefs under the banner of social meliorists, while Eisner and Vallance (1974) refer to them as social reconstructionists. Schubert's (1986) social behaviorists are described with similar characteristics and social reform goals.

Progressivism swept through the educational structure in the late nineteenth and early twentieth centuries. According to Tanner and Tanner, "Progressive schools of that era commonly designed their curricula so as to focus on such life-problem areas as personal and community health, conservation of natural resources, intercultural relations, world peace, consumer education, technology, housing, vocations and employment, economic relations, and so on" (1980, p. 144).

Progressivists believed that it was time to place the learner first; above the subject matter. Instead of tailoring the child to the curriculum (as advocated by Essentialists), the Progressivists created the child-centered school in which the needs and interests of the child were highly valued. Additionally, they believed that children learn best by experiencing their world, not by consuming predetermined content. The Progressivists also had a strong faith and allegiance to the concept of democracy. Hence, 
there was little room for the authoritarian teacher figure; instead the teacher and child were partners in the educational endeavor (Beyer \& Liston, 1996).

Some of the major scholars associated with the Progressive movement were Lester Ward, John Mayer Rice, and John Dewey. Ward's contribution to the Progressive movement emphasized the actual role of the school. By providing students with a realistic curriculum in "accurate touch with life" (Tanner \& Tanner, 1980, p. 289) children can experience that world (society) and learn from it. What children learned would in turn help them be more productive social problem solvers. Thus, Ward saw the purpose of the school as being one to improve society. To effect this change he believed there must be a strong relationship between the school and society. Rice was the founder of comparative methodology in educational research. In 1892 he surveyed American schools in 36 cities trying to discover what made some schools better than others. These comparative studies represented a new kind of scientific research in education and were his contribution to the Progressive movement (Schubert, 1986). According to Kliebard (1992) Dewey’s influence on the Progressive movement was strong; moreover, he spoke in the language of his contemporaries, but he meant something quite different. His position on curriculum issues were a re-interpretation of the ideas his colleagues were advocating.

The beginning of the Progressive movement is associated with the launching of Dewey's book The School and Society (1899) in which he establishes a link between the school and its society. Additionally Dewey proposed the idea of school as community and believed that a democratic community within the school offered hope for democratic reform of society in general. Democracy for Dewey was an "experience" rather than a form of government. Kliebard (1992) notes, 
Dewey certainly believed that in education lay the key to social progress. While the possibility exists, of course, that Americans share an inordinate faith in the power of education to correct social evils and promote social justice, inordinate or not, it became a powerful force in shaping of curriculum policy in the years to come. (p. 27)

Dewey and other progressivists emphasize education centering around the child's own experiences. On the other hand, Essentialists focus upon the importance of the subject matter, particularly cultivation of the existing heritage.

The main premise of Essentialism is that the purpose of schools is the transmission of cultural heritage. Followers seek to preserve society as it is and to adjust men and women to fit into the existing society. The goals of Essentialists focus on the cognitive and intellectual domains. The three R's and the hard academic subjects form the core of the Essentialist curriculum. They believe in tailoring the child to fit the curriculum. Additionally, Essentialists perceive education as preparation for some future purpose-for college, vocation, and life. Schubert's (1986) social behaviorism, as well as behaviorist principles in general, are in harmony with this philosophy.

The contemporary Perennialist sees the aims of education as disciplining the mind, developing the ability to reason, and the pursuit of truth. They believe that the truth is everlasting, unchanging, and eternal. They emphasize a highly academic curriculum focusing on grammar, rhetoric, logic, classical and modern languages, mathematics, and the great books of the Western World. In the great books one could find and study the truth, which in Perennialist thinking is the same today as it was in the past. The Perennialist agrees with the Essentialist in that education is preparation for life. Furthermore, the Perennialist looks back in time for the answers to social problems. 
Even though the four aforementioned philosophies or aims of education are quite different, they do have a commonality. Each one considers society in some way as a guiding force of curriculum concerns. In short, the Reconstructionists view the school as a primary agency for social change; the Progressivists view the school as a place where one can learn to improve society and correct social evils; the Essentialist strives to maintain society as it exists, to preserve it as it is; and the Perennialist looks back historically to the great books of the Western World to answer social problems.

Regardless of the belief, it is important to recognize that an important element in each is that school has a role in helping to meet society's needs. The resolution of social problems depends upon citizens who have the skill, knowledge, and inclination to tackle them. The kind of education the school provides causes the school to become a major factor in the improvement of society by helping young people develop the ability to respond intellectually to social problems. In this way whatever its underlying philosophy, the school serves not only the needs of the students but also the needs of the society.

If youth and children had no lives outside of the school environment, educators could simply ignore society as an influence on curriculum plans and intended outcomes. However, the fact is that young people do live in a world much larger than the schools. The world and their society influence both young people's attitudes and interests. Additionally, the school is an institution that is maintained, in part, by society, partly for the purpose of helping young people adapt to and prepare for life in society. Oliva (1992) writes, "The system that we call education responds to change as conditions in its suprasystem (society) change" (p. 45). For these reasons curriculum planners must 
consider the characteristics and needs of our current society as well as characteristics that are a prevision of the future. Tanner and Tanner (1980) write,

The survival of society is predicated upon its capacity to resolve practical problems - wide-ranging problems encompassing such varied concerns as water, food, energy, health, population growth, migration, ethnic relations, international relations, transportation, communication, housing, recreation, poverty, crime, employment, and so on. Thus society, of necessity, is mission-oriented. Its survival and prosperity derive from its capability of applying its knowledge to the resolution of practical problems. A host of institutions are created to accomplish this mission. The most global of these institutions other than government itself, is the educational institution - for it not only is concerned with the development of knowledge but also with making each rising generation more knowledgeable than its predecessor so as to make possible a better future society. (pp. 50-51)

\section{Sources of Curriculum Development}

Societal needs are often examined during the initial steps of curriculum development. This first step is most commonly referred to as the needs assessment. During the needs assessment three elements are considered: (a) the needs of the student, (b) the needs of society, and (c) the specific subject area needs (Tyler, 1949). These fundamental factors in the educative process have been considered for some time in the curriculum field. In 1902 Dewey noted the importance of: (a) the learner ("the immature, underdeveloped being"); (b) society ("certain social aims; meanings, values incarnate with the matured experienced adult"); and (c) organized subject matter ("the specialization and divisions of the curriculum") (pp. 4-8). Dewey warned these sources should not be considered separately but observed in "organic interaction" (p. 3).

Three decades later Boyd Bode (1931) observed that many of the conflicting curricular aims arise from three points of view or sources: (a) the viewpoint of the subject matter specialist, (b) the viewpoint of the practical man, and (c) the viewpoint or interest of the learner. Tanner and Tanner (1980) write "although Bode's second source may 
appear at first glance to be different from any of Dewey's sources, it actually corresponds to Dewey's second source, namely, 'certain social aims; meanings, values incarnate with the matured experience of the adults"' (pp. 79-80). Bode also expressed a warning that these sources should not be the only determinants in curricular concerns but that one must also examine what constitutes a good life in a good society.

Tanner and Tanner (1975) also observe that three major ends for schooling in the past have been proposed again and again:

Throughout the twentieth century educational opinion and practice have been sharply divided as to whether the dominate source and influence for curriculum development should be the body of organized scholarship (the specialties and divisions of academic knowledge), the learner (the immature developing being), or society (contemporary adult life).... (p. 95)

Similarly, Ralph Tyler's (1949) model of curriculum development most readily displays the needs of the students, society, and subject matter as sources from which tentative objectives are derived. Tyler did not arrange his curriculum development model into a diagram. However, W. James Popham and Eva L. Baker (1970, p. 87) did design an illustration which quickly and effectively displays the Tylerian model displayed in Figure 2.

In his book Basic Principles of Curriculum and Instruction Tyler (1949) lays out a 4-step approach to curriculum development. His approach to curriculum development is best known as "the Tyler rationale" and became the common sense approach to curriculum planning (Beyer \& Liston, 1996, p. 25). Elliot Eisner writes about Tyler:

What Tyler (1950) has given the field of curriculum through his monograph is a powerful, although in my view oversimplified, conception of what curriculum planning entails. Once learned Tyler's four questions are hard to forget. 
These questions are:

1. What educational purposes should the school seek to attain?

2. What educational experiences can be provided that are likely to attain these purposes?

3. How can these educational experiences be effectively organized?

4. How can we determine whether these purposes are being attained? (Eisner, 1994, p. 17)

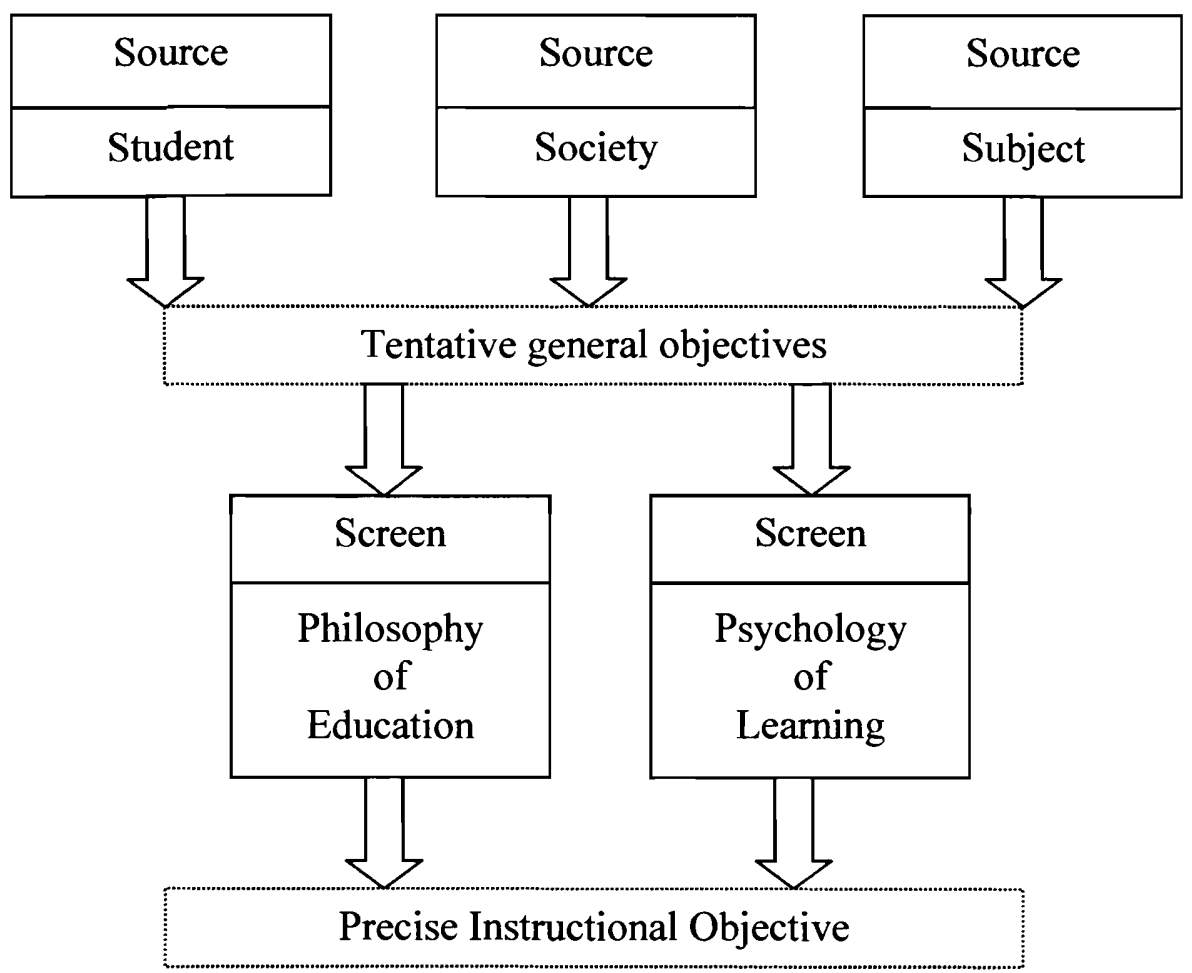

Figure 2. Tyler's curriculum rationale (Popham and Baker's model, 1970, p. 87).

The initial step of Tyler's model (selection of objectives from the three sources) has received a great deal of attention from other educators. These four fundamental questions must be answered when designing and developing a curriculum plan of instruction. However, in order to answer these questions effectively one must first examine the three sources of information. Tyler, like Bode and Dewey, also emphasized the importance of considering all three sources when developing a curriculum. Tyler (1949) stresses this point, “... no single source of information is adequate to provide a basis for wise and 
comprehensive decisions about the objectives of the school" (p. 5). Each of the three sources (students, society, and subject matter) has certain values that must be considered when planning any comprehensive curriculum program. Let us look further at this tripartite - learners needs, social needs, and subject area needs, in order to more closely examine the importance and relevance of each and what kind of information can be gained from each when considering them as a source in curriculum development.

It is vital that curriculum workers carefully study and analyze data which is relevant to students' needs and interest. Tyler (1949) defines the term "needs" in two ways. First, definition of "needs," according to Tyler, “. .. represents a gap between some conception of a desirable norm, that is, some standard of philosophic value and the actual status. Need in this sense is the gap between what is and what should be" (pp. 7-8). Tyler provides an example of children in the elementary school within a certain community who, after an investigation, are found to have dietary deficiency as well as poor physical condition. Tyler goes on to explain that these facts may suggest objectives in the area of health education, but that they suggest objectives only when viewed or compared to some conception of normal or desirable physical condition (p. 6). Tyler's second use of the term "needs" is one that refers to the "... tensions in the organism which must be brought into equilibrium for a normal healthy condition of the organism to be maintained" (p. 8). In order to maintain balance certain "needs" must be met. "In these terms one of the problems of education is to channel the means by which these needs are met so that the resulting behavior is socially acceptable, yet at the same time the needs are met and the organism is not under continuous, unrelieved tensions" (Tyler, 1949, p. 7). 
Schubert describes the basic human needs of food, shelter, clothing, water and oxygen, and social-cultural-biological needs of affection, love, and recognition (1986). Prescott (Cited in Tyler, 1949, p. 7) classifies the basic human needs into three categories: physical needs, social needs, and integrative needs. Physical needs include the need for food, for water, for activity and the like. Social needs include the need for belonging, for affection, for acceptance and respect from one's social group, and other similar needs. Integrative needs include the need for a basic understanding of life or the need for a philosophy of life. Oliva (1992) suggests analyzing the total range of needs such as educational, social, occupational, physical, psychological, and recreational. When considering these needs it is apparent that children share many of the same needs. "In this sense all children have the same needs and it is the responsibility of the school as with every other social institution to help children get these [physical, social, and integrative] needs met in a way which is not only satisfying but provides the kind of behavior patterns that are personally and socially significant" (Tyler, 1949, p. 7). When considering the student as a source of information concerning potential learning objectives, it is also important to consider students' interests in addition to their needs. This assertion is an extension of the Progressive education movement and theory that advocates the primary basis for developing educational objectives is derived from the interests of the learners themselves. For Tyler education is an interactive endeavor. "It involves the active efforts of the learner himself. In general, the learner learns only those things that he does. If the school situation deals with matters of interest to the learner he will actively participate in them and thus learn to deal effectively with these situations" (Tyler, 1949, p. 11). 
Tyler suggests several methods and techniques of social investigation for collecting data about students. Such methods include observations by teachers, student interviews, parent interviews, questionnaires, tests, community records, as well as school records. By examining students' needs and interests and incorporating the aforementioned techniques, the curriculum worker identifies a set of potential objectives.

Society has often influenced curricular decisions and has acted as a guiding force for school programs. "The function of the school and the model of curriculum embraced at a particular time are reflections of the demands and expectations of the larger society" (p. 148). Tanner and Tanner (1980, p. 148) continue " changing sociopolitical forces have exerted changing demands and expectations on the school. In various eras, the tendency is for the school to respond to whatever pressures are most dominant." Schubert (1986) agrees, "Today, it is quite evident that the values of society are perpetuated through schooling" (p. 197).

Tyler identifies two reasons to study society or, in his term, "contemporary life," to obtain educational objectives. The first reason is because contemporary life is so complex and life in society is continually changing. Therefore it is beneficial to study what is important at the present time and not waste time studying what was important years ago but is now outdated and has no current educational significance to the learner.

The second reason Tyler (1949) gives to study contemporary life grows out of findings related to transfer of learning.

Studies of transfer of training, however, indicated that the student was much more likely to apply his learning when he recognized the similarity between the situations encountered in life and the situations in which the learning took place. Furthermore, the student was more likely to perceive the similarity between the life situations and the learning situations when two conditions were met: (1) the 
life situations and the learning situations were obviously alike in many respects, and (2) the student was given practice in seeking illustrations in his life outside of school for the application of things learned in school. (pp.17-18)

The study of contemporary life is too vast to study as a whole unless, as Tyler suggests, curriculum planners develop a classification scheme in which this source can be broken down into manageable areas of investigation. It is important to identify subunits of observation in order to make sure no gaps occur and to make sure no important phase is omitted. Tyler provides such a classification scheme in which contemporary life can be studied: (a) health, (b) family, (c) recreation, (d) vocation, (e) religion, (f) consumption, and (g) civics. Tyler (1949) also provides an even more detailed classification when studying contemporary life. He reports that this classification was used in the Virginia State Curriculum Study and includes the following headings:

(a)Protection and Conservation of Life, (b) Natural Resources, (c) Production of Goods and Services and Distribution of the Returns and Production, (d) Consumption of Goods and Services, (e) Communication and Transportation of Goods and People, (f) Recreation, (g) Expression of Esthetic Impulses,

(h) Expression of Religious Impulses, (i) Education, (j) Extension of Freedom, (k) Integration of the Individual, and (1) Exploration. (p. 20)

No one classification of contemporary life is entirely satisfactory, but the purpose is to break down the huge concept of "life" into manageable subunits to ensure no area is omitted. Regardless of which classification system is used, its primary importance and purpose is to gain information about each subunit of contemporary life that is likely to have implications for educational objectives. From the study of society and contemporary life flows a prolific amount of data and information that can (when checked against other sources) be utilized as sources of potential learning objectives. 
The third source of data that can be utilized to obtain a set of tentative learning objectives is subject matter or subject specialists. This source of information is the one most commonly used in schools and universities. Many textbooks and courses of study are written by the subject specialist and largely reflect their views of the subject. Subject matter specialists are presumed to be up to date in their field, aware of the most recent discoveries in their particular area of interest and mindful of recent innovations; thus, they are assumed to possess a considerable amount of knowledge in their discipline. Schubert (1986) writes, “ the disciplines are the most important conceptual pillars of knowledge that should be learned, and subject matter specialist can best tell us what the structure of each discipline is" (p. 198).

Others have criticized the use of subject specialists arguing that the objectives they propose are often too specialized and technical; making them inappropriate for a large number of students. Tanner and Tanner (1980) explore this problem finding, "The influence of subject-matter specialists has been so pervasive that the curriculum often is conceived as merely a total list of separate subject matters with courses designed within the confines of each subject matter domain" (p. 160). Alfred North Whitehead (1929) also addressed this problem when he urged educators, "to eradicate the fatal disconnection of subjects which kills the vitality of our modern curriculum" (p. 10). Tyler (1949) also recognized this problem of curriculum fragmentation that may be brought on by knowledge specialization. Tyler assumes this problem can be solved by the subject matter specialist themselves if they ask the following questions: "What can your subject contribute to the education of young people who are not going to be specialists in your field; what can your subject contribute to the layman, the garden variety of citizen?" 
(1949, p. 26). If the subject specialists can answer these questions they should be able to suggest possible curricular contributions for the general population.

Tyler (1949) suggests that in many curriculum reports (written by various subject specialist groups) the subject specialists are making helpful suggestions to answer the aforementioned questions. Tyler goes on to say that many of these reports begin with an outline emphasizing the important conceptions of the field itself. He then moves on to make suggestions in ways the field can contribute to general education. Tyler says two kinds of suggestions can be obtained from these reports as far as learning objectives are concerned. "The first is a list of suggestions regarding the broad functions a particular subject can serve, the second is with regard to particular contributions the subject can make to other large functions which are not primarily functions of the subject concerned" (pp. 27-28). Tyler (1949) gives several illustrations in which these two types of suggestions can be gained from the reports. One illustration he provides is from a report of science committees.

One such report suggests three major functions sciences can serve for the garden variety of citizen. The first of these is to contribute to the improvement of health, both the individual's health and public health. This includes the development of health practices, of health attitudes and of health knowledge, including an understanding of the way in which disease is spread and the precautions that can be taken by the community to protect itself from disease and from other aspects of poor health. (pp. 29-30)

The second function of science according to this report deals with the use and conservation of natural resources. "The third function of science is to provide a satisfying world-picture, to get clearer understanding of the world as it is viewed by the scientist and man's relation to it, and the place of the world in the larger universe" (p. 30). From these suggested functions of science one can gather many important objectives from the 
field, objectives not only relating to science but also science related attitudes, knowledge, interests and problem solving. By this we observe not only the function of the particular subject but also more specific contributions the subject can make to broaden educational functions.

When considering subject matter as a source one must also examine scope. Scope is often defined as "the breadth" of the curriculum (Oliva, 1992; Pinar, Reynolds, Slattery, \& Taubman, 1995). Goodlad and Su (1992) refer to scope as curriculum viewed horizontally "across, for example, the array of courses offered by a secondary school in a given year to those taken or to be taken by a given student" (p. 330). Additionally, the scope of a particular grade level or subject is the summed content including topics, learning experiences, and activities for that grade level or subject. "When teachers select the content that will be dealt with during the year they are making decisions on scope. When curriculum planners at the district or state level set the minimum requirements for graduation from high school they are responding to the question of scope" (Oliva, 1992, p. 507). The horizontal organization becomes a concern when considering subject matter as a source because the scope of information available to scholars and subject matter specialists is enormous. "Estimates of the rate at which organized knowledge doubles its volume ranged from every seven years in the mid-1960s to every two years by the mid1970s" (Wiles \& Bondi, 1984, p. 31).

If the information explosion continues at the present pace, by the time a child born today graduates from college, the amount of information in the world will have increased fourfold. By the time the child is 50 years old, information will have increased 32 times, and 97 percent of everything known in the world will have been learned since the child was born. (Lewis, 1979, p. 2) 
Curriculum planners, with the help of subject matter specialists, must choose the basic knowledge, skills, and concepts from each discipline to be included in the curriculum. "A central problem of this horizontal organization that we call scope is the delimitation of the concepts, skills, and knowledge to be included" (Oliva, 1992, p. 508).

The needs of students, the needs of society, and the needs of subject matter specialists influence the scope of the curriculum. In the field of health and physical education these needs converge and the schools are called upon to help solve many health-related problems experienced by today's youth.

When analyzing Tyler's three sources and the philosophy behind the Fitnessgram an obvious relationship emerges. The needs of students include health, fitness, and fun. The needs of society center around society's unhealthy and unfit lifestyles. The subject area needs focus around the Fitnessgram program. Tyler explains that "needs" represent a gap between a desired norm and the actual status (Tyler, 1949, pp. 7-8). There is a huge gap between the desired health levels of Americans and their actual state of health. This is but one example; the schools have often been called upon to meliorate many other social ills centering on health and wellness.

Self-Preservation, Health and Wellness as Curricular Concerns

For centuries, self-preservation, health, and wellness have been social concerns as well as a part of curriculum concerns. In 1860 Herbert Spencer asked, "What knowledge is of most worth?" He answered his own question by focusing on science as the relevant subject matter for preparing children for complete living. According to Spencer, the key to complete living is science: "for preservation of health, earning a living, effective parenthood, good citizenship, the highest production and enjoyment of the arts, and 
intellectual and moral discipline" (Tanner \& Tanner, 1980, p. 143). Spencer deemed the only way of determining the worth of an educational program was to first classify the leading activities of life, and then evaluate the educational program by the extent to which it prepared children for these activities of life. According to Tanner and Tanner (1980),

Spencer's classification of life activities, in order of their importance, was as follows:

1. Those ministering directly to self-preservation.

2. Those securing the necessities of life (ministering indirectly to selfpreservation).

3. Those which aid in the rearing and discipline of offspring.

4. Those involved in maintaining one's social and political relations.

5. Those which occupy the leisure part of life, gratifying tastes and feelings. (p. 217)

It is significant to note the most important life activities according to Spencer were those directly related to self-preservation. Similarly, in 1918 the Cardinal Principles of Education included health as the most important and the first of seven objectives of education.

"One of the most influential documents in the United States education was the pamphlet Cardinal Principles of Education, a statement of seven goals issued in 1918 by the NEA Commission on the Reorganization of Secondary Education" (Haas, 1994, p. 47). Since its publication in 1918 over 150,000 copies have been sold giving it the status as a "government best seller." But, more important is the fact that this document has influenced thousands of curricular programs. Additionally, it has encouraged a shift in the purpose of education in American secondary education programs. Formerly, the focus was college preparation for the few and then a shift to life preparation for the many. According to Gross (1978), 
Sixteen specialized committees, issuing as many preliminary reports on topics ranging from art to vocational education, preceded the synthesis embodied in the final Seven Cardinal Principles. These were enumerated as follows by the commission:

1. Health. "The secondary school should provide health instruction, inculcate health habits, organize an effective program of physical activities..."

2. Command of fundamental processes. "Proficiency [in reading, writing, arithmetical computation, and elements of oral and written expression] may be increased more effectively by the application of new material..."

3. Worthy home membership. "This objective applies to both boys and girls."

4. Vocation. "Vocational education should equip the individual to secure a livelihood for himself and those dependent on him... and, as far as possible, to find in that vocation his own best development."

5. Civic education. "[This] should develop in the individual those qualities whereby he will act well his part as a member of neighborhood, town or city, state, and nation, and give him a basis for understanding international problems."

6. Worthy use of leisure. "Education should equip the individual to secure from his leisure the re-creation of body, mind, and spirit..."

7. Ethical character. "In a democratic society ethical character becomes paramount among the objectives of the secondary school." (pp. 291-292)

In the years following 1918, there was the worst influenza epidemic in American history and thousands of men, women, and children died. Other dangerous diseases were common as well, and the need for personal and community hygiene was obviously important. Health was understandable as a first priority.

Health and physical well-being continued to surface as goals to be considered in schooling in the United States. In 1984 John Goodlad (1984) and his colleagues addressed themes of social purposes served by the schools and generally accepted goals for schooling in the United States to include a section on "emotional and physical wellbeing." More specifically this section addressed the need to "develop a knowledge of one's own body and adopt health practices that support and sustain it, including avoiding the consumption of harmful or addictive substances" (p. 50), and among other related goals to "develop physical fitness and recreational skills" (p. 50). 
Self-preservation, health, and wellness have been the cornerstone of many curriculum projects. These three aforementioned topics have often been noted under the banner of "processes of life." These have often been considered the focus in curriculum organization. Taba (1962) states, "Perhaps the best known attempt to organize the curriculum around the processes of life was the Virginia State Curriculum program" ( $p$. 398). O.I. Frederick and Lucile J. Farquear reported nine areas of life processes that were incorporated and used for curriculum organization in Virginia, as well as several other Southern states. The following are the nine areas of life as reported by Frederick and Farquear (1937): “1. Protecting life and health, 2. Getting a living, 3. Making a home, 4. Expressing religious impulses, 5. Satisfying the desire for beauty, 6. Securing education, 7. Cooperating in social and civic action, 8. Engaging in recreation, and 9. Improving material conditions" (pp. 672-679).

For decades curriculum planners have considered life processes and, more specifically, self-preservation, health and wellness as a guiding force when considering the scope of the curriculum. More recently there have been several instances in which the scope of the curriculum has been influenced by the health concerns of our nation.

Recent Societal Health Concerns and Health Curriculum

The scope of the curriculum has recently been affected by many health concerns of our nation. The convergence of societal concerns (or needs) and students' needs are apparent when we analyze some of the health-related problems experienced by today's youth. Not only are schools offering its young people programs focusing on physical fitness, nutrition and health, but these programs have also been confronted with a number of health related problems or national health crises which have demanded the attention of 
curriculum planners. The schools have been called upon, once again, to act as the cure all of society's ailments. More specifically schools are being asked to respond to such problems as substance abuse, tobacco use, teen pregnancy, and rates of youth contracting acquired immune deficiency syndrome (AIDS) and other sexually transmitted diseases.

The statistics on these health related problems in our nation are alarming. Thus, the scope of the curriculum has expanded in order to include additional preventive programs that encompass knowledge and strategies to combat these problems.

There are currently numerous preventive programs of all types offered in schools each year. Surveys indicate that over $70 \%$ of all school districts have some type of curricula designed to prevent smoking, alcohol use, drug use, and physical health problems in children (Holtzman et al., 1992); 85\% of school-aged children receive some form of sex education (Alan Guttmacher Institute, 1994). As a result millions of schoolaged children are exposed to some type of prevention oriented programs and many children are exposed to more than one. School-based prevention has become very popular within the past decade, and for good reason when analyzing trends of some of our nation's most obvious public health problems.

Currently there are 65 million people living in the United States with an incurable sexually transmitted disease (STD). Each year an additional 15 million of them contract lifelong infections (Cates, 1999). Teenagers account for approximately one-fourth of these new infections (Centers for Disease Control and Prevention, 2000). Nearly four million of the new cases of STDs each year occur in adolescents (U.S. Department of Health and Human Services, 2000). The total cost of most STDs and their complications 
is conservatively estimated at $\$ 17$ billion annually (Institute of Medicine, 1997). These infections comprise a significant public health problem.

The U.S. government has been proactive in attempting to control this epidemic through education.

Prior to the Education (No. 2) Act 1986, there were no specific obligations resting with schools and local education authorities (LEAs) concerning the provision of sex education or its content. Under that Act, however, it became mandatory for schools governing bodies both to determine their policy on whether sex education should form part of the secular curriculum and to ensure that, when sex education was given, moral values were promoted. Today, following the enactment of the Education Act 1993, sex education provision is compulsory for children of secondary school age, subject to a parental right of exemption in respect of their child. (Harris, 1996, p. 1)

AIDS education is a much more recent phenomenon that has demanded the attention of school agencies. AIDS education is now mandated or recommended by all 50 state departments of education (Kirby et al., 1994).

Two controlled studies of AIDS education offered to inner-city Latino and African American adolescents show significant differences favoring program participants over comparison groups. Program participants displayed more positive results in terms of greater condom use, less sex with high-risk partners, and sex with fewer partners (Jemmott, Jemmott \& Fong, 1992; Walter \& Vaughan, 1993). Additionally, under former Mayor Sharon Pratt Kelly, the District of Columbia implemented the Adolescent AIDS Prevention Program in all of its public senior high schools and in four junior high schools in September 1992. “The program was part of Mayor Kelly’s response to the rising incidence of HIV infection in the District. The program's objective is to prevent the spread of HIV infection among high school students in the D.C. Public Schools through a combination of (1) prevention education, (2) individual counseling, and (3) condom 
access" (United States General Accounting Office, 2000). As a result of this program there were fewer than five new cases of AIDS reported for D.C. teenagers aged 13-19 in 1999 and there have been fewer than 10 newly reported cases for D.C. teenagers in any given year since program implementation in 1992 (United States General Accounting Office, 2000). In this same report D.C. public schools also indicate a decline of the number of pregnancies among its public high school students since the 1992-93 school year.

"Few teens plan their first intercourse; $21 \%$ never use contraception, accounting for $75 \%$ of approximately one million teenaged pregnancies per year, involving four out of ten girls before they turn 20" (Hedgepeth \& Helmich, 1996, p. 7). In 1998, the birth rate in the United States was 52.1 per 1,000 females aged 15-19 (Centers for Disease Control, 2002). "Adolescent mothers are at risk for chronic educational, occupational, and financial difficulties, and their offspring are also at risk for medical, educational, and behavioral problems. In fact, intergenerational effects are possible, given that the offspring of adolescent mothers are more likely to become pregnant when they reach adolescence" (Durlak, 1995, p. 67). Thus, the prevention of unwanted teen pregnancies can have substantial practical significance for our nation.

In 1996 the welfare reform law defined "abstinence education" as an educational and motivational program that includes: teaching the social, psychological, and health gains of abstaining from sexual activity; teaching abstinence outside of marriage as the expected standard; teaching abstinence is the only way to prevent sexually transmitted diseases and out-of-wedlock pregnancy; and teaching that a mutually faithful 
monogamous relationship within a marriage is the expected standard (House of Representatives, 2002).

Nationally, the birth rate for adolescents dropped more than one-fifth between 1991 and 1998, which indicates a promising national trend and the possibility that abstinence-only education is working (United States General Accounting Office, 2000). Even in light of these promising results, teen pregnancy continues to be a national concern. Similarly, substance abuse is another area of national concern that has received much needed attention.

Drugs and alcohol abuse are major problems in the United States. Youth today are experimenting with a wide variety of illicit drugs including marijuana, cocaine, heroin, acid, inhalants, and methamphetamines, as well as, the abuse of prescription drugs, street drugs and alcohol.

In 1994 more than 25 million people were estimated to have used an illicit drug in the past year; 3.9 million used cocaine, and about 350,000 used heroin. A large proportion of illicit drug users are marijuana users. Additionally, about 140 million people aged 12 and older were estimated to have used alcohol in the past year, and about 73 percent of high school seniors surveyed had consumed alcohol in the past year (Drug And Alcohol Abuse: Billions Spent Annually for Treatment and Prevention Activities, October 1996, p. 1). Of any industrialized nation, the United States has the highest teen alcohol-and drug abuse rate. (At-Risk and Delinquent Youth: Multiple Federal Programs Raise Efficiency Questions, March 1996)

To help combat drug and alcohol abuse, the Anti-Drug Abuse Act of 1988 (P.L. 100-690) was passed. This public law requires the Office of National Drug Control Policy (ONDCP) to develop a national drug control strategy, in consultation with agency and department heads and others involved in drug control matters. The strategy is 
submitted annually to Congress with the President's approval (Drug And Alcohol Abuse: Billions Spent Annually for Treatment and Prevention Activities, October 1996).

Preventative programs are the key to this public problem. The younger a person becomes a habitual user of illicit drugs, the stronger the addiction and the more difficult it is to stop use. Treatments for individuals who have established habits of drug taking typically show limited success and relapse to prior drug habits is high (Schinke, Botvin, \& Orlandi, 1991). Because of this, it makes sense to intervene to prevent drug use among school-aged children.

Drug prevention programs are the most popular school based preventive interventions. Most school districts have included some type of drug education and prevention programs into the curriculum. Most of the current programs are educational in nature and funded by the federal government. For example, Project Dare, a federally funded program conducted and taught by police officers, has been used in over $50 \%$ of all school districts nationwide (Ennett, Tabler, Ringwalt, \& Flewelling, 1994).

Durlak (1995) indicates that prevention works, "in the sense that participants display increased competencies and reduced problems following intervention" (p. 33). The practice of school based prevention is impressive. Surveys indicate that more than $70 \%$ of all school districts have received curricula designed to prevent such things as smoking, alcohol use, drug use, and physical health problems in children (Holtzman et al., 1992).

Preventable physical health problems of school-aged children are a growing area of school-based prevention programs. These programs focus primarily on emerging habits and lifestyles that affect health. 
The literature makes it clear that youth today are faced with many health-related problems.

Depending on the criteria and methodology used, up to $30 \%$ of children have elevated total cholesterol levels, $5 \%$ have hypertension, $15 \%$ are obese, $60 \%$ do not get adequate exercise, and approximately one fifth of high school seniors are regular smokers. In fact, up to $60 \%$ of children have at least one risk factor for coronary heart disease by age 12 . (Durlak, 1995, p. 59)

Coronary heart disease could prove to be our nation's toughest fight thus far.

\section{Cardiovascular Diseases}

Cardiovascular diseases such as coronary heart disease and stroke are the number one killers of all Americans. Haskell $(1988$, p. 74$)$ lists the 10 leading causes of death in the United States and at the top of the list is heart disease. In the 1996 Surgeon General's Report on Physical Activity and Health (U.S. Department of Health and Human Services, 1996) coronary heart disease in the United States had a higher mortality rate than all types of cancer combined. This disease is thought to begin in childhood and results in atherosclerotic plaques or fatty substances in the arteries of the heart which reduces blood flow and oxygen delivered to the heart (The President's Council on Physical Fitness and Sports, 1996). Before the 1970s the common wisdom was that heart disease was of geriatric origin and was found only in older adults. In 1973 Glass conducted a study in the Iowa public schools. A sample of 5,000 youngsters was examined over a 2-year period. Of these students, $70 \%$ had some symptoms of coronary heart disease. "Coronary heart disease, once considered to be a geriatric problem, is now recognized as being largely of pediatric origin" (Wilmore \& McNamara, 1974, p. 531). Kimm and Kwiterovich (1995, p. 269) go on to explain that many adulthood chronic diseases have their "biological and ecological roots in childhood." As reported by the American 
Academy of Pediatrics (Olsen, 1990), a startling 40\% of children ages 5 to 8 have at least one risk factor for coronary heart disease. These cardiovascular diseases kill hundreds of thousands of Americans each year.

Each year about 165 of every 100,000 women and 265 of every 100,000 men in the United States die of heart disease, making it the number one killer of both American women and men. About 12 million people in the United States have coronary heart disease (U.S. Department of Health and Human Services, 2000). But what is heart disease and what are cardiovascular diseases? Cardiovascular diseases include coronary heart disease, heart attack, high blood pressure, stroke, angina, and rheumatic heart disease. These are diseases of the heart and blood vessel system (Sandmaier, 1998). Coronary heart disease is a disease of the blood vessels of the heart. It is a condition in which the blood flow to the heart muscle is lessened. The heart, like any other muscle of the body, needs a constant flow of oxygen and nutrients, which are carried to it by the blood in the coronary arteries. When these coronary arteries become clogged or are narrowed by fatty substances of plaque, they cannot supply enough oxygen to the heart. If the heart is not supplied with enough oxygen carrying blood, the heart responds with angina or pain. When blood flow to the heart is cut off completely a heart attack occurs. As a result of a heart attack part of the heart muscle dies from not receiving enough oxygen (U.S. Department of Health and Human Services, 2000). In the United States each year about 1.1 million people experience a heart attack. In $1996,476,000$ people died as a result of heart attacks (National Heart, Lung, and Blood Institute, 1998). The risk of heart attack and coronary heart diseases can be reduced by controlling the risk factors associated with coronary heart diseases (CHD). 
Risk factors associated with coronary heart diseases include: smoking, high blood pressure, high blood cholesterol, diabetes, being overweight, and physical inactivity. While one risk factor will increase the chances of developing heart related problems, if there is more than one risk factor present the possibility of developing heart related diseases increase even more. For example, if a person smokes and has high blood pressure the chances of developing coronary heart disease go up dramatically. But if a person smokes, has high blood pressure, and also has high cholesterol, then the risk of developing CHD is 5 times higher than a person with no risk factors (Sandmaier, 1998).

Smoking is the single most preventable individual risk factor associated with CHD. "Smoking results in more deaths each year in the United States than AIDS, alcohol, cocaine, heroin, homicide, suicide, motor vehicle crashes, and fire combined" (U.S. Department of Health and Human Services, 2000). The Minnesota Heart Survey showed the number of cigarettes smoked from 1995-1997 decreased to less than a pack a day (Arnett, McGovern, Jacobs, Shahar, Duval, Blackburn, et al., 2002). However, this trend may not continue. Smoking increased among school students by about $50 \%$ between 1988 and 1996 and also increased among college students some $30 \%$ between 1993 and 1997 (Morbidity Mortality Weekly Report, 1998). There is no safe way to smoke. Low-tar and low nicotine cigarettes may reduce the possibility of some cancers but do not lessen the risks of heart disease (Sandmaier, 1998). The best course of action is not to smoke at all.

High blood pressure is known as the "silent killer," it is also known as hypertension and remains one of the major risk factors for CHD. In the United States 50 million adults have high blood pressure (U.S. Department of Health and Human Services, 
2000). Most people who have high blood pressure don't even feel sick; that is why it's called the "silent killer." Blood pressure is the amount of force exerted by the blood on the walls of the arteries (Sandmaier, 1998). Blood pressure is usually expressed in two numbers (i.e., 120/80), and is measured in millimeters of mercury. The first number is the measure of the force used when the heart pumps or beats and is known as systolic blood pressure. The second number is the pressure that exists in the arteries between beats and is known as diastolic blood pressure. Blood pressure can increase or decrease through the course of the day depending on activity levels.

Over 50 million adults in the United States have high blood pressure, or hypertension, defined as having a systolic blood pressure greater than or equal to 140 $\mathrm{mmHg}$ and/or diastolic blood pressure greater than or equal to $90 \mathrm{mmHg}$ and/or taking medications to control hypertension (He, Whelton, Appel, Charleston, \& Klag, 2000). Hypertension among the United States population is unacceptably high; nearly three quarters of black people and one half of whites age 60-74 years have high blood pressure (Burt et al., 1995). Being overweight and consuming a high intake of salt have proven to be risk factors for developing hypertension (He \& Whelton, 1997). High blood pressure can rarely be cured, but it can be controlled with treatment. In most cases, if the high blood pressure is not extreme it can be controlled by losing weight if the person is overweight, participating in regular physical activity, and cutting down on alcohol consumption as well as salt intake (Sandmaier, 1998).

Cholesterol is one of many types of fats essential for good health. To function normally the body needs cholesterol. However, the body naturally makes enough cholesterol to fulfill its needs. Consuming additional cholesterol over a period of years 
can result in higher than normal cholesterol levels known as hypercholesterolemia. High blood cholesterol or hypercholesterolemia is another major risk factor for coronary heart diseases. In the United States more than 50 million adults have blood cholesterol levels that require treatment (Sempos et al., 1993). Additionally, more than 90 million adults have cholesterol levels that are higher than desirable (Expert Panel on Detection, Evaluation, and Treatment of High Blood Cholesterol in Adults, 1994). According to Sandmaier (1998) lipoproteins are the packages that carry cholesterol in the blood. There are two types of lipoproteins, low-density lipoprotein (LDL) and high-density lipoproteins (HDL). LDL carries most of the cholesterol in the blood and is often called the "bad" cholesterol, because too much LDL can cause fatty deposits to form in the arteries. As a result, blood flow to the heart is impeded and the risk of heart disease increases. But the other lipoprotein known as HDL is known as the "good" cholesterol because it actually helps to remove cholesterol from the blood thus decreasing the chances of cholesterol build-up in the arteries. For the first time research reported in the 1980s showed that lowering high blood cholesterol reduces the risk for heart attacks (U.S. Department of Health and Human Services, 2000). In addition, studies show that a low fat, low saturated fat diet, along with weight control and physical activity can lower blood cholesterol levels (He et al., 2000; Leiter et al., 1999).

Diabetes is a serious condition that many do not know they have. Approximately 13 million people have diabetes in the United States alone. Of the 13 million, 90-95\% of these individuals have noninsulin-dependent diabetes mellitus (NIDDM), better known as Type II diabetes (Kriska, Blair, \& Pereira, 1994). Type I diabetes, also known as insulindependent diabetes mellitus, can occur at any age but usually occurs before the age of 30 
(Heyward, 1998). Type II diabetes is a major contributor to cardiovascular disease mortality and morbidity in the United States (Cooper et al., 2000). Approximately $75 \%$ of people who have diabetes die from some type of cardiovascular disease (Sandmaier, 1998). Diabetes occurs when the sugar in the blood is high and as a result the body can not use the food as energy. It can lead to heart attacks, blindness, amputations, and kidney disease (Your Heart Your Life: A Lay Educators Manual, 1999). Regular physical activity can reduce the risk of developing NIDDM. In 1991 Manson et al. reported that women who exercise vigorously at least once a week have a reduced risk of diabetes. Manson et al. (1992) reported the risk of diabetes decreased 23\% for a group of male physicians who exercised vigorously once a week. A decrease of $38 \%$ was observed when the vigorous exercise sessions increased to two to four times a week, and the risk of diabetes decreased some $42 \%$ when the vigorous exercise session occurred five or more times a week. Vigorous activity was defined as physical activity that lasts for a duration which causes the production of sweat. There is no cure for diabetes but this disorder can be controlled. Nearly $80 \%$ of all NIDDM diabetics are overweight (Sandmaier, 1998). Physical activity and weight loss may help prevent or postpone Type II diabetes.

Being overweight and obesity are growing public health concerns, affecting adults and children. Nearly $55 \%$ of adults in the United States are overweight or obese (U. S. Department of Health and Human Services, 2000). The National Institute of Health reports a 5\% increase in obesity and overweight adults in the U.S. between 1994 and 1999. This same report estimates an even higher percentage of overweight or obese adults in the U.S., reaching nearly $61 \%$. Currently, being overweight and obesity are defined by body mass index [weight in kilograms/ (height in meters) ${ }^{2}$ ]. "A body mass index of 25 to 
29.9 defines overweight, and one greater than or equal to 30 defines obesity" (Cooper et al., 2000). There has been a rapid increase in obesity (body mass index of greater than 30 $\mathrm{kg} / \mathrm{m}^{2}$ ). Mokdad et al. (1999) identified an increased prevalence of obesity among U.S. adults from 1991-1998. Cooper et al. (2000) also report nearly $60 \%$ of men and $50 \%$ of women being identified as overweight and $20 \%$ of men and $25 \%$ of women being identified as obese. Heyward (1998) also supports the prevalence of obesity in the United States stating “... one out of every three adults and more than one out of every five adolescents and children are overweight" (p. 9). More specifically, Cooper et al. (2000) identified a $13 \%$ to $15 \%$ prevalence of overweight children 6 to 12 years of age and an $11 \%$ to $12 \%$ prevalence in children ages 12 to 17 years. Today's children have more body fat than children of earlier generations: Obesity has increased 54\% in children age 6 to 11 (Bar-Or, 1987).

Excess body weight and fatness pose a threat to the longevity and quality of one's life. Obese individuals have a much greater risk of developing CHD, hypertension, hypercholesterolemia, diabetes mellitus, certain cancers, as well as other pulmonary and osteoarthritic conditions (National Institutes of Health, 1985). Overweight individuals are much more likely to develop CHD and heart-related problems even if they have no other risk factors present (Hubert et al., 1983; Sandmaier, 1997; U.S. Department of Health and Human Services, 2000).

Controlling obesity in the United States is difficult. Bar-Or and Baranowski (1994) suggest that physical activity in adolescence (defined as ages 11-12) reduces the risk of obesity and helps in its treatment. Heyward (1998) suggests 30 minutes or more of moderate-intensity physical activity to benefit health and prevent disease. 
All of the risk factors associated with CHD discussed thus far suggest that physical activity will aid in the treatment or control of such risk factors (i.e., smoking, high blood pressure, high blood cholesterol, diabetes, and overweight). However, physical inactivity is also a risk factor for developing CHD and increasing the level of physical activity remains a challenge. "Although physical inactivity is on the decline in the U.S., 60 percent of all Americans still do not get the recommended amount of physical activity needed for health benefits" (Heyward, 1998, p. 9). A person can gain health benefits with as little as 20 minutes of physical activity a day. However, nonphysical activities are becoming more popular among young people.

Welcome to what Sports Illustrated calls, 'the Twinkie-eating, T.V. watching, video-game-playing younger generation' in which even participation in youth sports is on the decline. Not exactly what Ben Franklin had in mind when he called for schools to have provisions for running, leaping, wrestling, and swimming. (Maier, 2001, p. 3.)

Children living in the United States are less active and more obese than ever before. Currently, the most popular activities among youngsters are watching television and playing video games (Luepker, 1999). Children watch approximately 25-27 hours of television a week (Dietz \& Gortmaker, 1985). Some health enthusiasts and scholars have made a connection between excessive television viewing and childhood inactivity and decreased fitness levels (Dietz \& Gortmaker, 1985; Groves, 1981; Raithel-Simmons, 1988). In contrast, youngsters spend only 14 minutes a day engaged in physical activity (Fry, 1999). As a result, physical inactivity has become a serious problem in our country.

The National Children and Youth Fitness Study indicates that one-third of all youth ages 10 to 18 do not engage in sufficient physical activity to provide aerobic or endurance benefits (McGinnis, 1987). Additionally, more than $50 \%$ of U.S. adults do not 
meet the recommended levels of moderate activity, and about $25 \%$ engage in no leisure time physical activity at all (Physical Activity and Health: A Report of The Surgeon General, 1996). Inactivity is more prevalent among those with lower income and education. Inactivity is higher among females than males, and inactivity is more prevalent among black females than white females (NIH, 1995; Physical Activity, 1996).

Moreover, participation in all types of physical activity declines tremendously as age or grade in school increases (Physical Activity, 1996). This is unfortunate mainly due to the fact that physical inactivity is a risk factor directly related to CHD.

The American Academy of Pediatrics reported that an alarming $40 \%$ of children ages 5 to 8 have at least one risk factor for coronary disease (Olsen, 1990). When examining the developmental history of coronary heart disease in humans, Rose (1968) identified the first signs as appearing among 2-year-olds. It is feared that unhealthy inactive children will grow into unhealthy inactive adults.

Health benefits can be derived simply by becoming more physically active. Furthermore, cardiovascular risk factors can be reduced and physical fitness levels enhanced with low to moderate levels of physical activity (40-60\% of a person's maximal aerobic capacity) (Blair \& Connelly, 1996). The Centers for Disease Control (CDC) define a moderate level of physical activity as one that includes activity sessions that use approximately 150 calories of energy per day, or 1,000 calories per week (1996, p. 2).

Regular physical activity that is performed on most days of the week has positive health outcomes. Regular physical activity can reduce the risk of developing or dying from some of the leading causes of illness and death in the United States. According to the CDC, 
... regular physical activity improves health in the following ways: reduces the risk of dying from heart disease, reduces the risk of dying prematurely, reduces the risk of developing diabetes, reduces the risk of developing high blood pressure, reduces the risk of developing colon cancer, reduces feelings of depression and anxiety, helps control weight, helps build and maintain healthy bones, joints, and muscles, and promotes psychological well-being. (1996, p. 1)

Given the numerous health benefits of physical activities, the hazards of being inactive are apparent. Physical inactivity is a serious problem nationwide. "Its scope poses a public health challenge for reducing the national burden of unnecessary illness and premature death" (CDC, 1996, pp. 1-2).

In 1990 the United States Public Health Services released, Healthy People 2000: National Health Promotion and Disease Objectives. Many of these objectives are specifically directed towards improving the health profile of American children. In addition, the objectives focus on improving health status, reducing health risks, and providing and improving various preventative services and interventions (McGinnis, Kanner, \& Degraw, 1991). Improving the health of American children requires a wide range of social and economic interventions. "Primary prevention, specifically through lifestyle changes and interventions that promote heart-healthy behaviors, is a major strategy to reduce the development of CDC" (U.S. Department of Health and Human Services, 2000 , p. 5). The school site physical education programs were specifically cited as one of the possible intervening programs.

The elementary physical education programs appear to be the ideal site to accomplish increased physical fitness goals and objectives. Sallis and McKenzie (1991, p. 124) report that up to $97 \%$ of elementary school children participate daily in some 
kind of physical education program. Where else could more children be taught the importance of a physically active lifestyle?

Since the implementation of the Fitnessgram in 1998 the scope of the physical education curriculum in Florida and more specifically in M-DCPS, has shifted to include several goals and objectives directly related to improving, enhancing, fostering, and maintaining an active healthy lifestyle among students.

Physical Education Curriculum

The scope of the curriculum includes the goals and objectives, which determine the focus and direction of a particular program. When program objectives are accomplished they should make a significant contribution to the overall goals of schooling in the United States society-the development of well-rounded individuals ready, able, competent, and capable of contributing to society. Quality programs are focused and driven by objectives, which move children toward high achievement. Over the past 10 years professionals have worked to develop and identify a set of standards that give direction to physical education. To help pave the way for nationally accepted quality physical education standards, the National Association for Sport and Physical Education (NASPE) in affiliation with the American Alliance for Health, Physical Education, Recreation and Dance (AAHPERD), appointed the Outcomes Committee to answer the question "What should students know and be able to do?" The work of this committee resulted in the publication of the book Outcomes of Quality Physical Education Programs (1992). The "Outcomes Project" culminated in the development of a definition of the physically educated person, which was described in 20 major outcomes, listed under five categories covering the psychomotor, affective, and cognitive learning 
domains (See Appendix A). The five categories of a physically educated person include: (a) has learned skills necessary to perform a variety of physical activities; (b) is physically fit; (c) does participate regularly in physical activity; (d) knows the implications of and the benefits from involvement in physical activities; and (e) values physical activity and its contributions to a healthful lifestyle (Pangrazi, 1998, p. 6).

A more recent publication by NASPE, entitled Moving into the Future (1995), moves beyond the previous outcomes and more specifically delineates content standards for physical education. "A positive result of efforts to identify standards is that there is general agreement among most professionals about what a physical education program should accomplish. NASPE identified seven major content standards for physical education that provide a basis for describing a physically educated person" (Pangrazi, 2001, p. 10). The "Content Standards in Physical Education" as developed and described by NASPE (1995) in Moving into the Future are:

A physically educated person:

1. Demonstrates competency in many movement forms and proficiency in a few movement forms.

2. Applies movement concepts and principles to the learning and development of motor skills.

3. Exhibits a physically active lifestyle.

4. Achieves and maintains a health-enhancing level of physical fitness.

5. Demonstrates responsible personal and social behavior in physical activity settings.

6. Demonstrated understanding and respect for differences among people in physical activity settings.

7. Understands that physical activity provides opportunities for enjoyment, challenge, self-expression, and social interaction. (p. 1)

In general, experts in physical education agree on the major content standards that comprise categories of emphasis for quality physical education instruction. Many states and school districts have adopted or developed similar sets of standards. 
The Florida Sunshine State Standards were approved by the State Board of Education in 1996 to provide expectations for students' achievement in the State of Florida. These benchmarks are a set of statewide academic standards that represent the skills and knowledge Florida students will need in order to achieve and succeed in work or college. "The Sunshine State Standards are not minimal skills, on the contrary, they represent rigorous, high stakes academic expectations that will prepare Florida students to compete in one of the toughest marketplaces our nation and world have ever known" (www.SunshineStateStandards.net, 2003). These standards describe student achievement that the state will hold schools accountable for. The standards concern students' learning in the following subject areas: language arts, mathematics, science, social studies, foreign language, visual arts, music, theatre, and physical education.

The Florida Standards for Health Education \& Physical Education grades Pre K through fifth look very similar to the seven major content standards developed by NASPE (1995). The Sunshine State Standards (Florida State Board of Education, 1996, pp. 1-2) for health and physical education are:

Physical Education Literacy

Standard 1: The student demonstrates competency in many movement forms and proficiency in a few forms of physical activity.

Standard 2: The student applies concepts and principles of human movement to the development of motor skills and the learning of new skills.

Standard 3: The student analyzes the benefits of regular participation in physical activity.

Responsible Physical Activity Behaviors

Standard 1: The student achieves and maintains a health-enhancing level of physical fitness.

Standard 2: The student demonstrates personal and social behavior in physical activity. 
Advocate and Promote Physically Active Lifestyles

Standard 1: The student understands how participating in physical activity promotes inclusion and an understanding of the abilities and cultural diversity of people.

Standard 2: The student understands the physical activity provides the opportunity for enjoyment, challenge, self-expression, and communication.

These broad standards are further broken down into grade level benchmarks. (See Appendix B)

As part of the Florida Curriculum Framework these standards have been correlated to the Miami-Dade County Public Schools (M-DCPS) own Competency-Based Curriculum (CBC) for Physical Education.

Physical Education is an integral part of the total Dade County Public Schools Curriculum. By using the Competency-Based Curriculum, it shares with all other disciplines the aim of providing a well balanced program of learning experiences that will assist all students in achieving the broad goals of education. The Competency-Based Curriculum in physical education is further aligned with the Sunshine State Standards, the National Standards for Physical Education, and the SCANS Report, preparing students for the work force. (M-DCPS, preface) (See Appendix C)

One recurring area of emphasis in the physical education curriculum, as evidenced in the standards, at the national, state, and county levels, is one of achieving and maintaining optimal levels of physical fitness that in turn leads to promoting healthy, active lifestyles. Graham, Holt/Hale, and Parker (2004) build on this area of emphasis as they describe several key concepts: (a) the focus of fitness in elementary school physical education has shifted from strenuous exercise programs to physical activity as a preventative for disease and a formula for good health; (b) physical fitness for youngsters centers around understanding the health-related fitness components and concepts of fitness, and appreciating the importance of being physically active; (c) physical fitness becomes a process, maintained through a physically active lifestyle that begins in 
childhood; and (d) the purpose of fitness assessment is to identify areas of concern and assist youngsters in establishing personal fitness goals (p. 38).

Miami-Dade County Public Schools Physical Fitness Testing

Many of the objectives as outlined in the Miami-Dade County Public Schools

(M-DCPS) $\mathrm{CBC}$ focus on physical fitness and promoting healthy active lifestyles. Thus, M-DCPS adopted the Fitnessgram, which is a health related physical fitness assessment tool, as an integral part of the annual curriculum. Dr. Jayne Greenberg, district supervisor for physical education in M-DCPS writes,

In recent years, the emphasis on the assessment of physical fitness of our students has changed from an analysis based on level of skill to one based on level of health. As the physical fitness and health concerns of our student population become more prevalent, the need to make health-related fitness testing an integral part of our annual curriculum becomes more apparent. (M-DCPS, 1997, p. i)

The district physical fitness testing program, the Fitnessgram, was recommended for the 1997-98 school year and then became required during the 1998-99 school year. All M-DCPS are currently required to administer the Dade County Public Schools Fitness Testing Program (Fitnessgram) to all Physical Education students in grades 4-12.

Prior to the 1998-1999 school year M-DCPS incorporated the "President's Challenge" testing program as the district fitness assessment tool. "This [President's Challenge] program is norm referenced, meaning individual students scores indicate a student's relationship to the scores of the population being tested (i.e., a 9-year old boy performs five pull-ups, giving him an 85 percentile score. He scores better than 84 percent of the boys his age)" (M-DCPS Physical Fitness Testing Program, 1988, p. 2). This (President's Challenge) fitness assessment program consists of five tests: 1 -mile run/walk, sit and reach, shuttle run, pull-ups, and sit-ups. These tests are used to assess 
the main components of fitness for performance and health, and also to focus on some of the weaknesses of school-aged youth. This program which began in 1988-89 recognizes outstanding physical fitness among children and youth ages 6-17. However, passing rates for this test were very low. For example, during the 1998-99 school year only $19 \%$ of the students at Redland Elementary actually passed the test. Additionally, Going and Williams (1989) emphasize

... the use of norm-referenced testing for motivating physically inactive individuals and low-level performers may be limited. When norm-referenced fitness standards are used without consideration of the absolute score, it is possible to statistically mask or reverse absolute improvements in student performance and to discourage rather than encourage future efforts to improve. (p. 35)

The district has since replaced this assessment tool with the more current Fitnessgram. The reason for the change in tests was stated earlier, “... emphasis on the assessment of physical fitness of our students has changed from an analysis based on level of skill to one based on level of health" (M-DCPS, 1997, p. i). In keeping with the national concern about the health and fitness levels of American youth, it only makes sense that M-DCPS would select an assessment tool more closely aligned with current professional philosophy.

\section{Fitnessgram}

The past two decades have seen tremendous changes in the assessment of youth physical fitness. Such changes include the development of health-related physical fitness tests with criterion-referenced standards (Safrit \& Wood, 1995). The nationally recognized Prudential Fitnessgram (Cooper Institute for Aerobics Research, 1992) is one 
such assessment that incorporates fitness tests as one component in a comprehensive fitness program. Emphasis is placed on knowledge, motivation, and assessment.

Measurement and evaluation are important and closely related components of the process of achieving lifetime physical activity and fitness. When appropriate tests are utilized and part of a comprehensive fitness program, the testing process aids students in developing a lifelong commitment to regular physical activity. When the purpose of the test is to determine which and how many students meet a predetermined level of performance, criterion-referenced test measures are used because they are defined as a test with predetermined standards of performance tied to a specified domain of behavior (Safrit, 1986). This is the preferred type of test when attempting to motivate children to become physically active.

The physical fitness testing program, the Fitnessgram, is a comprehensive criterion-referenced program for school-aged children and youth. It consists mainly of a health-related fitness assessment, a computerized program for reporting scores, a behavioral oriented recognition system, and educational materials for teachers to utilize when accomplishing the primary objective of youth fitness programs; which is to aid and assist students in establishing daily physical activity as part of their daily lives.

The goals of Fitnessgram are to promote enjoyable regular physical activity and to provide a comprehensive physical fitness assessment and reporting program for children and youth. The Fitnessgram seeks to develop affective, cognitive, and behavioral components related to participation in regular physical activity in all children and youth, regardless of gender, age, disability, or any other factor. It is believed that regular physical activity contributes to good health, function, and well-being, and is important throughout a person's lifetime. Therefore, school programs should have the long-term view of promoting appropriate physical activity rather than focusing only on testing and developing physical fitness in children and youth. The Fitnessgram emphasizes participation in a variety of 
physical activities to develop and maintain an acceptable level of physical fitness. (M-DCPS, 1997, p. 1)

The Fitnessgram consists of six tests, each of which assesses one or more healthrelated components of physical fitness. The health-related components of physical fitness include cardiorespiratory endurance, muscular strength, muscular endurance, flexibility, and body composition. Cardiorespiratory endurance is probably the most often cited health-related component of physical fitness. It involves the ability of the heart and lungs to supply oxygen to the working muscles for an extended period of time (Hinson, 1995, p. 6). Muscular strength is the amount of force a muscle can produce (Graham, Holt/Hale \& Parker, 2004, p. 42). On the other-hand, muscular endurance is the ability of a muscle or group of muscles to exert force over an extended period of time (Pangrazi, 2001, p. 228). "Flexibility is the ability to use joints fully; it's the capacity of a joint to move through its potential range of motion" (Graham, Holt/Hale \& Parker, 2004, p. 42). Body composition is an integral part of the health-related components of fitness and is the proportion of body fat to lean body mass (Pangrazi, 1998, p. 236). Table 2 quickly and effectively displays the Fitnessgram tests and the health-related component evaluated. The description and testing procedure as well as the criterion-referenced standards for each test can be found in Appendix D.

Since the Fitnessgram program was implemented by M-DCPS in 1999 the physical fitness test scores at one particular elementary school have shown improvement. The Fitnessgram physical fitness test results obtained from Redland Elementary School for the years 1999 through 2003 are displayed in Table 3. The total awards earned can be further broken down into two categories, gold, and silver. In order for a child to receive a 
Table 2

Fitnessgram Tests and the Health-Related Fitness Component(s) Assessed

Fitnessgram Test

Health-Related Fitness Component(s)

One Mile Walk/Run

Cardiorespiratory Endurance

Body Composition

Body Composition

Curl-Up

Muscular Strength

Muscular Endurance

Trunk Lift

Muscular Strength

Flexibility

Push-Up

Muscular Strength

Muscular Endurance

Backsaver Sit and Reach

Flexibility

gold card he/she must meet the criteria established for six out of six tests. To receive a silver card the child must meet the criteria established for five out of six of the tests. Table 4 displays the total number of award winners at Redland Elementary School for the years 1999-2003, who received either a gold card or a silver card for the Fitnessgram physical fitness tests. This information looks promising but because the Fitnessgram is new to the M-DCPS district, as educators, it is important and beneficial that we take a closer look at this program to examine if it increases student knowledge about fitness and if it encourages children to be physically active at home.

As regular participation in activity and fitness becomes even more recognized as a major contributor to the health of all Americans, a greater emphasis will be placed on 
Table 3

Fitnessgram Test Results From Redland Elementary School from 1999-2003

Year

\# of

Students Tested
Total Awards

Earned
$\%$ of Total

Award Winners

1999

312

176

$56 \%$

2000

347

225

$65 \%$

2001

332

250

$75 \%$

2002

341

245

$72 \%$

2003

404

314

$78 \%$

Table 4

Fitnessgram Total Award Winners, Gold Card, and Silver Card Award Winners at Redland Elementary School for Years 1999-2003

Year

Total Awards

Gold Cards

Silver Cards

1999

176

114

62

2000

225

134

91

2001

250

150

100

2002

245

145

100

2003

314

181

133 
children becoming more physically active. As this takes place it will become increasingly important to explore students' knowledge and perceptions of physical fitness testing.

Examining students' knowledge and perceptions is important because the way children perceive the Fitnessgram experience and what they know about fitness may influence their future activity levels.

\section{The Cloak of Perception}

While the affective domain has been largely ignored in educational curricula in the past educators are becoming more aware of the vital importance of students' perceptions. Moving in this new direction this study was not limited to exploring students' knowledge about fitness and students out of school activity levels, but also examined students' perceptions of the Fitnessgram program.

Students' needs and interests provide the curriculum worker with important information that can be utilized in preparing student learning objectives and experiences. However, students needs, interests, and perceptions are not often explored and as a result the curriculum worker fails to accomplish the "organic interaction" (Dewey, 1902) previously described. For these reasons it is important to understand more about perception and what students think and feel about the fitness testing experience.

Student perception is important because everything we know we know by perceiving it-experiencing it through our senses. But experiences are viewed differently by different people.

The process of human perception is highly selective.

When looking at the same scene, design, or object, different people will see different things. What people "see" is highly dependent on their interests, bias, and backgrounds. Our culture tells us what to see; our early childhood 
socialization instructs us how to look at the world; and our value systems tells us how to interpret what passes before our eyes. (Patton, 1990, p. 200)

Different people can perceive objects and experiences very differently, and the same person may perceive the same object or experience differently at different times. These variations in perception are often due to subjective differences. These variations in one's "mode of knowledge" or perception is in part a function of what a person has reason to believe (Carruthers, 1986, p. 11).

During the seventeenth and eighteenth centuries the "representative theory of perception" was a powerful and persuasive theory that was and continues to be widely accepted by many philosophers. This theory of knowledge suggests that immediate objects of cognition are our own sense-impressions, from which we make deductions about the existence and nature of things in the material world (Horner \& Westacott, 2000, p. 39). Our senses represent this world to us, but our only access to it is through senseperception. Thus, perception is the awareness or apprehension of the material world through the senses (Horner \& Westacott, 2000, p. 253). "Our human apprehension of the world is not direct but indirect in that nothing can be apprehended at all until it has been filtered, as it were, through the five senses and through the human intellect" (TeichmanWhite, 1995, p. 39).

Perception has been defined as a "causal process" where things in the world interact with our senses giving rise to beliefs. Roderick Chisholm (1957) offers the following explanation of this "casual process," "“X appears ... to S' means that X causes S to sense ... thus X is a causal condition of S's sensing" (p. 143). For something or some event to be perceived it must actually exist, thus the only things that actually exist are 
things in the material world. "Simply put, you can't interact with a merely possible event; you can interact only with an actual one" (Appiah, 2003, p. 190).

John Locke and Bishop Berkeley, both philosophers, emphasized the central role of sense experience in the search for knowledge. Both had argued that “... what is known of the material world, if there is a material world, consists merely of the data provided by the five senses" (Teichman \& White, 1995, p. 40). "Locke's position is that all 'the materials of human knowledge' are gathered either directly from the physical world, through our senses, or indirectly from our internal, mental world through introspection" (Cohen, 2002, p. 197). Similarly Berkeley developed the doctrine "“to be is to be perceived,' in other words, that material objects - everything - exists only through being perceived by conscious beings" (Cohen, 2002, p. 192). Similar thoughts are expressed in the area of perceptual psychology.

Perceptual psychology is of more recent vintage. Its theory of learning is harmonious with the progressivist views on education. It flourished under the ideas of Earl Kelley, Donald Snygg, Arthur Combs, Abraham Maslow, and Carl Rodgers. These perceptualists emphasize dealing with people's perceptions of the world that surrounds them. "The perceptualist maintains that it is more important to know how the learner perceives the facts than what the facts of the given situation are" (Oliva, 1997, p. 186). For example, by observing the behavior of children in the physical education (PE) context one may indicate what their experience might be but it is unlikely for one to determine what their experience actually was. The visible evidence gained by observing may misrepresent what is really happening as far as the individual is concerned. For this reason, "the intangible perceptions that the child has of the PE program clearly need to be 
identified in order that a distinction may be made between what we believe to be happening, as portrayed by behavior, and what we may come to know of the child's experience through actually asking them" (Hardy \& Mawer, 1999, pp. 23-24).

Dyson (1995) indicates that although the students are central to the educational process they are rarely consulted; and when they are, there has been a tendency to treat their views as incidental. This is due in part to the Essentialist views and the allegiance of the American public education system has to these views. More specifically, the Essentialists adopting the behaviorist school of psychology, place “... the learner in a passive role as a recipient of the many stimuli to which he or she must respond" (Oliva, 1997, p. 181). As a result students are rarely asked about their perceptions of educational programs. However, if we are seeking to identify children's knowledge and perceptions of the physical fitness testing experience, it is essential that we take a back seat and accept the child's version (or perceptions) of reality without imposing upon it our own interpretation and assumptions.

Living an active, healthy life is an outcome closely aligned with the Fitnessgram program. If educators are to encourage students to reach this goal successfully, we must know and understand the perceptions of the fitness experience and whether it, in fact, promotes the perception of a healthy lifestyle through physical activity. "Actually, the best guarantee we have that a person will be able to deal with the future effectively is that he has been successful in the past. People learn that they are able, not from failure, but from success" (Combs, 1962, p. 53). For this reason we must learn more about the Fitnessgram testing experience from the child's point of view. By doing so, we may 
provide students with a more meaningful, enjoyable, and successful experience that promotes the goals and objectives of the program.

\section{Physical Fitness Summary}

The goal of a quality physical education program for children is to enable them to develop healthy and active habits that will become a lifestyle change throughout adolescence and adulthood. According to Graham, Holt/Hale, and Parker (2004) there are two important factors in attaining this goal at the elementary level. First, children must enjoy the fitness activities. Secondly, children must master the basic skills of physical education that will enable them to successfully participate in activities that promote physical fitness. Many authors reviewing the impact of activity and fitness on health benefits recommend that physical fitness instruction should emphasize increased participation in and enjoyment of moderate to vigorous physical activity (Hinson, 1995; Irverson, Fielding, Crow, \& Christenson, 1985; Pangrazi, 2001; Riopel et al., 1986; Sallis, 1987). If fitness is fun, elementary aged children are more likely to pursue it outside the school setting and continue through middle school, high school, and beyond. Decline in physical activity levels of children begins before they leave elementary school and results in adolescents becoming more vulnerable to developing sedentary lifestyles, which in turn is a well-established risk factor for developing CHD. Research indicates a combination of environmental, psychosocial, and biological factors contribute to the decline in physical activity levels of middle and high school aged children (Hovell et al., 1999; Rowland, 1999). If children are to develop lifelong health fitness habits, they must enjoy exercise and physical activity, as well as understand and appreciate the importance of physical fitness. On a similar note Russell Pate (1983) has recommended that 
promoting skills, knowledge, and long-lasting positive attitudes toward health and physical fitness should be the fundamental goal of physical fitness programs. To ensure children acquire all three objectives they must be taught the basic knowledge of concepts and principles related to fitness. "The earlier children are exposed to the basics of fitness, the better chance that this knowledge will become integral to their lives" (Hinson, 1995, p. 10).

A successful physical education program would result in children exercising throughout their lives. Certain activities may prove to be more likely to stimulate exercise outside of the school setting. There is some indication (Glasser, 1976) that if the following conditions of activity are met, exercise becomes addicting and a necessary part of one's life. These conditions imply that many individual activities like walking, jogging, swimming, hiking, biking, and similar activities are exercises that students will use for fitness during adulthood. The conditions include: the activity must be noncompetitive and the student must want to or choose to do it; the activity must not require a lot of mental effort; the activity can be done alone; the students must believe in the value of exercise for improving health; students must believe the activity will become easier if they persist; and lastly the activity should be accomplished in such a way that the student is not self-critical. To become a positive addiction the activity must be done for a minimum of 6 months.

Physical activity alone only slightly increases fitness levels in children. Studies have shown the relationship between physical activity and physical fitness levels of children is low (Pate, Dowda, \& Ross, 1990; Pate \& Ross, 1987; Ross, Pate, Caspersen, Damberg, \& Svilar, 1987). Physical activity is an important variable in achieving 
physical fitness, but there are other factors that are of equal or greater importance.

Research indicates family support for physical activity and parental modeling are the most important predictors for adopting and maintaining regular physical activity by children (Kimiecik \& Horn, 1998; Stucky-Ropp \& DiLorenzo, 1993; U.S. Department of Health and Human Services, 2000). The evidence strongly suggests that patterns of activity cannot be developed solely by the school but that active life styles must also be encouraged at home.

Given the plethora of research that has been generated about physical fitness it is surprising that little research has been conducted on the perception and knowledge of students about physical fitness testing. One such study was located (Hopple \& Graham, 1995) that had some interesting conclusions. The study found that most elementary students did not have a clear understanding of why they take the physical fitness tests, many students disliked certain fitness tests, and if given the chance, many students would have changed parts of the fitness test to make it more fun. As mentioned previously, enjoyment is a major factor contributing to the most important goal of a quality physical education program-life time activity. The need for further research is summarized by Pate (1991):

It would be desirable to know how children respond to participation in these [physical fitness] tests... Are tests viewed as fun? Do tests have differential effects on different types of children? Though irrelevant from a strict measurement perspective, these issues may determine the appropriateness of fitness testing in the school setting. (p. 233)

\section{Summary}

For decades the field of curriculum has been greatly affected by society and societal concerns. More recently, the public school system has been called upon again to 
meliorate societal problems. Substance abuse, tobacco use, teen pregnancy, AIDS, sexually transmitted diseases, and cardiovascular diseases are some examples. Curriculum developers have addressed these concerns and as a result, preventative programs have been implemented into schools as part of the scope of many curricula. As a result, self-preservation, health, and wellness became critical areas that curriculum developers consider and incorporate into the scope of many educational programs.

The demands placed upon systems of public education by society have extended to the field of physical education. As a result, the scope of school based physical education programs have begun to focus on public health. The call by Sallis and McKenzie (1991) for physical educators to pursue a public health goal for school physical education programs and to join forces with other professionals in the field of public health in the pursuit of improved health for the citizens of the United States is both appropriate and timely. At all levels, national, state, and county, the scope of the curriculum has expanded to include many goals, objectives, and assessment standards that would provide students with the knowledge and skills necessary to develop healthy active lifestyles. This study seeks to determine how students perceive this curriculum goal by examining their knowledge, thoughts, and feelings about the Fitnessgram physical fitness testing program. 


\section{CHAPTER III}

\section{METHODS}

This study examined the effect of physical fitness testing on students to determine how the students perceive the health-related components of physical fitness after participating in the M-DCPS Fitnessgram program. The purposes of Chapter III are to describe: (a) the sample population selected for this study; (b) the instruments that were administered for data collection; (c) the methods, materials and procedures utilized to implement and collect the data for the study; and (d) the selection and use of statistical procedures employed in the analysis of the collected data.

\section{Basic Research Design}

The preliminary purpose of this study was to determine if the physical fitness testing experience promotes an understanding of the health related physical fitness components and to examine the relationship between individual test scores and length of time spent engaged in physical activity outside the school setting. Additionally, an inquiry of students' feelings about the six tests was conducted. In light of these study purposes it was originally determined that the most appropriate design would be a combination of a descriptive and correlational analysis. Additionally, the researcher found it most beneficial to collect and report data by both quantitative and qualitative means.

\section{Preliminary Procedures}

Prior to the implementation of this study, a review of physical fitness literature was completed as well as a review of a specific school's physical fitness test scores to formulate a proposal for research. Project approval for use of human subjects was issued 
by Florida International University: University Research Council (F.I.U.-U.R.C.) (See Appendix E). Approval from M-DCPS Office of Educational Evaluation was completed. As directed by Dr. Joseph J. Gomez of the Miami-Dade County Public Schools, Office of Educational Evaluation, the researcher made some minor changes in the Spanish version of the Informed Consent and the project was accepted. Data collection began on December 1, 1999.

\section{Selection of the Sample}

The M-DCPS Redland Elementary School was the site selected to carry out this investigation. This site was preferred because of its accessibility and convenience to the researcher. However, it is assumed that Redland Elementary School is representative of other elementary schools in the M-DCPS system. Redland Elementary School is situated in one of the last rural areas in Miami-Dade County. In 1992, Hurricane Andrew destroyed the original Redland Elementary School building that was built in 1926 . The new Redland Elementary School, located in southern Miami-Dade County at 24501 S.W. 162nd Avenue, opened its doors in 1996. The new state of the art two-story building has 43 classrooms with at least three computers in each classroom that are connected to the Internet. There are separate art, music, and physical education areas. The cafeteria has a large stage. The Media Center has a closed circuit TV system and 14 computers, 10 of which are dedicated to student usage.

"The vision of Redland Elementary School is to provide society with engaged, productive members who put knowledge to work. Redland Elementary School strives to educate and nurture students to reach their full potential. To achieve this, the entire 
school community focuses on meeting individual student needs" (School Performance Plan, 2003, p. 4).

Redland Elementary School is a quality school that is dedicated to the educational excellence of students. Realizing that literacy is the cornerstone of excellence in education, the administration, professional faculty and staff as well as the other stakeholders are all deeply committed to providing all students with learning experiences that enhance student achievement. This student achievement can be displayed with the school's most recent School Performance Grades: $2003=\mathrm{B}, 2002=\mathrm{A}, 2001=\mathrm{B}$, and $2000=$ C. These School Performance Grades are a direct result of the A+ plan for renovating education. This plan was implemented in 1999 under Florida's Governor Jeb Bush. Redland Elementary School, like all public schools in the state of Florida, received grades on an $\mathrm{A}$ to $\mathrm{F}$ scale based on:

* Overall performance of their students on the Florida Comprehensive Assessment Test (FCAT), the state's standardized test.

* The percentage of eligible students who take the test.

* Whether or not students have made annual learning gains in reading and math, with particular attention to the reading scores of the lowest $25 \%$ of students in the school. (Rosenthal, http://www.greatschools.net)

Redland Elementary School employs 65 full-time staff members. Of these staff members, 2 are administrators, 36 are general education homeroom teachers, 6 are special area teachers, 2 are physical education teachers, 5 are exceptional student education teachers, 4 are Spanish teachers, 3 are ESOL teachers, 1 is a speech teacher, 1 is a media specialist, 1 is a microsystem technician, and 2 are guidance counselors. The average number of years employed as a teacher in Florida (as of 2002) for the teaching staff is 12 years. In the year $2002,25.5 \%$ of the teachers held advanced degrees. Support 
to this instructional staff is provided by four part time and 1 one-to-one classroom paraprofessionals, 5 clerical or office employees, 3 cafeteria managerial staff members, and 14 part time cafeteria workers, 3 part time cafeteria monitors, 1 security monitor, 1 zone mechanic, and 5 custodial service workers.

Redland Elementary School serves students from the surrounding neighborhood and includes grades kindergarten through fifth. The 1079 members that make up the student body are diverse, culturally rich and part of a strong, agriculturally based community. Of the student population, $66.3 \%$ are general education students, $10.7 \%$ are ESE students, and $13 \%$ are ESOL students. Almost half of the student population qualifies for free and reduced price meals. The racial/ethnic makeup of the student body is $61 \%$ Hispanic, $32 \%$ Anglo(White), 4\% African American, $1 \%$ Asian, 1\% multi-ethnic, and $>1 \%$ American Indian.

The subjects participating in this study $(N=110)$ were selected from the fifth grade population within Redland Elementary School. Fifth grade students were targeted because they are the highest grade at this elementary school required to participate in the Fitnessgram testing program. Informed consent forms, both the English and Spanish versions, were sent home with each fifth grade student $(N=192)$. Of the 192 informed consent forms (See Appendix F) sent home, 114 forms were returned with the appropriate parent signature required to participate in this investigation. Four of the original 114 students who returned the informed consent form withdrew from Redland Elementary School before the data collection was completed. As a result, insufficient data from these students was available and subsequently they were dropped from the investigation 
leaving the total sample size at 110 . From this sample $(N=110)$ there were 62 girls $(n=62$; $56.4 \%)$ and 48 boys $(n=48 ; 43.6 \%)$.

\section{Instrumentation}

Information and data for this study was gathered from two sources: (a) the M-DCPS Fitnessgram Physical Fitness Testing Program (DCPS, 1988) (See Appendix D), and (b) a set of six student questionnaires (See Appendix G) related to each of the six subtests of the Fitnessgram Physical Fitness Testing Program. Each is described below.

\section{The M-DCPS Fitnessgram Physical Fitness Testing Program}

In recent years, there has been a shift in the emphasis of assessing the physical fitness levels of students. "Tests of athletic and motor ability [skills] were once major determinants of fitness testing" (Hinson, 1995, p. 3). Now, the current testing trends are focusing on determining fitness levels through health-related components. Moreover, fitness tests are being evaluated using criterion referenced health standards rather than norm referenced standards. This change in test type greatly benefits today's youth. Fitness of a child should not be judged based on how he/she compared to the performance of other children, instead it should be individualized and defined by clear health standards (Cooper Institute for Aerobics Research, 1992). The purpose of testing for fitness is not to see how well a child compares to another, but is to see how physically fit the child is and what implications it makes for his/her health. The goal of fitness is not only for children to be fit now, but also to be fit in the future.

To accomplish this goal and provide congruence with the M-DCPS Competency Based Curriculum (CBC) and the Sunshine State Standards for promoting physically active lifestyles, M-DCPS adopted the Fitnessgram, a health-related fitness program as an 
evaluation tool. All schools are required to administer this test to all Physical Education students in grades 4-12. This new test was suggested for the 1997-1998 school year and then became mandatory beginning with the 1998-1999 school year.

The Fitnessgram was developed in 1982 by the Cooper Institute for Aerobics Research in Dallas, Texas and is endorsed by the American Alliance for Health, Physical Education, Recreation, and Dance (AAHPERD). The Fitnessgram is also sponsored by Prudential Insurance and in some textbooks is referred to as the "Prudential Fitnessgram" (Pangrazi, 1998, 2001; Pangrazi \& Dauer, 1995). The primary goal of the Fitnessgram is to assist students in grades 4-12 in establishing physical activity as part of their daily lives. "We believe that it is essential that our students be educated to better develop and maintain optimal levels of physical fitness which lead to healthy lifestyles. Through selected activities and appropriate fitness education strategies, children can be motivated to adhere to proper fitness and exercise habits, as well as, learn to take responsibility for their own fitness levels" (M-DCPS, 1997, p. i).

Students are assessed in the different areas of health-related fitness: cardiovascular endurance, body composition, muscular strength, muscular endurance, and flexibility. The six tests selected by M-DCPS for use from the Fitnessgram are: One Mile Walk/Run, Percent Body Fat, Curl-Up Test, Trunk Lift, 90 degree Push-Up, and the Backsaver Sit and Reach. Each of these tests was selected to assess important aspects of a student's health and related fitness, not skill or motor ability. Since the tests are not norm-referenced, students are not compared to each other but instead to health fitness standards that were carefully established for each age and gender to indicate good health. 
These standards or criteria are indicated as the Healthy Fitness Zone (HFZ) (See Appendix H: Healthy Fitness Zone).

The Fitnessgram standards are based on a foundation of fitness knowledge established based upon research conducted by the Cooper Aerobics Institute and supported by the Centers for Disease Control. These Healthy Fitness Zone Standards represent an acceptable level of fitness required to maintain an active and healthy lifestyle, as well as, a level of fitness that reduces preventable diseases resulting from a sedentary or inactive lifestyle. In essence, the HFZ standards are used to promote changes in students' activity levels that support healthy living.

The criterion-referenced health standards for aerobic fitness were based upon a study by Blair et al. (1989). They reported a significant reduction in risk of all-cause mortality that occurred from rising above the bottom $20 \%$ of the population with regard to aerobic activity. The study also showed that the risk of all-cause mortality continued to decrease as fitness levels increased but less dramatically. The aerobic capacity standards for the Fitnessgram HFZ have been established so that the lower end of the HFZ corresponds to achieving a fitness level slightly above the lower $20 \%$ of the population. The upper end of the HFZ corresponds to a fitness level that would include up to $60 \%$ of the population.

Body fat criterion-referenced health standards are calculated from equations reported by Slaughter et al. (1988). The body fat percentages were also set by following the suggestions offered by current research. William et al. (1992) reported that boys with body fat levels above $25 \%$ and girls with body fat levels above $30 \%-35 \%$ are more likely to exhibit elevated cholesterol levels and hypertension. The lower limit of the 
Fitnessgram HFZ corresponds to the body fat level of $25 \%$ for boys and $30 \%-35 \%$ for girls.

Criterion-reference health standards have not been established as of yet for abdominal strength, upper body strength and flexibility. Instead, criterion referenced activity standards are utilized to assess these areas of fitness. The lower limit of the Fitnessgram HFZ represent a performance level that youngsters should be able to accomplish if they were reasonably active. These standards represent reasonable expectations for children who are sufficiently active. Pangrazi and Dauer (1995, p. 276) explain it another way, “... it is difficult to determine whether a lack of upper body strength is important for quality health [thus]... standards have been established that reflect how many push-ups students who are active should be able to perform."

The six tests of the Fitnessgram: Backsaver Sit and Reach, Curl-Up, Trunk Lift, 90 degree Push-Up, One Mile Walk/Run, and Body Composition, have been found to have acceptable reliability. Recent studies (Hui \& Yuen, 2000; Hui, Yuen, Morrow, \& Jackson, 1999) have established reliability for the Backsaver Sit and Reach with correlation's of .93 to .99 . In regard to the Curl-Up test Robertson and Magnusdottir (1987) indicate a high reliability $(\mathrm{R}=.97)$ for college students but the Anderson et al. (1997) study of younger children (ages 6-10) indicated a much lower reliability of .70; however this degree of reliability is considered acceptable for younger students. Reliability studies for the Trunk Lift (Jackson, Morrow, Jensen, Jones, \& Schultes, 1996; Patterson, Rethwisch, \& Wiksten, 1997) were found to be high (.85-.96). For the 90 degree Push-Up, Saint Romain and Mahar (2001) reported R=.644-.99. Reliability for the 12-minute Walk/Run test was reported to be .94 by Doolittle and Bigbee (1968). 
When assessing Body Composition, Jackson and Pollock (1978) and also Jackson, Pollock, and Ward (1980) reported reliability of .842-.905 for men and women utilizing generalized equations. The items selected for the Fitnessgram by the Cooper Institute for Aerobics Research were assumed to be valid reflections of the health related components of physical fitness: cardiovascular endurance, body composition, muscular strength, muscular endurance, and flexibility. Heyward (1998, p. 34) indicates that physical fitness field tests typically have validity coefficients in excess of .80. Johnson and Nelson (1986) go on to note that logical validity and content validity have been assumed for many criterion-reference physical fitness tests (p. 71).

Each of the Fitnessgram test items reviewed in this section were administered and scored as indicated in the 1997 M-DCPS Fitnessgram Physical Fitness Testing Program:

\section{One Mile Walk/Run}

The One Mile Walk/Run measures cardiovascular efficiency, which “... is the body's ability to undergo vigorous exercise for a long time" (Graham, Holt/Hale \& Parker, 2004, p. 42). This measurement is taken by having the student walk and/or run for the distance of one mile. The student should be encouraged to keep the fastest pace possible. If the student can not run or jog the entire distance, walking is permitted.

Before administering this test it is important that several weeks of training occur. Such training or conditioning should include gradually increasing the distance to be run as well as increasing the duration of these training sessions. During these training sessions teachers should introduce the concept of pace which may help children with their performance on the One Mile Walk/Run. The test is scored by timing how long it 
would take the student to walk/run one mile. The score is recorded in minutes and seconds.

\section{Body Composition}

The Body Composition test measures skinfold thickness at two sites, the triceps, and the inside of the calf muscle, for the calculation of percent of body fatness. These two sites were chosen for the Fitnessgram because they are easy to measure and are directly related to total body fat. These two measurements are taken on the right side of the body. The tricep skinfold is taken on the backside of the arm midway between the elbow and shoulder. The calf skinfold should be taken on the inside of the right leg at the level of maximal calf girth. This should be done by having the student place his/her right foot on an elevated surface with the knee at a 90 -degree angle. The skinfold in both locations should be taken vertically by pinching the fold of skin and then measuring the fold with a skinfold caliper. Each skinfold measurement is done three times and is registered on the dial of the caliper. The recorded score is the median of the three scores. It is important to note the reliability of this test is directly related to the skill of the person taking the measurements. The more practice a person has at taking these measurements the more reliable the results (Johnson \& Nelson, 1986).

\section{Curl-Up}

The Curl-Up test is an evaluation of muscular strength and muscular endurance. The students complete as many curl-ups possible to a specified cadence or pace. The student lies supine on a mat; knees are bent at an angle of approximately 140 degrees, with feet flat on the floor, legs slightly apart, and arms straight and parallel to the trunk with palms resting lightly on the mat. The object to the curl-up is to keep the feet flat on 
the floor and curl the body up slowly sliding the fingers along the mat past a designated length of 4.5 inches and then curling back down until the head gently touches the mat. The movement should be slow, controlled, and performed to a cadence of about 20 curlups a minute. The teacher can call out the cadence or use a prerecorded cadence tape or CD. The student continues to the cadence without pausing until he/she can no longer continue or until he/she has completed the maximum number of 75 curl-ups.

The score for this test is recorded as the total number of correct curl-ups completed to the cadence. If the student lifted his/her feet or buttocks off the mat then that curl-up is not included in the final number of curl-ups recorded.

\section{Trunk Lift}

The Trunk Lift is a test of extensor strength and flexibility. Flexibility is an important fitness factor. Pangrazi (2001, p. 228) notes that people who are flexible usually have good posture and often are less likely to suffer from lower-back pain.

The objective of this test is for the student to lift his/her upper body 12 inches off the floor using the back muscles and hold this position long enough to allow for the measurement to be taken. In order to do this the student should lie face down on a mat. Toes should be pointed, arms parallel with the trunk, with hands tucked under the thighs. The student should focus on a spot on the ground close to his or her nose and this focus should be maintained during the entire test. On the teacher's command, the student slowly and carefully lifts his or her upper body off the floor to a maximum height of 12 inches. This position should be held long enough for the tester to place a ruler vertically on the floor in front of the student and measure the distance between the student's chin and the floor. Once the measurement is taken the student returns to the original starting 
position and the test is repeated a second time with the highest score being the one recorded. The score is recorded in inches to the nearest inch. Distances above 12 inches are recorded as 12 inches.

Push-Up

The Push-Up test is an assessment of upper body strength and endurance. The objective of this test is to correctly complete as many push-ups (to an elbow angle of 90 degrees) as possible to a cadence of 20 push-ups per minute.

The student lies face down on the mat with hands placed directly under the shoulders, fingers spread, and legs straight and slightly apart with toes tucked under. The student pushes off the mat until his/her arms are straight. His/her legs and back must be kept firm and also straight. In order to be counted as a correct push-up the back should be kept in a straight line from the head to the toes during the entire test. The student then lowers his/her body until the elbows are bent at a 90-degree angle with the upper arm parallel to the floor. This movement is repeated as many times as possible to the cadence of 20 push-ups per minute. Students are stopped when a second correction to form is made. Corrected push-ups are not counted in the total number recorded. Scoring for this test is recorded as the number of push-ups completed correctly to the cadence.

\section{Backsaver Sit and Reach}

The Backsaver Sit and Reach is a test of lower back and hamstring flexibility. The objective of this test is to reach as far as possible or to a specified distance on both the right and left sides of the body. The measurement is performed with one side of the body at a time. A Sit and Reach box that is approximately 12 inches high is 
recommended for this test. The Sit and Reach box has a measuring scale on top of the box with a 9-inch mark even with the near edge of the box.

To take this test the student first removes his/her shoes and sits down with one leg fully extended and the foot flat against the end of the box. The other knee is bent with the foot flat on the ground about 2-3 inches from the extended leg. Hands should be placed one on top of the other with fingertips from both hands even; arms are extended forward over the measuring scale on the box. With palms facing down the student reaches forward and back four times holding the position on the fourth try. This position should be held for a minimum of 1 second. After measuring one side the student switches position of the legs and the above procedure is repeated on the other side of the body. This test is scored by the number of inches on each side to the last whole inch reached to a maximum score of 12 inches.

Student Questionnaires Related To Each Fitnessgram Test

For the purpose of this study the researcher developed six student questionnaires one for each of the six tests. When designing and constructing these questionnaires the researcher followed suggestions on "designing questions to be good measures" in Survey Research Methods (Fowler, 1993). Each of the six questionnaires constructed contains six questions; of these six questions two are open type questions, and four are closed type questions (See Appendix G). The items were designed to elicit responses of student perceptions about the Fitnessgram physical fitness test in which all subjects participated.

The six student questionnaires are: (a) Questionnaire Fitnessgram: One Mile Walk/Run, (b) Questionnaire Fitnessgram: Body Composition, (c) Questionnaire 
Fitnessgram: Curl-Up, (d) Questionnaire Fitnessgram: Trunk Lift, (e) Questionnaire Fitnessgram: Push-Up, and (f) Questionnaire Fitnessgram: Backsaver Sit and Reach.

The items in the student questionnaires (Appendix G) are related to two of the three major research questions: (a) Do children who participate in the Fitnessgram physical fitness test, know and understand the health-related physical fitness components? Do these children have the knowledge of activities that promote specific components of physical fitness and, (b) Was there any relationship between individuals' tests scores and the length of time they spent being physically active outside the school setting? The following two tables (Tables 5 and 6) display the two aforementioned research questions and the correlating questions answered by the students in the student questionnaires. These student questionnaires were reviewed by Dr. Rendulic who coded the numerous variables. Dr. Rendulic was a professor and statistician at F.I.U. during the time the data were collected. He possessed the expertise necessary to help design these student questionnaires. Some of the first draft questions were omitted due to the extensive volume of data that would have been produced. Dr. DeFrancesco, a professor in the Department of Health, Physical Education and Recreation, as well as Dr. Rendulic, concurred that the questions asked on the student questionnaires were valid for the research being conducted.

Immediately after taking each Fitnessgram physical fitness tests students were given approximately 10 minutes to fill in the specific student questionnaire correlated to that test. If the students needed additional time to fill in the questionnaire they were allowed the extra time. In most cases students completed the questionnaires within 10 minutes. Answers were marked directly on the questionnaire (See Appendix G: Student 
Questionnaires). Content validity was established for the student questionnaires by

conferring with Dr. C. DeFrancesco, an expert in the field of physical education. The

researcher having worked many years as a physical education teacher also assumed the

Table 5

Research Question 1 Correlated to Student Questionnaire

Student

Questionnaire
Specific Questions Concerning Student Knowledge of Health-Related

Fitness Components

1. Why do physical education teachers have you take the One Mile Walk/Run test?

A. to measure muscular strength

B. to measure body fatness

C. to measure cardiorespiratory endurance

D. to measure muscular endurance

E. to measure flexibility

One Mile

Walk/Run
2. What activities have you done during your daily physical education class time that would help you do well on this test?

3. Do you participate in any physical activities outside of school that would help you with the One Mile Walk/Run test? YES or NO If YES, what activity?

1. Why do physical education teachers have you take the Body Composition test?

A. to measure muscular strength

B. to measure body fatness

C. to measure cardiorespiratory endurance

D. to measure muscular endurance

E. to measure flexibility

Body

Composition
2. What activities have you done during your daily physical education class time that would help you do well on this test?

3. Do you participate in any physical activities outside of school that would help you with the Body Composition test? YES or NO If YES, what activity?

1. Why do physical education teachers have you take the Curl-Up test?
A. to measure muscular strength
B. to measure body fatness
C. to measure cardiorespiratory endurance
D. to measure muscular endurance
E. to measure flexibility

Curl-

Up

2. What activities have you done during your daily physical education class time that would help you do well on this test?

3. Do you participate in any physical activities outside of school that would help you with the Curl-Up test? YES or NO If YES, what activity? 
Student

Questionnaire
Specific Questions Concerning Student Knowledge of the Health-Related Fitness Components

1. Why do physical education teachers have you take the Trunk Lift test?
A. to measure muscular strength
B. to measure body fatness
C. to measure cardiorespiratory endurance
D. to measure muscular endurance
E. to measure flexibility

Trunk

Lift

2. What activities have you done during your daily physical education class time that would help you do well on this test?

3. Do you participate in any physical activities outside of school that would help you with the Trunk Lift test? YES or NO

If YES, what activity?

1. Why do physical education teachers have you take the Push-Up test?
A. to measure muscular strength
B. to measure body fatness
C. to measure cardiorespiratory endurance
D. to measure muscular endurance
E. to measure flexibility

Push-

Up

2. What activities have you done during your daily physical education class time that would help you do well on this test?

3. Do you participate in any physical activities outside of school that would help you with the Push-Up test? YES or NO If YES, what activity?

1. Why do physical education teachers have you take the Backsaver Sit and Reach test?
A. to measure muscular strength
B. to measure body fatness
C. to measure cardiorespiratory endurance
D. to measure muscular endurance
E. to measure flexibility

Backsaver

Sit and Reach
2. What activities have you done during your daily physical education class time that would help you do well on this test?

3. Do you participate in any physical activities outside of school that would help you with the Backsaver Sit and Reach test? YES or NO If YES, what activity?

role of "expert" and determined the content of the questionnaires was appropriate and appropriate and valid for the content area, as well as, for the participants of this study. In addition to the student questionnaires six students were identified from the total fifth grade sample population of 110 for the student interviews. Stratified sampling was used in order for the boys and girls subgroups to be equally represented from the sample 


\section{Table 6}

\section{Research Question 2 Correlated to Student Questionnaire}

$\begin{aligned} & \text { Student } \\ & \text { Questionnaire }\end{aligned}$
$\begin{gathered}\text { Specific Questions Concerning Possible Relatio } \\ \text { Scores And the Amount of Time Spent Being }\end{gathered}$
* Question one was answered only if
to OM3.
1. How much time do you spend particis
(related to the One Mile Walk/Run)

2. In general, how much time do you spend outside of school, exercising or just being active during a one week period? minutes

* Question one was answered only if the participant answered "YES" to $\mathrm{BC} 3$.

1. How much time do you spend participating in out of school activities (related to the Body Composition) during a one-week period?

A. 0 minutes -15 minutes

B. 16 minutes -30 minutes

Body

C. 31 minutes -60 minutes

Composition

D. more than 60 minutes

2. In general, how much time do you spend outside of school, exercising or just being active during a one week period? minutes

* Question one was answered only if the participant answered "YES" to CU3.

1. How much time do you spend participating in out of school activities (related to the Curl-Up) during a one-week period?
A. 0 minutes -15 minutes
B. 16 minutes -30 minutes
C. 31 minutes -60 minutes
D. more than 60 minutes

Curl-

Up

2. In general, how much time do you spend outside of school, exercising or just being active during a one week period? minutes

* Question one was answered only if the participant answered "YES" to TL3.

1. How much time do you spend participating in out of school activities (related to the Trunk Lift) during a one-week period?
A. 0 minutes -15 minutes
B. 16 minutes -30 minutes
C. 31 minutes -60 minutes
D. more than 60 minutes

Trunk

Lift

2. In general, how much time do you spend outside of school, exercising or just being active during a one week period? minutes 
Student Questionnaire
Specific Questions Concerning Possible Relationship Between Individual Test Scores And the Amount of Time Spent Being Active Outside of School

* Question one was answered only if the participant answered "YES" to PU3.

1. How much time do you spend participating in out of school activities (related to the Push-Up) during a one-week period?
A. 0 minutes -15 minutes
B. 16 minutes -30 minutes
C. 31 minutes -60 minutes
D. more than 60 minutes

Push-

Up

2. In general, how much time do you spend outside of school, exercising or just being active during a one week period?

minutes

* Question one was answered only if the participant answered "YES" to SR3.

1. How much time do you spend participating in out of school activities (related to the Backsaver Sit and Reach) during a one-week period?
A. 0 minutes -15 minutes
B. 16 minutes -30 minutes
C. 31 minutes -60 minutes
D. more than 60 minutes

Backsaver

Sit and Reach

2. In general, how much time do you spend outside of school, exercising or just being active during a one week period?

minutes

population, thus three girls and three boys were selected for the interview process. Steps

for selecting the stratified sample were as follows in accordance with Gay (1987, pp. 107108). First the original population of 110 was divided into two subgroups, boys and girls.

Next, each subgroup was numbered: girls were numbered 1 thru 62 and boys were numbered 1 through 48 . Lastly, the participants, three from each subgroup, were selected randomly by using a table of random numbers (Gay, 1987, pp. 520-521). Because stratified random sampling was used, four of five classes were represented for the student interviews. Classes were identified by the teacher's last name initial, thus the representation of students by class for the interview process was as follows: $S=1$ boy and 1 girl; $W=1$ boy and 1 girl; $M=1$ girl; $G=1$ boy; and $D=$ none. This is a result of the random sample technique used. The student interviews were conducted after all six 
Fitnessgram tests were completed. Each interview was conducted by the researcher on a one-to-one basis in accordance with the guidelines suggested by Patton (1990) and took approximately 30-40 minutes to complete. The interviewer designed, constructed, and followed an interview guide (See Appendix I). When designing this interview guide the researcher incorporated suggestions from Fowler (1993), Patton (1990), and Gay (1987). The purpose of these student interviews was to gain additional information about each of the Fitnessgram tests and to extend responses relating to the third research question which focuses on examining children's perceptions of the fitness testing experience.

The items discussed during the student interviews focused on the six Fitnessgram tests: (a) One Mile Walk/Run, (b) Body Composition, (c) Curl-Up, (d) Trunk Lift, (e) Push-Up, and (f) Backsaver Sit and Reach. While discussing each test, questions focused on the following themes: (a) student knowledge of their own test scores, (b) feelings about their own test scores, (c) feelings during the actual test, (d) general thoughts/feelings about the specific test, (e) favorite test, and (f) least favorite test (See Appendix I: Student Interview Guide).

\section{Procedures}

The researcher is one of two full time physical education teachers at Redland Elementary School. Thus, prior to implementation of the study, it was necessary that the researcher first set up a meeting with the school site Principal. The meeting was arranged and took place in September 1999 in order to briefly review the project and gain his approval to conduct research at the school site. He agreed and subsequently, the researcher arranged an informal meeting with the other full time physical education teacher who also agreed to allow his fifth grade students to participate in the study. His 
cooperation was important because he was responsible for more than $50 \%$ of the target population group. As a result, the sample size of 110 was large enough for results to be considered generalizable to the entire fifth grade population. Gay (1987, p. 119) suggests $10 \%$ of the population for descriptive research and a minimum of 30 subjects for correlational research. This study incorporated a combination design (descriptive and correlational) thus the sample size of 110 out of a total fifth grade population of 192 well exceeds Gay's guidelines of sample size and allows generalizability to the target population. The appropriate administrative offices in M-DCPS also approved the research project.

During the last week in November 1999, all fifth grade students received brief instructions about the research that would be conducted during the 6 months of administration of the Fitnessgram test. Students were then given the informed consent forms, both the English and Spanish version, and asked to have them signed by parents and returned the following day (See Appendix F: Informed Consent: English and Spanish Versions). Many informed consent forms were returned the next day; however, the researcher accepted signed forms up until the first Fitnessgram test was administered in mid December, 1999.

Of the original 192 informed consent forms sent out, 114 were returned with the appropriate signatures. Of this number the sample size was ultimately 110 after four students withdrew from Redland Elementary School. Once the informed consent form was returned students were checked-off on a master list indicating participation in the study and then assigned a number in order to keep all information gained confidential. All fifth grade students, regardless of whether they returned the informed consent form, 
were required by district policy to participate in the Fitnessgram physical fitness assessment. The two physical education teachers worked together, following the M-DCPS Fitnessgram Test Manual, and administered each test to all fifth grade students between December 1, 1999 and May 1, 2000. Because the Fitnessgram Physical Fitness test is an annual requirement as designated by the M-DCPS Division of Life Skills and Special Projects, the physical education teachers were relatively familiar with test administration.

Prior to administering each test, the physical education teachers, following the guidelines for proper conditioning and training, had students practice each test for approximately 4 weeks before the actual test administration. During the weeks preceding the tests students not only practiced the actual tests but also participated in activities and discussions directly associated with the health-related component evaluated by each test. For example, specific activities such as jump rope, low impact aerobics, vigorous team sports, and obstacle courses were emphasized to promote cardiovascular endurance, muscular endurance, and improve body composition. Dance and static stretching routines were offered to help students improve flexibility. Lastly, rope climbing, tug-o-war, and various calisthenics were incorporated into the physical education program to improve muscular strength. The health benefits of participating in each of these physical activities were reviewed as part of instruction prior to students participating in these activities. For example, when introducing jump rope skills, students were instructed of the various health benefits of jump rope such as improving cardiorespiratory endurance, muscular endurance, and coordination. 
The Fitnessgram physical fitness tests were administered during the students' regularly scheduled physical education time. After each test was administered the students involved in the sample immediately attended a brief meeting with the researcher who gave concise instructions on how to correctly fill out the student questionnaire. Students were then allowed approximately 10 minutes to fill in the answers and return them to the researcher. This same process was repeated after the administration of each test resulting in a set of six questionnaires for each subject in the study.

After all six tests were administered and all student questionnaires administered and collected, the researcher randomly selected a stratified sample of six students from the original sample to participate in student interviews. Each of the six randomly selected students was then interviewed individually by the researcher. These interviews were tape recorded and lasted approximately 30-40 minutes, during which time the researcher followed the interview guide. These interviews were then transcribed (See Appendix J: Audiotaped Student Interview Transcription) and analyzed qualitatively for common broad themes that will be described in detail in the next chapter. Analysis of interview notes followed Patton's (1990, pp. 371-459) guidelines for qualitative data analysis and interpretation. During the months of test administration and data collection the researcher secured all test raw scores, questionnaire data, and interview data. Throughout the duration of the study every effort was made to accommodate the needs of the student sample involved in test administrations and data collection.

Analysis of Data

To determine if the physical fitness testing experience promotes an understanding of the health related physical fitness components, a univariate analysis was used. For this 
purpose a measure of frequency for each test and student questionnaire response of what fitness component was measured by that test, was taken (Bryman \& Duncan, 1997). Frequency tables were established and percentages were calculated as a means of describing the data. The second part of this question was analyzed by categorizing data from the open ended questions concerning activities that promote each health-related component. Based on data from these responses, two tables of common themes were created.

Important to this research was whether or not a relationship existed between students' test scores and the length of time they engaged in physical activity outside the school setting. In order to demonstrate the presence or absence of a relationship it was necessary to perform crosstabulations (Stevens, 1990). Additionally, Somers' $d$ correlations (Bryman \& Duncan, 1997) were calculated as a means of establishing a .05 level of significance. This level (0.05) of significance was considered adequate in light of the sample size of 110 subjects. The set of data was processed using the SPSS program (SPSS 10.0 for Windows, 1998). In addition to the quantitative analysis it was also essential to incorporate some qualitative analysis into the collection and interpretation of data collected for this research.

Because it is difficult to analyze student feelings from only questionnaire data, the researcher conducted six student interviews to probe individuals' perceptions about each test, and to find out what students' perceptions were of each of the Fitnessgram tests. These important aspects of the research were appropriately analyzed by the researcher who analyzed the interview data to explore the selected research themes. This was done by creating cross-classification matrices in a number of areas. The researcher also 
triangulated student interview responses with their questionnaire information and raw score data. This triangulation was done in order to further examine student knowledge of the health-related components of fitness, student perceptions of the tests and participation in out of school physical activities.

\section{Summary of the Chapter}

Chapter III has presented a detailed review of sample selection; instrumentation to collect data; methods, materials and procedures utilized to implement the study; and basic procedures employed in the analysis of collected data.

Because of the nature and purpose of this study the research design included quantitative as well as qualitative/phenomenological research techniques (Patton, 1990, pp. 68-69). Data generated from 110 students were analyzed. The following chapter, Chapter IV, presents the results of the study. 


\section{CHAPTER IV}

\section{RESULTS}

In this chapter, data are presented and analyzed according to the purposes described in Chapter I and the procedures described in Chapter III. Results of data analysis relating to hypotheses outlined in Chapter I are presented both quantitatively and qualitatively. For this reason Chapter IV is divided into the following two sections: (a) quantitative analysis of data and (b) qualitative analysis of data. Results of all statistical analyses relating to the hypotheses described in Chapter I are further presented. The analyses involved descriptive and inferential statistical procedures and included univariate analysis as well as bivariate analysis. The statistical procedures involved were analysis of frequency, crosstabulations (Bryman \& Duncan, 1997), and Somers' $d$ Correlation (Bryman \& Duncan, 1997). The results were considered significant if $p<.05$ (Kennedy \& Bush, 1985). The set of data was processed using the SPSS program (SPSS 10.0 for Windows, 1998). In addition to this quantitative statistical analysis the researcher also included qualitative data analysis. This further broadened the information and provided a detailed understanding of the examination of data. Conclusions were drawn from both the quantitative and qualitative analyses.

This chapter will present the results obtained utilizing the student survey questionnaires and the student interviews. One hundred ten students were asked to complete a total of six student questionnaires, one after participating in each of the six Fitnessgram tests. The data produced from these questionnaires helped answer two of the three research questions, "Do students who participate in the Fitnessgram physical fitness testing program acquire the basic knowledge and understanding of the health-related 
components of fitness?" and "Is there a relationship between individuals' test scores and the length of time they spend being physically active outside of the school setting?" The results of these two research questions are discussed in the quantitative analysis of data section of this chapter. However, results of the third research question, "What are students' perceptions of the Fitnessgram physical fitness testing experience?" will be discussed in the qualitative data analysis section of this chapter. Qualitative data were collected from six $5^{\text {th }}$ grade students who were individually interviewed after participating in the Fitnessgram tests.

Statistical procedures that were previously described in Chapter III were performed to determine if children know the health-related components of fitness, if a relationship existed between individuals' tests scores and level of physical activity outside of the school, and lastly to explore students' perceptions about the Fitnessgram experience. The data concerning the knowledge and perceptions of students in regard to the Fitnessgram were analyzed in an attempt to determine if this experience is meaningful and relevant to the learners.

\section{Quantitative Data Analysis}

One of the short-term objectives of the Fitnessgram program is to provide students with opportunities to learn about fitness components while participating in program activities. Additionally, the Fitnessgram program seeks to develop behavior components related to regular participation in physical activity (Meredith \& Welk, 1999). This quantitative section examines these two program objectives. 
For the purpose of determining if students gained the basic knowledge of which health-related components were tested with each of the Fitnessgram tests, the researcher found it helpful to create a frequency table. Included in this table are the number of correct responses to the question asked, "Do you know why the physical education teachers have you take the test?" This question was asked after the completion of each of the six tests. Each time the question was asked, the blank was filled in with the title of the fitness test most recently taken. For example, after the researcher administered the One Mile Walk/Run test the questionnaire read, "Do you know why the physical education teachers have you take the One Mile Walk/Run test?" This was a multiple choice question with the following answers:
A. to measure muscular strength
B. to measure body fatness
C. to measure cardiorespiratory endurance
D. to measure muscular endurance
E. to measure flexibility

The order of the answers A, B, C, D, and E remained the same each time the question was asked. The correct answer for each test is displayed in Table 7. Frequencies for correct student response are displayed in the Table 8. Based upon the percentages displayed in Table 8 it is suggested that if the participants answered correctly, they mastered the knowledge of which health-related component was tested by that specific test. 
Table 7

Physical Fitness Test and Correct Fitness Component Answer

Physical Fitness Test

Correct Answer

One Mile Walk/Run

C. to measure cardiorespiratory endurance

Body Composition

B. to measure body fatness

Curl-Up

D. to measure muscular endurance

Trunk Lift

E. to measure flexibility

Push-Up

A. to measure muscular strength

Backsaver Sit and Reach

E. to measure flexibility

Table 8

Frequency of Correct Student Response

$n$

Test

One Mile Walk/Run

Body Composition

Curl-Up

Trunk Lift

Push-Up

Backsaver Sit and Reach
44

100

30

52

50

68
$\%$

of Correct Responses 
From these percentages (Table 8) it can be assumed that almost all of the participants (90.9\%) understood what health-related component was tested through participating in the Body Composition test; $61.8 \%$ understood what health-related component was tested by the Backsaver Sit and Reach test; $47.3 \%$ understood what health-related component was tested by the Trunk Lift test; $45.5 \%$ understood what health-related component was tested by the Push-Up test; $40.0 \%$ understood what healthrelated component was tested by the One Mile Walk/Run test; and only $27.3 \%$ understood what health-related component was tested by the Curl-Up test.

To further examine students' knowledge of specific health-related components tested by each Fitnessgram test the researcher asked, "What activities have you done during your daily physical education class time that would help you do well on this test?" This is an open-ended question that generated the following data displayed in Table 9 of common themes of physical education activities. These themes or activities were described by students as activities that promote the physical fitness component related to each test in which they participated during physical education class. When analyzing the data that was used to form Table 8, the following activity themes appeared from students' responses: (a) sports skills activities that included responses such as soccer, football, baseball, basketball, and dodgeball; (b) aerobic endurance activities that included responses such as jogging, running, swimming, bicycling, and jumping rope; (c) calisthenics that included student responses of sit-ups, push-ups, jumping jacks, stretching, and trunk lifts; (d) rhythmic activities that included responses of dancing and cheerleading, and lastly; (e) gymnastics skills that included responses of gymnastics, stunts, tumbling, and karate. In addition to these five major themes, combinations of 
Table 9

Common Themes of Physical Education Activities

\begin{tabular}{|c|c|c|c|c|c|c|}
\hline \multirow[b]{2}{*}{ Common Activity Theme(s) } & \multicolumn{6}{|c|}{$\begin{array}{c}\text { Fitnessgram Tests } \\
\end{array}$} \\
\hline & $\begin{array}{l}\text { One Mile } \\
\text { Walk/Run }\end{array}$ & $\begin{array}{c}\text { Body } \\
\text { Composition }\end{array}$ & $\begin{array}{l}\text { Curl } \\
\text { Up }\end{array}$ & $\begin{array}{c}\text { Trunk } \\
\text { Lift }\end{array}$ & $\begin{array}{l}\text { Push } \\
\text { Up }\end{array}$ & $\begin{array}{l}\text { Backsaver Sit } \\
\text { and Reach }\end{array}$ \\
\hline Sports Skills Activities & 26 & $33^{*}$ & 19 & 15 & 22 & 21 \\
\hline Aerobic Type Activities & $43^{*}$ & $31^{*}$ & 9 & 23 & 11 & 15 \\
\hline Calisthenics & 1 & 9 & $41^{*}$ & $31^{*}$ & $41^{*}$ & $43^{*}$ \\
\hline Rhythmic Activities & 1 & & 3 & $3^{*}$ & 3 & $2^{*}$ \\
\hline Gymnastics & & & $1^{*}$ & $1^{*}$ & $1^{*}$ & $2^{*}$ \\
\hline $\begin{array}{l}\text { Sports Skills \& Aerobic Type } \\
\text { Activities }\end{array}$ & $29 *$ & $16^{*}$ & 1 & 2 & 2 & 3 \\
\hline Sports Skills \& Calisthenics & & $2^{*}$ & $2^{*}$ & $1^{*}$ & $1^{*}$ & \\
\hline $\begin{array}{l}\text { Sports Skills \& Rhythmic } \\
\text { Activities }\end{array}$ & & & & & & 1 \\
\hline Sports \& Gymnastic Skills & & & & & & 1 \\
\hline $\begin{array}{l}\text { Aerobic Type Activities \& } \\
\text { Calisthenics }\end{array}$ & $9^{*}$ & $3^{*}$ & 2 & 5 & 3 & $2^{*}$ \\
\hline $\begin{array}{l}\text { Aerobic Type Activities \& } \\
\text { Gymnastic Skills }\end{array}$ & & & & 1 & & 3 \\
\hline Calisthenics \& Gymnastic Skills & & & & & 1 & \\
\hline Absence of correct response & 1 & 16 & 32 & 28 & 25 & 17 \\
\hline $\begin{array}{l}\text { Total number that answered } \\
\text { correctly }\end{array}$ & 107 & 85 & 44 & 41 & 43 & 49 \\
\hline$\%$ of correct responses & 97.2 & 77.4 & 40 & 37.3 & 39 & 44.5 \\
\hline
\end{tabular}

Note. Reported physical education activities that fit into appropriate activity themes for a Fitnessgram health related component are marked with an *.

these themes were also identified because in many cases student responses incorporated more than one theme. Based on which physical activities enhanced which components of fitness, themes were specifically judged to be appropriate for the particular health-related components being assessed by the Fitnessgram tests. For example, if a person wanted to 
improve his or her flexibility he or she would engage in particular activities such as yoga, static stretching, or karate.

Each of these five activity themes contributes to one or more of the health-related physical fitness components tested by the Fitnessgram test. Table 10 displays the relationship of each theme to the Fitnessgram tests and corresponding fitness component. The data included in the table of common themes reinforce the data from the previous frequency Table 8. Together they indicate that a large number of students did not acquire basic knowledge of the health-related components of fitness by participating in the Fitnessgram experience.

Table 10

Common Themes Related To Health Components

\begin{tabular}{lll}
\hline & \multicolumn{3}{c}{ Common Activity Theme } \\
\cline { 2 - 4 } $\begin{array}{l}\text { Fitnessgram } \\
\text { Tests }\end{array}$ & $\begin{array}{c}\text { Sports } \\
\text { Skills } \\
\text { Activities }\end{array}$ & $\begin{array}{c}\text { Aerobic } \\
\text { Endurance } \\
\text { Activities }\end{array}$ \\
$\begin{array}{l}\text { One Mile Walk/Run } \\
\text { (cardiorespiratory endurance) }\end{array}$
\end{tabular}


To probe further into student knowledge of the health-related components of fitness the researcher asked the students, "In what activities do you participate in outside of school that would help you do well on each test?" Table 11 displays the frequencies of YES or NO responses that indicated if the students participated in out of school activities to enhance the health-related component of each test. Table 11 shows that the majority of students do participate in many physical activities outside of school. But when asked to describe those activities in terms of which ones contribute to the health-related physical fitness components students' responses indicated a high percentage were able to identify correctly activities performed outside of school that contributed to cardiorespiratory endurance and body composition but a lesser percentage were able to identify activities which enhance muscular strength, muscular endurance, and flexibility. For cardiorespiratory endurance (One Mile Walk/Run) and Body Composition correct Common Activity Themes which were indicated by students included responses centered around (a) sports skills activities such as soccer, basketball, and football; (b) aerobic type activities such as jogging, bicycling, and skating; (c) a combination of sports skills and aerobic skills; (d) a combination of sports skills and rhythmic activities (i.e., dance, ballet, aerobic dance); and lastly a combination of aerobic type activities and calisthenics. Calisthenics included jumping jacks, sit-ups, push-ups, and various stretches. Correct activities themes are the same for both cardiorespiratory endurance and body composition because activities that improve one of these components also improve the other component. 
Table 11

Frequency of Student Participation in Out of School Physical Activities

\begin{tabular}{lcccc}
\hline Test & $\begin{array}{c}n \\
\text { YES participation } \\
\text { outside of school }\end{array}$ & $\begin{array}{c}\% \\
\text { YES }\end{array}$ & $\begin{array}{c}\text { NO participation } \\
\text { outside of school }\end{array}$ & $\begin{array}{c}\% \\
\text { NO }\end{array}$ \\
\hline One Mile Walk/Run & 86 & 78.2 & 24 & 21.8 \\
Body Composition & 79 & 71.8 & 31 & 28.2 \\
Curl-Up & 63 & 57.3 & 47 & 42.7 \\
Trunk Lift & 62 & 56.4 & 48 & 43.6 \\
Push-Up & 66 & 60.0 & 43 & 39.1 \\
Backsaver Sit \& Reach & 60 & 54.5 & 50 & 45.5 \\
\hline
\end{tabular}

Common activities that promote muscular strength were categorized under (a) calisthenics (described above), (b) gymnastics that includes activities such as karate, stunts and tumbling, and (c) aerobic type activities/calisthenics.

Correct response to muscular endurance type activities were categorized under (a) calisthenics, (b) gymnastics, and (c) combination of sports skills and calisthenics. Lastly, flexibility type activities were categorized as (a) calisthenics, (b) rhythmic activities, (c) gymnastics, (d) combination sports skills/gymnastics, and lastly (e) combination aerobic type activities/calisthenics.

Table 12 indicates common themes from the activities students have participated in outside the school that they describe as helping them with each test. From this table (Table 12 ) it is clear that $67.3 \%$ of the participants were able to correctly identify 
Table 12

Common Themes of Out of School Activities

\begin{tabular}{|c|c|c|c|c|c|c|}
\hline \multirow[b]{2}{*}{ Common Activity Theme(s) } & \multicolumn{6}{|c|}{ Fitnessgram Tests } \\
\hline & $\begin{array}{l}\text { One Mile } \\
\text { Walk/Run }\end{array}$ & $\begin{array}{c}\text { Body } \\
\text { Composition }\end{array}$ & $\begin{array}{l}\text { Curl } \\
\text { Up }\end{array}$ & $\begin{array}{c}\text { Trunk } \\
\text { Lift }\end{array}$ & $\begin{array}{l}\text { Push } \\
\text { Up }\end{array}$ & $\begin{array}{c}\text { Backsaver Sit } \\
\text { and Reach }\end{array}$ \\
\hline Sports Skills Activities & $37^{*}$ & $29^{*}$ & 14 & 12 & 15 & 16 \\
\hline Aerobic Type Activities & $28 *$ & $16^{*}$ & 8 & 5 & 6 & 4 \\
\hline Calisthenics & & 5 & $7^{*}$ & $10^{*}$ & 9* & $10^{*}$ \\
\hline Rhythmic Activities & 1 & 2 & 3 & $4^{*}$ & 2 & $4^{*}$ \\
\hline Gymnastics & & 2 & $2^{*}$ & $3 *$ & $4^{*}$ & $4^{*}$ \\
\hline $\begin{array}{l}\text { Sports Skills \& Aerobic Type } \\
\text { Activities }\end{array}$ & $6^{*}$ & $7^{*}$ & 4 & 3 & 4 & 2 \\
\hline Sports Skills \& Calisthenics & & & $1^{*}$ & & & \\
\hline $\begin{array}{l}\text { Sports Skills \& Rhythmic } \\
\text { Activities }\end{array}$ & $2^{*}$ & $2^{*}$ & & & 1 & \\
\hline Sports \& Gymnastic Skills & & & & & & $1^{*}$ \\
\hline $\begin{array}{l}\text { Aerobic Type Activities \& } \\
\text { Calisthenics }\end{array}$ & $1^{*}$ & $3^{*}$ & & $2^{*}$ & $1^{*}$ & \\
\hline $\begin{array}{l}\text { Aerobic Type Activities \& } \\
\text { Gymnastic Skills }\end{array}$ & & & & & & \\
\hline Calisthenics \& Gymnastic Skills & & & & & & $1^{*}$ \\
\hline Absence of correct response & 35 & 44 & 71 & 71 & 68 & 68 \\
\hline $\begin{array}{l}\text { Total number that answered } \\
\text { correctly }\end{array}$ & 74 & 57 & 10 & 19 & 14 & 20 \\
\hline$\%$ of correct responses & 67.3 & 52 & 9.1 & 17.3 & 12.8 & 18.2 \\
\hline
\end{tabular}

Note. Reported out of school activities that fit into appropriate activity themes for a Fitnessgram health related component are marked with an *.

activities they do at home that help develop cardiorespiratory endurance. Additionally, $52 \%$ of the participants were able to identify activities done at home that help to enhance body composition. Students were less able to identify activities that promote muscular strength (12.8\%), muscular endurance (9.1\%), and flexibility $(52 \% \& 18.2 \%)$. 
Conclusions Concerning Student Knowledge of the Health-Related

Components of Physical Fitness

Combined results of the frequencies, percentages, and common themes tables showed that many students demonstrated little understanding of why they take each Fitnessgram test or the health-related component measured by each test. For Curl-Ups $27.3 \%$ of the students answered the multiple choice question correctly; $40 \%$ were able to correctly identify physical education activities that help with Curl-Ups and a much lower percent, $9.1 \%$, were able to identify outside of school activities that would help with Curl-Ups. For Trunk Lift, the percentages were higher; $47.3 \%$ correctly answered the multiple choice question, $37.3 \%$ correctly identified helpful physical education activities, and $17.3 \%$ correctly identified out of school activities that help with this test. The percentages for Push-Ups were $45.5 \%, 39.0 \%$, and $12.8 \%$. The last three tests yielded higher percentages that indicate that some health-related components may be easier for children to comprehend.

Body Composition results were $90.9 \%, 77.7 \%$, and $52.0 \%$. Sit and Reach percentages were $61.8 \%, 44.0 \%$, and $18 \%$. The $44.0 \%$ and the $18.0 \%$ were percentages from the open ended written response question indicating some difficulty in identifying activities related to flexibility. Lastly, the percentages for the One Mile Walk/Run were $40.0 \%, 97.0 \%$, and $67.3 \%$. It does appear from this information that students expressed more of an understanding of body composition and cardiorespiratory endurance but lacked in understanding the other three health-related components of fitness: muscular strength, muscular endurance, and flexibility. This lack of knowledge in connecting the 
test with the health-related component may be consistent with Piaget's theories on cognitive development (Solso, 1991).

Most students who participate in the Fitnessgram test at the elementary level are 9 and 10 years old. According to the general principles of Piaget's theory of cognitive development, that age would put the participants of the study at the Concrete Operational Period of cognitive functioning. "The child during this period is limited to coordinating concrete things in an actual situation. What the student cannot yet do is to coordinate possible things in a hypothetical or more abstract formalized situation" (Solso, 1991, p. 378). When the researcher asked the participants to identify activities out of context and describe the abstract concepts of fitness, this may have been intellectually more than the students could internalize and comprehend.

Possible Relationships between Individual Test Performance and Time Spent Being Physically Active Outside of School

To answer the major research question, "Is there a relationship between Individuals' test scores and the amount of time students spend being physically active outside of school?" relationships between the variables of interest were examined using crosstabulations and Somers' $d$ correlation for ordinal-by-ordinal data. An alpha level of .05 was used for all statistical tests.

The relationship between students' performance on the Fitnessgram tests components and how much time students spent being physically active outside of school was examined. For each of the six tests students were asked how much time they spend being physically active (in activities specifically related to each test) outside of school. After computing crosstabulations and Somers' $d$ for ordinal data there was not a 
Table 13

Crosstabulations between Test Score and Amount of Time Spent Being Physically Active Outside of School

Fitnessgram Test *

$d$

$p$

One Mile Walk/Run

.035

.696

Body Composition

.032

.704

Curl-Up

.170

.014

Push-Up

.108

.154

Backsaver Sit and Reach

.189

.015

Note. ${ }^{*}$ Because all participants met the criteria for the Trunk Lift test, Somers' $d$ could not be calculated. significant association found between variables that included the One Mile Walk/Run, Body Composition, Trunk Lift, and Push-Up tests. However, there was a significant positive association found for two of the six tests. A relationship between individuals' test scores and the amount of time spent outside of school participating in activities related to that test, was found for the Curl-Up and the Backsaver Sit and Reach tests (See Table 13).

These results indicate a significant correlation between test component score and the amount of time spent physically active outside of school for these two test components.

As a result, the null hypotheses for Curl-Up and Backsaver Sit and Reach components were rejected and it was concluded that the correlation $(\delta)$ is greater than zero in the population. This indicates that the correlation is significant and a relationship 
exists between Curl-Up score and out of school activity levels and Backsaver Sit and Reach scores and out of school activity levels.

There was no significance relationships found for the remaining four fitness tests: One Mile Walk/Run, Body Composition, Push-Up, and Trunk Lift. But, in most cases the lack of an existing relationship can be substantiated with basic exercise physiology and research.

When analyzing cardiorespiratory endurance (One Mile Walk/Run) it is questionable whether young children can improve their fitness level by being physically active. A common question among physical education teachers is whether training will increase aerobic performance. "Some researchers have found an increase in aerobic power through training, whereas others report that training has no impact on the aerobic system" (Pangrazi, 2001, p. 28). Payne and Morrow's (1993) findings, after reviewing 28 studies dealing with aerobic capacity, found that training had little or no effect on aerobic capacity in young children. Because of this it is of no surprise that the researcher found no relationship when analyzing the amount of time spent exercising and students' scores on the One Mile Walk/Run test (which is the test to assess cardiorespiratory endurance). Body Composition refers to the ratio of fat to lean body tissue within the body. When analyzing for a possible relationship between amount of outside activity and scores for Body Composition there was no significance found. The researcher struggled with this because there is evidence that suggests a linear relationship between obesity and physical activity. For example, many obese people appear to have a decreased tendency for physical activity. As weight increases, the urge to be physically active declines further. Lack of physical activity is common in obese children. Corbin and Fletcher 
(1968) filmed normal weight and overweight children at play and found a "great difference" in activity levels between the two groups. However, the finding from this research indicated no significant relationship between the two variables.

When analyzing the Push-Up test there was no significance found between the amount of time being physically active outside of school and the Push-Up test score. Research (Beunen, 1989) indicates that muscular strength increases linearly with chronological age during the elementary school years. Muscular strength is directly related to the number of muscle fibers an individual possesses, which is genetically determined. "So an individual is therefore somewhat muscularly limited by genetic restrictions" (Pangrazi, 2001, p. 27). This may in part explain why no significant relationship was found between Push-Up scores and amount of time spent outside of school being physically active in muscular strength type activities. There was also no significant relationship found between this variable and the Trunk Lift test.

There was no significant relationship found between the students' scores on the Trunk Lift test and the amount of time they spent being physically active outside of school. No relationship was found because of the most obvious reason-every child in the sample population passed this test. In the qualitative section of this paper, students interviewed indicated that this test was "too easy" and the standard for this test should be "raised." In essence, there was no challenge or exertion necessary to do well on this test. It is interesting to note that criterion-referenced health standards have not been established for flexibility that is the health-related component tested by the Trunk Lift. Instead, criterion-referenced training standards are used in this area of fitness. These standards represent a "reasonable expectation" for students who are "somewhat active." 
All students are encouraged to meet the criteria but it's unusual that all do. For this reason, the flexibility standards may in fact be set too low.

Conclusion of Possible Relationship between Individual Test Performance and Time Spent Being Physically Active Outside of School

Data from questionnaires completed by 110 fifth grade students identified a significant association between the Curl-Up test and the amount of time students spent being physically active (in related activities) outside of school. Similarly, a significant association was identified between the Backsaver Sit and Reach and the amount of time students spent being physically active (in related activities) outside of school. No significant associations were found between the One Mile Walk/Run, Body Composition, Trunk Lift, and Push-Up tests when compared with how much time students spent being physically active in out of school activities related to each test.

In addition to analyzing possible relationships between the Fitnessgram tests and the amount of physical activity, the researcher also examined student knowledge of the health-related fitness components tested by the Fitnessgram tests. The last area of focus of the research project is students' perceptions of the Fitnessgram testing experience. Students' thoughts and feelings about the Fitnessgram will be discussed in detail in the following qualitative analysis of data section.

\section{Qualitative Data Analysis}

One of the major purposes of this research project was to determine children's perceptions of the Fitnessgram physical fitness testing experience.

The intangible perceptions that the child has of the P. E. programme clearly need to be identified in order that a distinction may be made between what we believe 
to be happening, as portrayed by behavior, and what we may come to know of the child's experience through actually asking them. (Laws \& Fisher, 1999, p. 24)

Because perceptions such as attitude and feelings are difficult to measure from a purely quantitative approach, the researcher found it beneficial to also include qualitative methods.

It is surprising to note that there has been little research conducted to determine how physical fitness testing affects students' perceptions including their knowledge, attitude, and feelings (Hopple \& Graham, 1995). Pate (1991) summarizes the need for such research:

It would be desirable to know how children respond to participation in these [physical fitness] tests ... Are tests viewed as fun? Do tests have differential effects on different types of children? Though irrelevant from a strict [quantitative] measurement perspective, these issues may determine the appropriateness of fitness testing in the school setting. (p. 233)

Research methods that focus on interpretation such as student interviews are being employed as a primary means of answering such questions. Laws and Fisher (1999) write,

... pupil interviews provide(d) entry into what is effectively another world in which pupils exercise their own, often complex, sets of interpretations about P. E. which have relevance within their own frame of reference and which may or may not be available to the teacher. (p. 23)

Interviewing students allows the researcher to study selected issues in depth and detail. In the past decade interviewing children has begun to gain popularity among physical educators (Hopple \& Graham, 1995; Manross, 1994; Rattliffe, Imwold, \& Conkell, 1994).

In keeping with this trend, interviews were used as a means of determining what $5^{\text {th }}$ grade students thought and felt about the Fitnessgram physical fitness tests. The major 
research question explored through these interviews was, "What are children's perceptions of the Fitnessgram physical fitness testing experience?" In order to answer this question the interviews focused around three themes: (a) students' knowledge of their score for each of the six Fitnessgram tests, (b) students' feelings during each of the six Fitnessgram tests, and (c) students' thoughts about each Fitnessgram test. Six students were interviewed individually, three boys and three girls. The interviews were audio taperecorded and lasted approximately 45 minutes each (See Appendix I \& J).

\section{Data Analysis}

The student interviews were analyzed according to the following procedures. Interview data was "cut and pasted" onto six large sheets of paper, one sheet dedicated to each of the six Fitnessgram tests. Each of these six large papers were then divided into three parts focusing on the three main research themes: (a) students' knowledge of scores for each test, (b) students' feelings about each test, and (c) students' thoughts about each test. When analyzing this data the researcher worked inductively using logical analysis (Patton, 1990) to explore these themes. This was done by creating cross-classification matrices in a number of areas.

First, the researcher found it beneficial to briefly describe each student interviewed and provide a synopsis of their Fitnessgram raw test scores for each test (See Figure 5). Students' real names are not used; instead each child was assigned a pseudonym. Students will be identified as Fred, Ian, Tom, Nancy, Ellie, and Sissy. Figure 5 provides a concise description of the students' recorded test data and general fitness levels. In addition to participants' gender and age, fitness awards are also included in Table 14. The highest fitness award for the Fitnessgram administered in M-DCPS is 
Table 14

Student's Fitnessgram Tests Raw Scores and Pass or Fail Status

Participants

Fitnessgram Test

$\begin{array}{rllllll}\text { One Mile } & \text { Body } & \text { Curl } & \text { Trunk } & \text { Push } & \text { Backsaver } & \text { Fitness } \\ \text { Walk/Run } & \text { Composition } & \text { Up } & \text { Lift } & \text { Up } & \text { Sit and Reach } & \text { Award }\end{array}$

\begin{tabular}{|c|c|c|c|c|c|c|c|}
\hline $\begin{array}{l}\text { Fred } \\
\text { Male } \\
\text { Age: } 10\end{array}$ & 17:04 (F) & $50 \%(\mathrm{~F})$ & $2(\mathrm{~F})$ & $+12 "(\mathrm{P})$ & $5(\mathrm{~F})$ & $+9(\mathrm{P})$ & None \\
\hline $\begin{array}{l}\text { Ian } \\
\text { Male } \\
\text { Age:11 }\end{array}$ & $10: 30(\mathrm{P})$ & $33 \%(F)$ & $46(\mathrm{P})$ & $+12 "(\mathrm{P})$ & $12(\mathrm{P})$ & $+9(\mathrm{P})$ & Silver \\
\hline $\begin{array}{l}\text { Tom } \\
\text { Male } \\
\text { Age:11 }\end{array}$ & 7:57 (P) & $15 \%(\mathrm{P})$ & $22(\mathrm{P})$ & $+12 "(\mathrm{P})$ & $17(\mathrm{P})$ & $+9(\mathrm{P})$ & Gold \\
\hline $\begin{array}{l}\text { Nancy } \\
\text { Female } \\
\text { Age: } 10\end{array}$ & 9:12 (P) & $24 \%(\mathrm{P})$ & $31(\mathrm{P})$ & $+12 "(\mathrm{P})$ & $13(\mathrm{P})$ & $+9(\mathrm{P})$ & Gold \\
\hline $\begin{array}{l}\text { Ellie } \\
\text { Female } \\
\text { Age: } 10\end{array}$ & $14: 48(F)$ & $49 \%(F)$ & $22(\mathrm{P})$ & $+12 "(\mathrm{P})$ & $0(\mathrm{~F})$ & $+9(\mathrm{P})$ & None \\
\hline $\begin{array}{l}\text { Sissy } \\
\text { Female } \\
\text { Age:11 }\end{array}$ & 9:32 (P) & $24 \%(P)$ & $24(\mathrm{P})$ & $+12^{\prime \prime}(\mathrm{P})$ & $13(\mathrm{P})$ & $-9(F)$ & Silver \\
\hline
\end{tabular}

Note. $(\mathrm{P})=$ Pass and $(\mathrm{F})=$ Fail.

the Gold card. Tom and Nancy achieved this level, which means they passed the criteria set for each of the six Fitnessgram tests. The second fitness award for the Fitnessgram administered in M-DCPS is the Silver card. Ian and Sissy received the Silver card award that indicates that they each passed all but one of the six Fitnessgram tests. Fred and Ellie received no fitness award and that means they failed to meet the criteria for two or more of the Fitnessgram tests. 
Students' Knowledge of and Feelings about Their Fitnessgram Test Scores

Knowledge of results can be a huge factor in increasing the level of motivation among young children. "Knowledge of results is extrinsic feedback given after a skill has been performed" (Pangrazi, 2001, p. 48). Feedback improves student performances and can act as a motivational tool. In order to determine if participants possessed a basic "knowledge of results" and how they felt about their performance the researcher asked the following questions. How did you do on the (particular test) test? Do you know what your score was? How do you feel about your score? Figure 3 matrix displays the answers to the aforementioned questions. The figure consists of direct statements taken from the student interviews.

When analyzing the data included in Figure 3 it became apparent that the participants had "knowledge of results." There were only two instances (one for Fred and one for Ellie) when they did not remember if they passed or failed a test. It is interesting to note that Fred and Ellie are the two participants who scored poorly on these tests. Even though she passed it, Ellie was unable to recall her score for the Backsaver Sit and Reach test and Fred was unable to remember his (failing) score for the Push-Up test. The other participants; Ian, Tom, Nancy, and Sissy remembered their scores as well as how they performed. The score for each test is PASS or FAIL and performance refers to their personal feelings about how well or how poorly they performed. In addition to their "knowledge of results" students were asked how they felt about their performance. 
Fitnessgram Test

\begin{tabular}{|c|c|c|c|c|c|c|}
\hline & $\begin{array}{l}\text { One Mile } \\
\text { Walk/Run }\end{array}$ & $\begin{array}{c}\text { Body } \\
\text { Composition }\end{array}$ & $\begin{array}{l}\text { Curl- } \\
\text { Up }\end{array}$ & $\begin{array}{c}\text { Trunk } \\
\text { Lift }\end{array}$ & $\begin{array}{l}\text { Push- } \\
\text { Up }\end{array}$ & $\begin{array}{l}\text { Backsaver } \\
\text { Sit and Reach }\end{array}$ \\
\hline Raw Scores / Pass or Fail & 17:04 / Fail & $50 \% /$ Fail & 2 / Fail & $+12 ” /$ Pass & 5 / Fail & $+9 " /$ Pass \\
\hline $\begin{array}{l}\text { Participant } \\
\text { Fred }\end{array}$ & $\begin{array}{l}\text { "Not so well." } \\
\text { "I don't feel bad } \\
\text { because I know } \\
\text { I tried my best." }\end{array}$ & $\begin{array}{l}\text { "I think I did good } \\
\text { I felt good because } \\
\text { I had less than } \\
\text { last year." "I felt } \\
\text { good." }\end{array}$ & $\begin{array}{l}\text { "I did poor." } \\
\text { "I don't feel } \\
\text { good but I'll } \\
\text { just try } \\
\text { harder." }\end{array}$ & $\begin{array}{l}\text { "I passed. I was } \\
\text { passed the ruler." } \\
\text { "I felt good... } \\
\text { in my opinion I } \\
\text { felt that it was } \\
\text { easy or me." }\end{array}$ & $\begin{array}{l}\text { "... I didn't remember } \\
\text { what my score was. I } \\
\text { think I did better than } \\
\text { poor but not average." } \\
\text { "I felt good but I'm } \\
\text { going to practice more } \\
\text { to see if I can work } \\
\text { up to it." }\end{array}$ & $\begin{array}{l}\text { "I think I passed." } \\
\text { "I felt good ... } \\
\text { I felt fine." }\end{array}$ \\
\hline Raw Scores / Pass or Fail & $110: 30$ / Pass & $33 \% /$ Fail & 46 / Pass & $+12 " /$ Pass & 12 / Pass & $+9 "$ / Pass \\
\hline Ian & $\begin{array}{l}\text { "I did OK, good." } \\
\text { "I think I could } \\
\text { have done better." }\end{array}$ & $\begin{array}{l}\text { "Poor. Bad score. But I } \\
\text { got better this year than } \\
\text { last year." "Bad cause I } \\
\text { was not losing weight } \\
\text { a lot." }\end{array}$ & $\begin{array}{l}\text { "Good. Yeah. } \\
\text { I passed } \\
\text { Okay." } \\
\end{array}$ & $\begin{array}{l}\text { "I passed." "Good, } \\
\text { I passed all the } \\
\text { ruler." }\end{array}$ & $\begin{array}{l}\text { "Good, I passed." } \\
\text { "Kinda depressed } \\
\text { because I know I } \\
\text { can do better." }\end{array}$ & $\begin{array}{l}\text { "Excellent." } \\
\text { "Good." }\end{array}$ \\
\hline Raw Scores / Pass or Fai & 7:57 / Pass & $15 \%$ / Pass & 22 / Pass & $+12 " /$ Pass & 17 / Pass & + 9" / Pass \\
\hline Tom & $\begin{array}{l}\text { "I did good." } \\
\text { "Good, it's the } \\
\text { best I've done." }\end{array}$ & $\begin{array}{l}\text { "I passed." "I'm glad } \\
\text { I passed it." }\end{array}$ & $\begin{array}{l}\text { "I did great." } \\
\text { feel good cause } \\
\text { most people } \\
\text { didn't even } \\
\text { get to } 22 . "\end{array}$ & $\begin{array}{l}\text { "I "I passed it. } \\
\text { Past } 12 \text { inches." } \\
\text { I did good. It } \\
\text { was better than } \\
\text { most people did." }\end{array}$ & $\begin{array}{l}\text { "I did good. Yeah, I did } \\
\text { good on everything." } \\
\text { "It's a good number. } \\
\text { Seven's a lucky } \\
\text { number." }\end{array}$ & $\begin{array}{l}\text { "I did good." } \\
\text { "It was good. } \\
\text { At least l } \\
\text { could flex." }\end{array}$ \\
\hline
\end{tabular}

Figure 3. Students' knowledge and feelings related to each test. 
Fitnessgram Test

\begin{tabular}{|c|c|c|c|c|c|c|}
\hline & $\begin{array}{l}\text { One Mile } \\
\text { Walk/Run }\end{array}$ & $\begin{array}{c}\text { Body } \\
\text { Composition }\end{array}$ & $\begin{array}{l}\text { Curl- } \\
\text { Up }\end{array}$ & $\begin{array}{l}\text { Trunk } \\
\text { Lift }\end{array}$ & $\begin{array}{l}\text { Push- } \\
\text { Up }\end{array}$ & $\begin{array}{l}\text { Backsaver } \\
\text { Sit \& Reach }\end{array}$ \\
\hline Raw Scores / Pass or Fail & 9:12 / Pass & $24 \% /$ Pass & $31 /$ Pass & $+12 " /$ Pass & 13 / Pass & $+9 "$ / Pass \\
\hline $\begin{array}{l}\text { Participant } \\
\text { Nancy }\end{array}$ & $\begin{array}{l}\text { "I think I did pretty } \\
\text { good." "I think } \\
\text { that's the best score } \\
\text { I ever did. I was } \\
\text { happy." }\end{array}$ & $\begin{array}{l}\text { "I did good. My total } \\
\text { was twenty five." } \\
\text { "That's good. I did } \\
\text { better than last year, } \\
\text { though." }\end{array}$ & $\begin{array}{l}\text { "Good. I got } \\
\text { thirty - five." } \\
\text { I felt good } \\
\text { about it." }\end{array}$ & $\begin{array}{l}\text { "I passed. I } \\
\text { felt good." }\end{array}$ & $\begin{array}{l}\text { "Good, great actually." } \\
\text { "It made me feel } \\
\text { like happy because } \\
\text { I was practicing just } \\
\text { to do ten, but then } \\
\text { did more than what I } \\
\text { actually had to do." }\end{array}$ & $\begin{array}{l}\text { "Good, I know } \\
\text { I passed." "I } \\
\text { felt glad that } \\
\text { I passed it." }\end{array}$ \\
\hline Raw Scores / Pass or Fail & 14:48 / Fail & $49 \% /$ Fail & 22 / Pass & $+12 " /$ Pass & 0 / Fail & $+9 "$ / Pass \\
\hline Ellie & $\begin{array}{l}\text { "Bad, Fail." "I } \\
\text { felt bad a little." }\end{array}$ & $\begin{array}{l}\text { "Um ... bad." } \\
\text { "Bad." }\end{array}$ & $\begin{array}{l}\text { "I think I passed } \\
\text { that one. I'm not } \\
\text { sure." "I feel } \\
\text { good about it } \\
\text { because I didn't } \\
\text { know I could } \\
\text { actually do so } \\
\text { many sit-ups." }\end{array}$ & $\begin{array}{l}\text { "Good I think I } \\
\text { passed that one } \\
\text { also." "Good, } \\
\text { since I always } \\
\text { do that cause I } \\
\text { passed last year, } \\
\text { so I thought I } \\
\text { could pass this } \\
\text { year." }\end{array}$ & $\begin{array}{l}\text { "Bad. Fail." "Bad ... } \\
\text { I felt like I was the } \\
\text { only one that didn't } \\
\text { pass that test, even } \\
\text { though I know } \\
\text { some of my other } \\
\text { friends didn't pass } \\
\text { it, I guess." }\end{array}$ & $\begin{array}{l}\text { "I don't } \\
\text { remember. I } \\
\text { think I passed." } \\
\text { "Hmmmm... } \\
\text { good. Good." }\end{array}$ \\
\hline Raw Scores / Pass or Fail & 9:32 / Pass & $24 \%$ / Pass & 24 / Pass & $+12 " /$ Pass & $13 /$ Pass & -9" / Fail \\
\hline Sissy & $\begin{array}{l}\text { "Very well. } \\
\text { Passed." } \\
\text { "I loved it." }\end{array}$ & $\begin{array}{l}\text { "Good. Twenty five } \\
\text { exact." "Happy." }\end{array}$ & $\begin{array}{l}\text { "Good. Yes I } \\
\text { passed it." } \\
\text { "Good. I liked } \\
\text { it." }\end{array}$ & $\begin{array}{l}\text { "Good. Very } \\
\text { good." }\end{array}$ & "Very well." "Good." & $\begin{array}{l}\text { "Bad. I know I } \\
\text { Failed." "Bad. } \\
\text { Not so good." }\end{array}$ \\
\hline
\end{tabular}

Figure 3. Students' knowledge and feelings related to each test (Cont.) 
When asked to describe their feelings about their performance, the following connection was made: Students' feelings about their test scores were directly related to their test scores. For example, Tom, Nancy, Ellie, and Sissy used words such as, "good," "glad," "great," "I loved it," "very well," and "happy," when they passed a test. When describing how they felt about a failing score Fred, Ian, Ellie, and Sissy made comments such as: "I felt a little bad," "bad," "fail," “don't feel good," and "poor." There were two instances with Fred however, where he indicated that he felt "good" although he failed the test. In one instance when asked how he felt about his score for the Body Composition he said, "I felt good because I had less than last year," and when asked about his feelings of a failing score on the Push-Up test he said, "I felt good but I'm going to practice more to see if I can work up to it."

\section{Students' Feelings during the Fitnessgram Experience}

To further explore the major research question, "What are children's perceptions of the Fitnessgram physical fitness testing experience?" the researcher explored students' feelings during each of the six Fitnessgram tests by asking, "How did you feel during the test both physically and mentally?" Figures 4 and 5 display the data collected in response to that question. Figure 4 focuses on the participants' physical feelings during each test, whereas Figure 5 focuses on the mental aspects of how the participants felt and what they were thinking during each test.

When asked to describe how they felt physically during each test students reported the following information. For the One Mile Walk/Run, 3 participants felt fine during the test while the other three experienced some pain. Ian and Nancy both reported "tired legs" and Ellie reported "pain in her ribs." For Body Composition, Ian, Tom, 
Fitnessgram Test

\begin{tabular}{|c|c|c|c|c|c|c|}
\hline & $\begin{array}{l}\text { One Mile } \\
\text { Walk/Run }\end{array}$ & $\begin{array}{c}\text { Body } \\
\text { Composition }\end{array}$ & $\begin{array}{l}\text { Curl- } \\
\text { Up }\end{array}$ & $\begin{array}{c}\text { Trunk } \\
\text { Lift }\end{array}$ & $\begin{array}{l}\text { Push- } \\
\text { Up }\end{array}$ & $\begin{array}{c}\text { Backsaver } \\
\text { Sit and Reach }\end{array}$ \\
\hline \multicolumn{7}{|c|}{ Participant } \\
\hline Fred & "Good." & $\begin{array}{l}\text { "It hurt because } \\
\text { it pinched." }\end{array}$ & "I felt strained." & $\begin{array}{l}\text { "My neck didn't } \\
\text { feel... it felt good." }\end{array}$ & $\begin{array}{l}\text { "I felt like I was } \\
\text { working my } \\
\text { muscles. It was } \\
\text { making my } \\
\text { muscles stronger." }\end{array}$ & $\begin{array}{l}\text { "Um... my skin part } \\
\text { felt like it was } \\
\text { stretching. It was... } \\
\text { it hurt a little bit." }\end{array}$ \\
\hline Ian & $\begin{array}{l}\text { "My legs } \\
\text { some pain." }\end{array}$ & "No." & $\begin{array}{l}\text { "My stomach } \\
\text { was hurting." }\end{array}$ & $\begin{array}{l}\text { "Easy for my } \\
\text { body. No pain." }\end{array}$ & $\begin{array}{l}\text { "Didn't feel } \\
\text { anything } \\
\text { physically." }\end{array}$ & $\begin{array}{l}\text { "Yeah, on my leg. } \\
\text { A little bit." }\end{array}$ \\
\hline Tom & $\begin{array}{l}\text { "I felt great } \\
\text { "cause I run } \\
\text { two miles } \\
\text { every day." }\end{array}$ & "I felt normal." & $\begin{array}{l}\text { "It felt fine as } \\
\text { long as I didn't } \\
\text { like go to the side } \\
\text { or something. It } \\
\text { hurt... when I } \\
\text { went to the side." }\end{array}$ & $\begin{array}{l}\text { "It felt good. I } \\
\text { usually do that } \\
\text { all the time." }\end{array}$ & $\begin{array}{l}\text { "It really didn't } \\
\text { hurt 'cause I was } \\
\text { lifting weights } \\
\text { at that time." }\end{array}$ & $\begin{array}{l}\text { "I didn't feel any } \\
\text { pulling in my } \\
\text { body." }\end{array}$ \\
\hline
\end{tabular}

Figure 4. Feelings during each Fitnessgram test. 


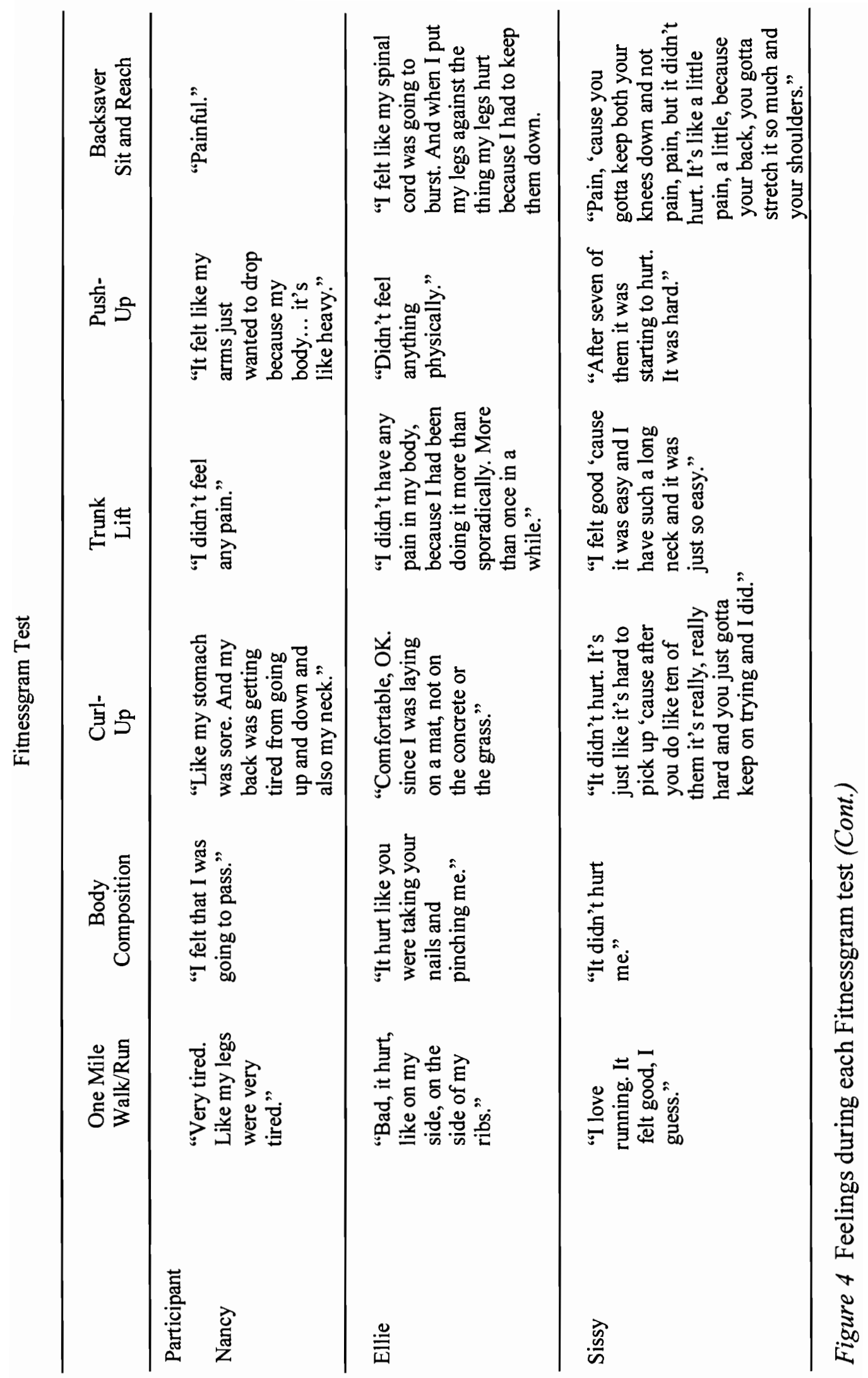




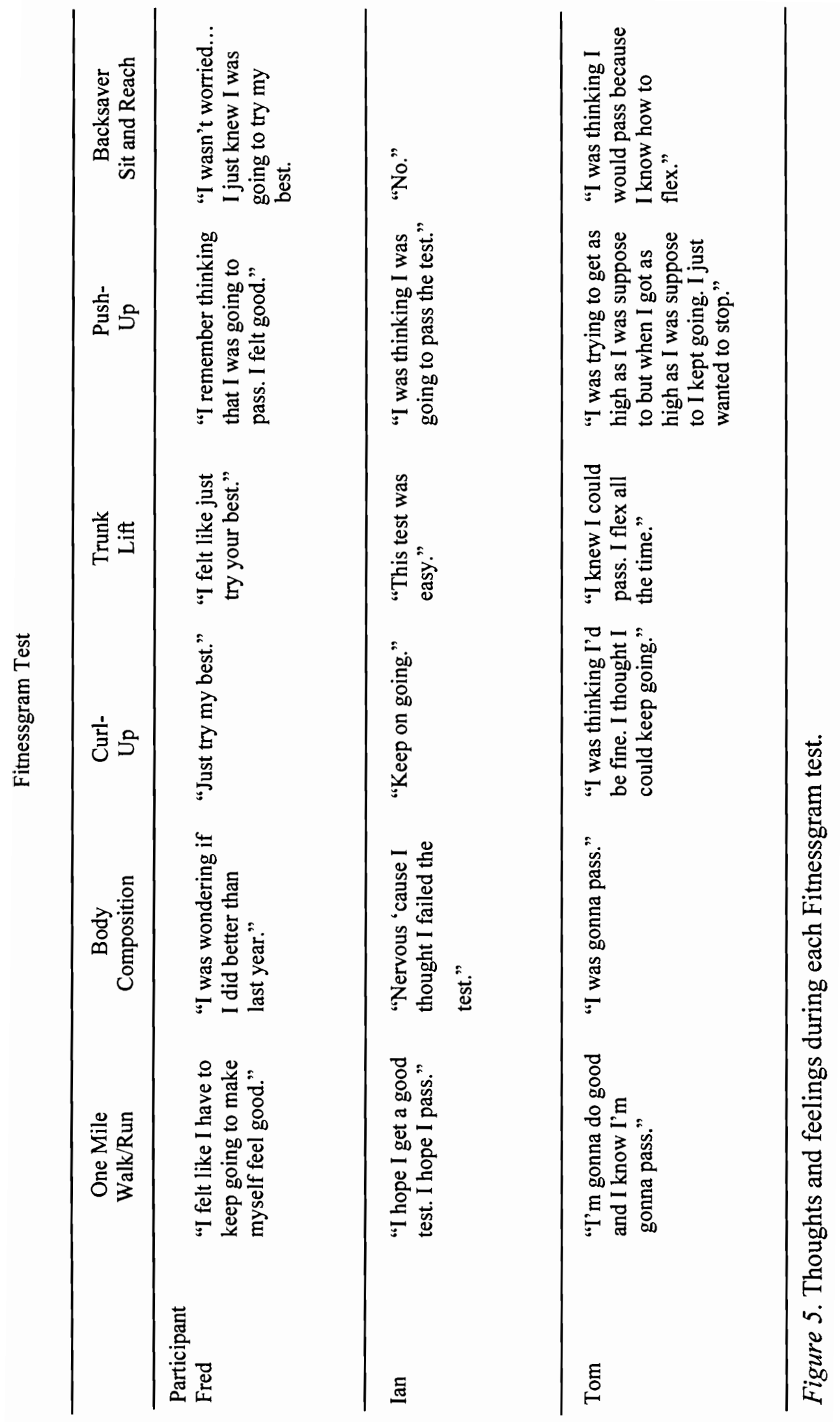


Fitnessgram Test

\begin{tabular}{|c|c|c|c|c|c|c|}
\hline & $\begin{array}{l}\text { One Mile } \\
\text { Walk/Run }\end{array}$ & $\begin{array}{c}\text { Body } \\
\text { Composition }\end{array}$ & $\begin{array}{l}\text { Curl- } \\
\text { Up }\end{array}$ & $\begin{array}{l}\text { Trunk } \\
\text { Lift }\end{array}$ & $\begin{array}{l}\text { Push- } \\
\text { Up }\end{array}$ & $\begin{array}{c}\text { Backsaver } \\
\text { Sit and Reach }\end{array}$ \\
\hline $\begin{array}{l}\text { Participant } \\
\text { Nancy }\end{array}$ & $\begin{array}{l}\text { "I just kept } \\
\text { thinking that } \\
\text { I had to keep } \\
\text { going or else } \\
\text { I would get a } \\
\text { bad grade." }\end{array}$ & "I felt positive." & $\begin{array}{l}\text { "I was just thinking } \\
\text { that my stomach } \\
\text { was going to be } \\
\text { sore for awhile } \\
\text { and it was, too." }\end{array}$ & $\begin{array}{l}\text { "I felt pretty } \\
\text { confident." }\end{array}$ & $\begin{array}{l}\text { "I just kept } \\
\text { thinking I } \\
\text { wanted to keep } \\
\text { going because I } \\
\text { wanted to make } \\
\text { a lot to make a } \\
\text { good grade." }\end{array}$ & $\begin{array}{l}\text { "I thought I was } \\
\text { going to fail } \\
\text { because I } \\
\text { couldn't reach } \\
\text { the number. It } \\
\text { made me feel } \\
\text { like I wasn't } \\
\text { going to pass." }\end{array}$ \\
\hline Ellie & $\begin{array}{l}\text { "I wasn't going } \\
\text { to pass the } \\
\text { test." }\end{array}$ & $\begin{array}{l}\text { "I thought I wasn't } \\
\text { going to pass." }\end{array}$ & $\begin{array}{l}\text { "Happy thoughts. } \\
\text { I knew I was going } \\
\text { to pass it." }\end{array}$ & $\begin{array}{l}\text { "That I was } \\
\text { going to pass } \\
\text { the test. I } \\
\text { had a good } \\
\text { feeling about } \\
\text { that." }\end{array}$ & $\begin{array}{l}\text { "I had to try... } \\
\text { miserable... } \\
\text { that's it." }\end{array}$ & $\begin{array}{l}\text { "I thought I was } \\
\text { going to pass it." }\end{array}$ \\
\hline Sissy & $\begin{array}{l}\text { "I really wanted } \\
\text { to pass it. I } \\
\text { didn't want to } \\
\text { fail it." }\end{array}$ & $\begin{array}{l}\text { "I was wondering } \\
\text { if I was going to } \\
\text { pass or fail. Happy." }\end{array}$ & $\begin{array}{l}\text { "I was really wanting } \\
\text { to pass that test. Because } \\
\text { all the boys said I couldn't } \\
\text { and I just proved to them } \\
\text { that I could 'cause they } \\
\text { think girls can't do nothing. } \\
\text { Can't do nothing and I } \\
\text { proved to them that we can." }\end{array}$ & $\begin{array}{l}\text { "That, that } \\
\text { test was so } \\
\text { simple." }\end{array}$ & $\begin{array}{l}\text { "I was trying to } \\
\text { hit twenty, but } \\
\text { I just couldn't do } \\
\text { it, because all the } \\
\text { boys said I } \\
\text { couldn't and I } \\
\text { guess didn't." }\end{array}$ & $\begin{array}{l}\text { "Nervous I guess. } \\
\text { I just wanted to } \\
\text { pass it, that's } \\
\text { what I was } \\
\text { thinking, } \\
\text { 'stretch more } \\
\text { Sissy', but I } \\
\text { couldn't." }\end{array}$ \\
\hline
\end{tabular}

Figure 5. Thoughts and feelings during each Fitnessgram test (Cont.). 
Nancy, and Sissy reported no pain, while Fred and Ellie reported some discomfort because of a "pinching" feeling. Ellie said, "It hurt like you were taking your nails and pinching me." For the Curl-Up test four participants, Fred, Ian, Tom, and Nancy, reported pain and soreness in the stomach area, Sissy described the feeling as "really hard" and Ellie was "comfortable" because she was laying on a mat and not the concrete. During the Trunk Lift all 6 participants reported no pain or discomfort. The most common statements were “it felt good” and "I didn't feel pain.” For Push-Ups it was interesting that the boys, Fred, Ian, and Tom, really didn't feel pain but all three girls did report pain in their arms and shoulders. Lack of upper body strength probably caused this pain.

During the Backsaver Sit and Reach, 5 of the 6 participants described pain associated with this test. Ellie reported "I felt like my spinal cord was going to burst." Tom was the only one who reported no "pulling in my body," indicating he has good flexibility. In summary, Table 15 displays the total number of $(+)$ positive physical feelings and (-) negative physical feelings for each test. Data suggests the Backsaver Sit and Reach is the most uncomfortable test for these participants. The Curl-Up test would also appear to be uncomfortable for these participants. In addition to these physical feelings the researcher also probed participants for their thoughts during each test (See Figure 8).

Table 15

Positive (+) and Negative (-) Feelings for Each Test

\begin{tabular}{cccccc}
\hline $\begin{array}{l}\text { One Mile } \\
\text { Walk/Run }\end{array}$ & $\begin{array}{c}\text { Body } \\
\text { Composition }\end{array}$ & $\begin{array}{c}\text { Curl- } \\
\text { Up }\end{array}$ & $\begin{array}{l}\text { Trunk } \\
\text { Lift }\end{array}$ & $\begin{array}{c}\text { Push- } \\
\text { Up }\end{array}$ & $\begin{array}{c}\text { Backsaver } \\
\text { Sit and Reach }\end{array}$ \\
\hline+3 & +4 & +2 & +6 & +3 & +2 \\
-3 & -2 & -4 & -0 & -3 & -5 \\
\hline
\end{tabular}


When analyzing students' thoughts and feelings during each Fitnessgram test it was interesting to find that in the majority of instances students had positive thoughts and feelings during the actual test administration. For the One Mile Walk/Run all participants except one (Ellie) experienced positive thoughts and feelings making statements such as, "I hope I get a good test," "I'm gonna do good," "I really wanted to pass it." Ellie on the other hand felt "I wasn't going to pass the test." For the Body Composition test Ian and Ellie were the only ones that experienced negative feelings and thoughts. Ian said, he felt "nervous 'cause I thought I failed the test." Ellie said "I thought I wasn't going to pass." All other participants indicated positive thoughts and feelings when asked about this test. For both the Curl-Up test and the Trunk Lift all participants experienced positive feelings and thoughts during the test. For the Push-Up test, only Ellie indicated that she felt "miserable" while the other 5 participants stated no negative feelings or thoughts. Lastly, for the Backsaver Sit and Reach, Nancy indicated that she thought she was going to "fail" and Sissy indicated that she felt "nervous." The other 4 participants indicated a positive experience for this test.

\section{Students' Thoughts about Each Fitnessgram Test}

The third and last area of focus during the student interviews was students' thoughts about each Fitnessgram test. During the interviews students were asked, "What do you think about the (specific) test?" From this question the researcher gained the following data which are displayed in Figures 6-11. When reviewing the data from Figures 9-14, which focused on the participants' thoughts about each Fitnessgram test, it appears that students have positive thoughts about these tests. Whether the participants passed or failed the test the most common statement was "keep the test." Another 
common statement made was "I think it's a good test..." When asked specifically about what they thought about the Trunk Lift test it was interesting to find that 3 of the 6 participants suggested that this test should be made more difficult or "raise" the standard because it's "too easy."

During the student interviews there were instances in which the students expressed in their own words why they thought these tests were important and relevant. A few examples of their comments follow.

- Push-Ups

Nancy: “... when you practice you get stronger, you get better at it.”

Tom: “... it's a great test and you learn how to get stronger."

- One Mile Walk/Run

Nancy: “... it teaches you to keep going."

Fred: "kids should be put to the max."

- Body Composition

Ian: "kids can find out how fat they are and then do exercise push-ups and situps to get skinnier."

- Curl-Up

Fred: “... it's part of the workouts of your body."

Tom: “... it tells you how good you done and how many sit-ups you can do..."

- Trunk Lift

Ellie: “... test how much someone can lift their upper part of the body." 


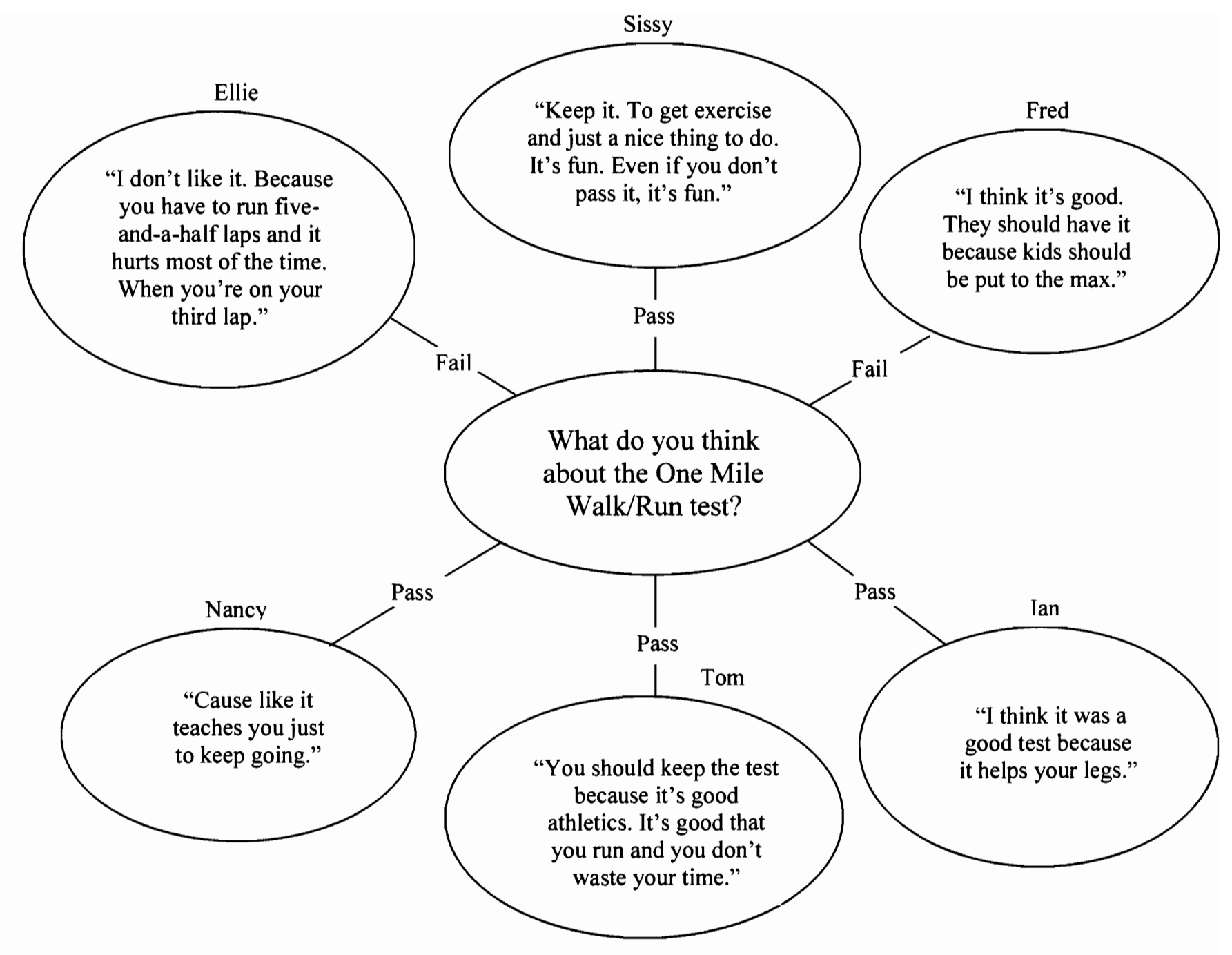

Figure 6. Students' thoughts about the One Mile Walk/Run test. 


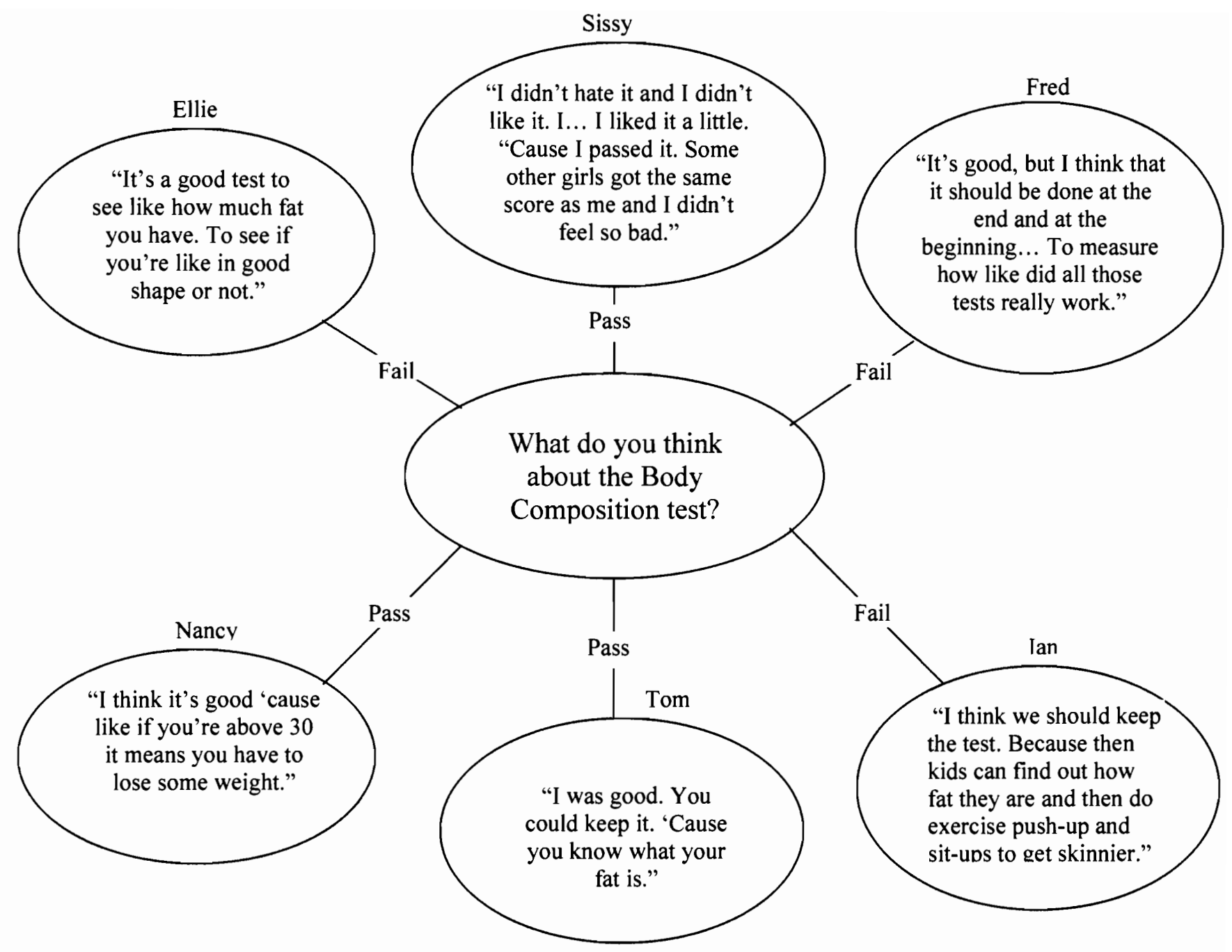

Figure 7. Students' thoughts about the Body Composition test 


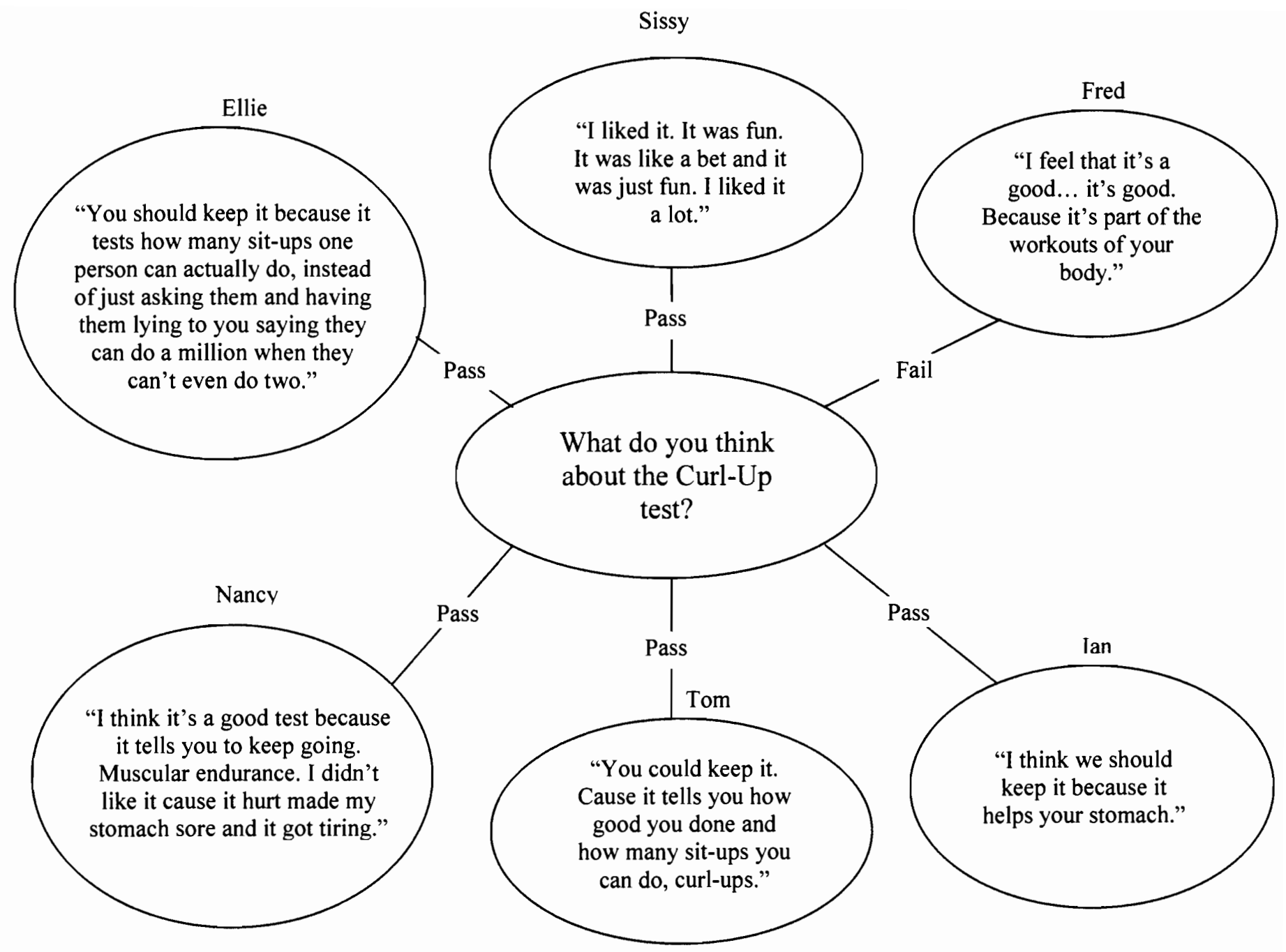

Figure 8. Students' thoughts about the Curl-Up test. 


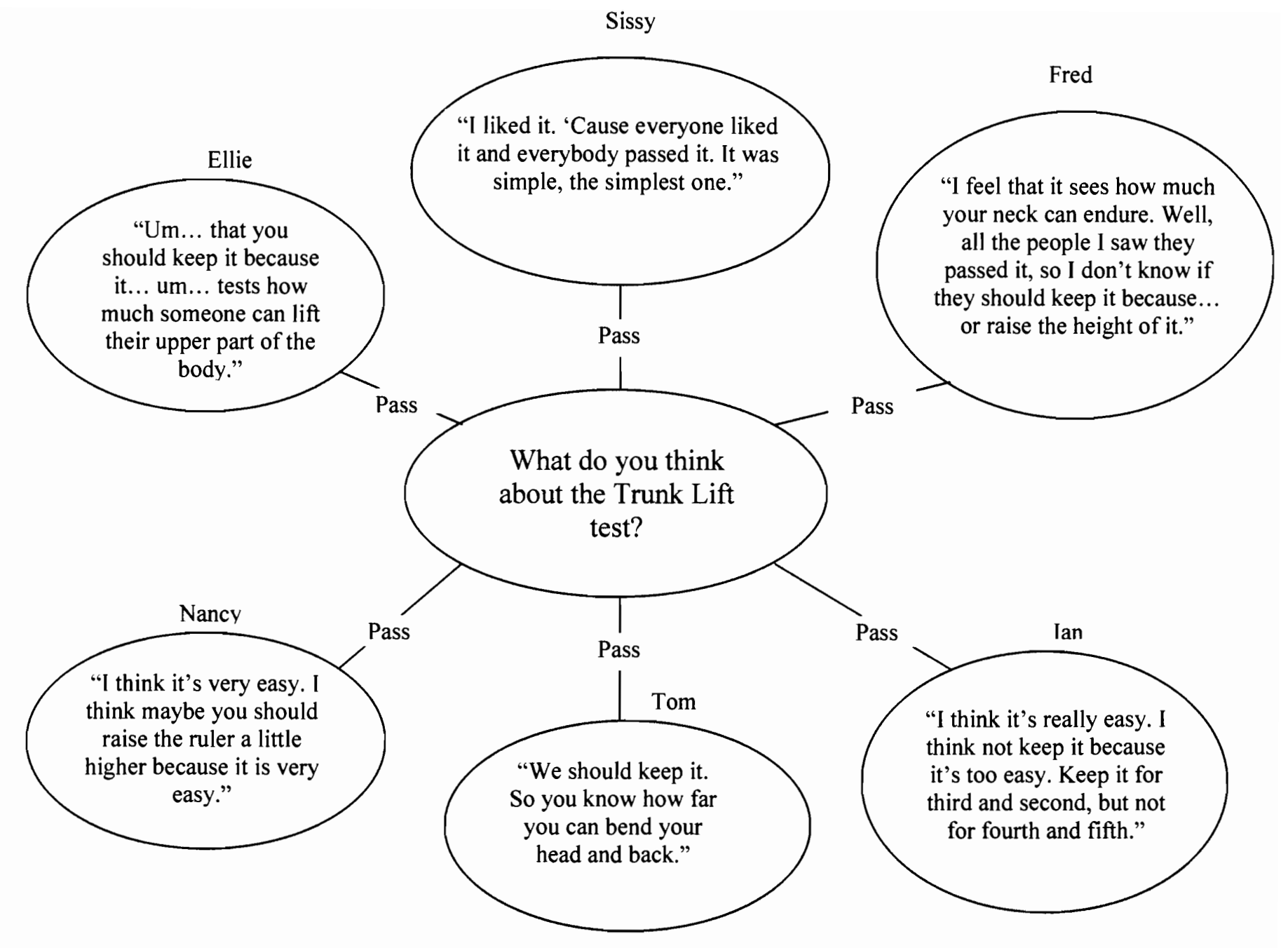

Figure 9. Students' thoughts about the Trunk Lift test. 


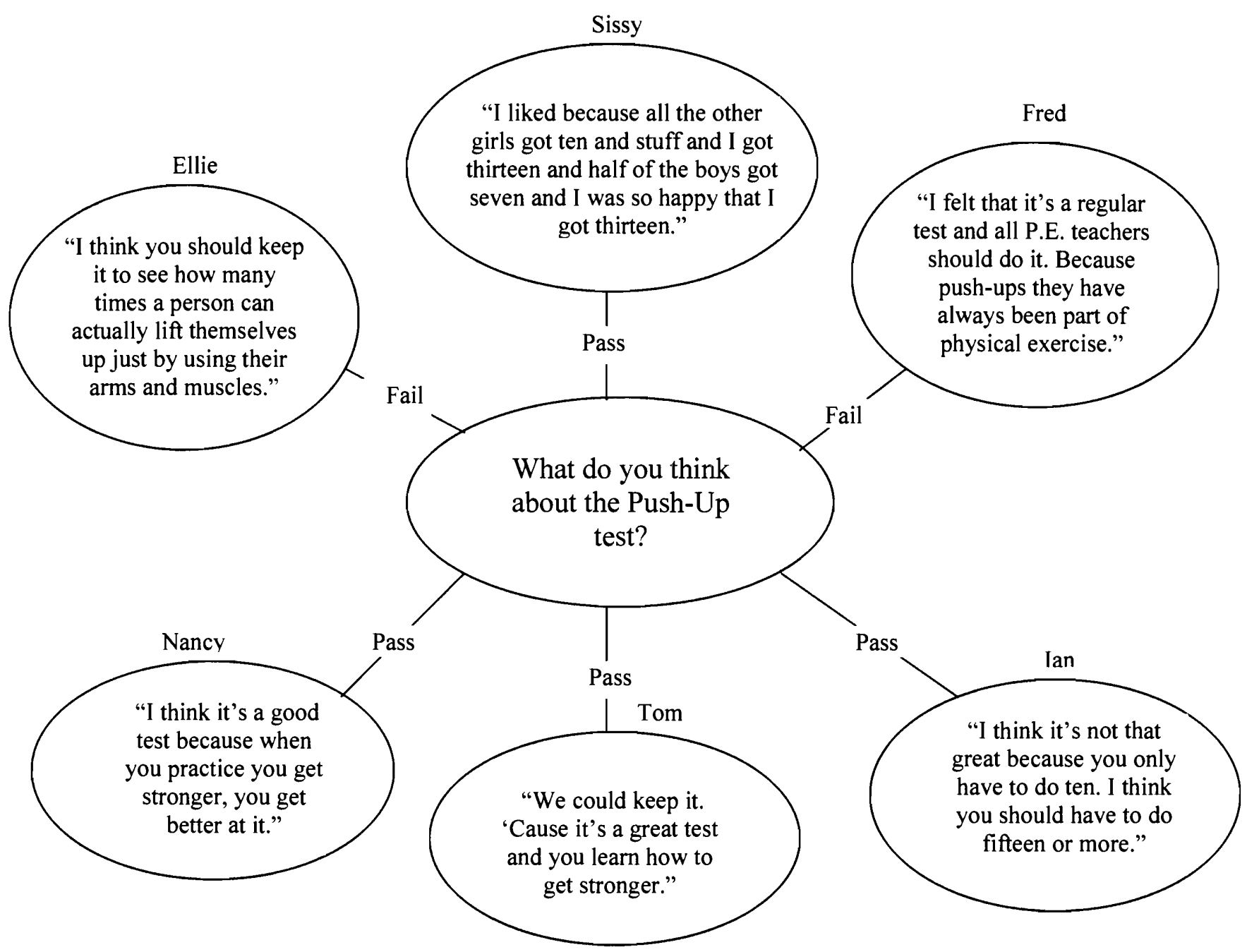

Figure 10. Students' thoughts about the Push-Up test. 


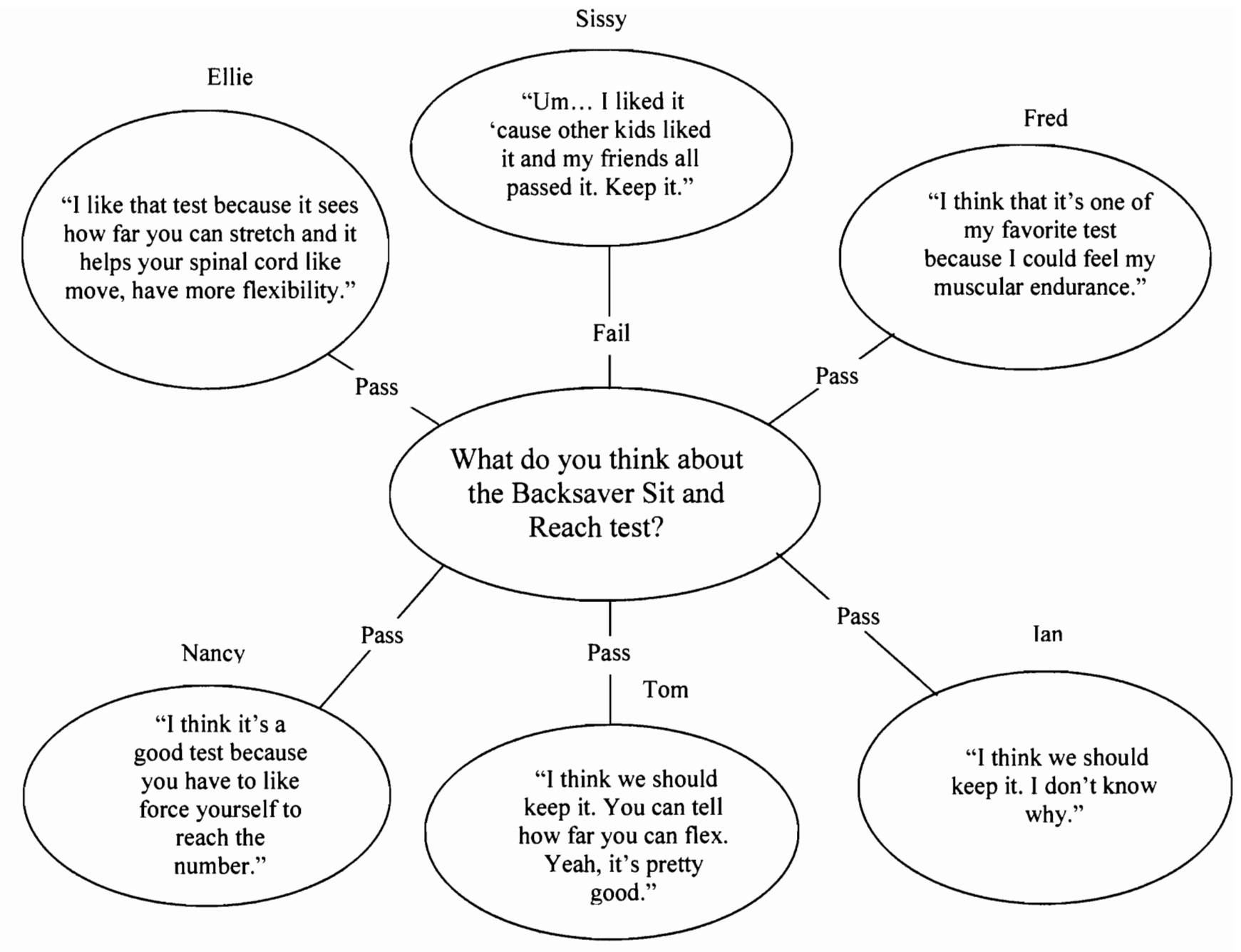

Figure 11. Students' thoughts about the Backsaver Sit and Reach test. 
Participants' Favorite and Least Favorite Fitnessgram Tests

The final question asked during the student interviews was "What was your favorite and least favorite Fitnessgram test?" From this question Table 16 was generated. When asked to indicate their favorite test all participants selected a test that they passed. When asked about their least favorite test 4 of the 6 participants indicated a test they failed as their least favorite. But Tom's least favorite was the Curl-Up test (even though he passed this test). He said, 'I don't like sit-ups as much as running. I just don't like them." Nancy indicated that her least favorite test (even though she passed it) was the Push-Up test because, “... when I first started I could only do one... it was like hard for me..." An important note must be made here; Tom and Nancy were both Gold card Table 16

Favorite (+) and Least Favorite (-) Fitnessgram Test Battery.

$\begin{array}{ccccccc}\text { Participant } & \begin{array}{c}\text { One Mile } \\ \text { Walk/Run }\end{array} & \begin{array}{c}\text { Body } \\ \text { Composition }\end{array} & \begin{array}{c}\text { Curl- } \\ \text { Up }\end{array} & \begin{array}{l}\text { Trunk } \\ \text { Lift }\end{array} & \begin{array}{l}\text { Push- } \\ \text { Up }\end{array} & \text { Sit and Reach }\end{array}$

Fred

$(-) \mathrm{F}$

$(+) P$

Ian

$(+) \mathrm{P}$

$(-) \mathrm{F}$

Tom

$(+) \mathrm{P}$

$(-) \mathrm{P}$

Nancy

$$
(+) \mathrm{P} \quad(-) \mathrm{F}
$$

Ellie

$(-) F$

$(+) \mathrm{P}$

Sissy

$$
(+) P
$$

$(-) \mathrm{F}$

Note. $\mathrm{P}=$ Pass and $\mathrm{F}=$ Fail 
winners which means they passed all of the six tests. When asked to describe their least favorite it could only be a passed test since they passed all six.

The researcher further analyzed the multiple sources of data from the six students interviewed. The data obtained from students' perceptions, students' questionnaires, and students' raw scores were triangulated. This provided further insight about their knowledge of the health-related physical fitness components, their feelings about the tests, and their participation in out of school physical activities.

From this triangulation it was found that the two students (Tom and Nancy) interviewed who passed all six Fitnessgram tests knew the most about the health-related components of fitness. During the interviews both students used correct terminology when describing their thoughts and feelings about four of the six tests while the other interviewees used correct terminology for only one of the six tests. Tom and Nancy also reported more time participating in out of school physical activities.

\section{Qualitative Summary}

The student interviews conducted during this study centered around three themes: (a) students' knowledge of their Fitnessgram test scores, (b) students' feelings during each Fitnessgram test and (c) students' thoughts about each Fitnessgram test. For theme one, in general students knew how well they performed and their feelings about their performance were directly related to how they performed. Concerning theme two, participants did indicate some physical pain and discomfort during certain tests, as well as nervousness in response to participating in some of these tests. With regard to the third area of focus, students indicated positive thoughts and feelings about the 
Fitnessgram physical fitness tests. Finally, when asked which test was their favorite and least favorite the participants response was indicative of their performance on that test.

In Chapter 1 the following hypothesis was stated: Students who score well on the Fitnessgram tests would have a more positive attitude about the fitness testing experience when compared to students who score poorly. From the data analyzed in the preceding section it would appear that this hypothesis is not true. These six participants, two Gold card winners, two Silver card winners, and two with no awards appeared to have similar thoughts and feelings about the tests. Regardless of how well or poorly they scored; these students perceived the Fitnessgram physical fitness tests as a generally positive experience.

When triangulating the multiple sources of data from the six students interviewed it was found that the two students (Tom and Nancy) who scored the highest displayed a greater understanding of the health components and reported more participation time in out of school physical activities. 


\section{CHAPTER V}

\section{DISCUSSION}

The major purpose of this research was to examine children's knowledge and perceptions of the Fitnessgram physical fitness testing experience. The Fitnessgram was implemented into the M-DCPS physical education curriculum beginning the 1998-99 school year as an assessment tool to measure the physical fitness levels of the students. This assessment device may be an integral part of the process of achieving lifetime physical activity and fitness. Continuing engagement in this process is one of the major desired outcomes of a comprehensive physical education program. The Fitnessgram emphasizes participation in a wide variety of activities to help develop and promote fitness and endorses the concept that physical activity should be fun and enjoyable (Cooper Institute for Aerobics Research, 1992, p. 3). The physical fitness outcomes "fitness habits for life" and "regular participation in physical activity" are included within the scope of the M-DCPS CBC. It would be to the district's advantage to know what children learned from the Fitnessgram test experience and what children think about each of the Fitnessgram tests. By understanding more about students' knowledge and perceptions of this experience educators can design more appropriate learning experiences that achieve desired goals of healthy living and will be meaningful and relevant for students.

\section{Research Methods}

The researcher surveyed 110 fifth grade students at one elementary school to find out if the students are acquiring basic knowledge and understanding of the health-related physical fitness components of the Fitnessgram tests. The researcher also examined if a 
relationship existed between students' individual test scores and the length of time they spent being physically active outside the school setting. For these two research questions a research design utilizing interview and survey techniques was used for data collection. After each Fitnessgram test was administered by the researcher, students were asked to complete the corresponding questionnaires. The researcher was able to obtain 110 completed surveys after each of the six Fitnessgram tests was administered. To obtain more information about the students' thoughts and feelings of the fitness testing experience, the researcher conducted individual interviews with six students who had participated in the Fitnessgram test program.

Results

There were three subsidiary research questions. The first subsidiary question addressed whether or not children who participate in the Fitnessgram physical fitness test know and understand the health-related physical fitness components. This aspect of the research was addressed by the first three questions on the survey. Ninety point nine percent of the students understood that the Body Composition test measured the percent of body fatness, which is the health-related physical fitness component associated with that test. Fewer students understood the health-related component measured by the five remaining tests; Backsaver Sit and Reach (68\%), Trunk Lift (52\%), Push-Up (50\%), One Mile Walk/Run (44\%), and Curl-Up (30\%). From these data it was clear that participation in the Fitnessgram physical fitness experience does not in and of itself ensure that children are learning about the health-related physical fitness components which is a major goal of the physical education program. 
The second subsidiary question addressed the relationship between individuals' test scores and the amount of time they spent being physically active outside the school setting. Individuals test scores were recorded as pass or fail for each test. This aspect of the research was addressed by questions four and five on each of the six student surveys. There was no statistically significant association between individuals' test scores and the length of time they spent being physically active outside the school setting for the One Mile Walk/Run, Body Composition, Push-Up, and Trunk Lift tests. However, a relationship was discovered between the level of physical activity performed outside of school and the Curl-Up and Backsaver Sit and Reach tests.

The third subsidiary question addressed what children think and feel about the Fitnessgram physical fitness testing experience. This aspect of the research was addressed through six individual interviews in which students were asked several questions. A student interview guide was created to address this third research question. The student interview guide included 31 opened-ended questions. Students were asked five questions directly related to each of the six tests, and the last question of the interview centered on the student's favorite and least favorite tests. The researcher explored themes related to the students' knowledge, thoughts, and feelings in the data. This was done by creating cross-classification matrices focusing on three main qualitative research themes: (a) student knowledge of scores for each test, (b) student feelings about each test, and (c) student thoughts about each test. Important findings associated with each of these three themes were discovered. These findings will be discussed below. 
Knowledge of results can be a huge factor in increasing the level of motivation among young children. "Students are more interested in learning and advancing to a higher performance level when they know what the goal is, and when they receive feedback concerning their progress toward the goal" (Johnson \& Nelson, 1986, p. 2). When analyzing the data surrounding this theme it became apparent that the participants had "knowledge of results." The first two questions on each of the six sections of the student interview guide addressed this theme. Of the 36 instances students were asked about their performance they answered correctly and had knowledge of their results in 34 of the 36 instances. In addition to "knowledge of results," students were asked how they felt about their performance. This was the third question of each interview.

When asked to describe their feelings about their performance it became apparent that students' feelings about their test scores (performance) were directly related to how they had performed. For example, if a student passed a specific test his or her feeling about the test performance was expressed using expressions such as, "good," "I loved it," "very well," etc. But when asked about a failing score the students replied, “don't feel good," "bad," and "fail." In most cases, performance appeared to be directly related to how students felt about their test scores.

Students' Feelings about Each Test

The researcher explored student feelings during each of the six Fitnessgram tests by asking, "How did you feel during the test both physically and mentally?" This was the fourth question asked on each of the six sections of the student interview guide. When asked specifically about feelings concerning the physical aspects of the tests, $50 \%$ of the 
participants reported no physical pain during each test. However, the other $50 \%$ did report pain and discomfort as a side effect to all but one of the tests. None of the 6 participants reported that the Trunk Lift caused pain or discomfort. In addition to feelings about their physical state during each test, students were asked about other thoughts and feelings concerning each test.

When analyzing student thoughts and feelings during each Fitnessgram test, it was found that in the majority of instances, students expressed positive thoughts and feelings about the test administration. For instance, students reported they "felt pretty confident," "[had] happy thoughts. I knew I was going to pass it," and made other similar statements. There was one student who did report negative feelings during three of the six tests. These negative feelings were reported for the three tests the student failed. These feelings and comments were connected to the first (knowledge of scores) theme; much of the time student thoughts are directly related to their performance.

\section{Students' Thoughts about Each Fitnessgram Test}

The third theme explored during the student interview focused on what students' thought about each test of the Fitnessgram. The theme was addressed by question five on each of the six sections of the student interview guide. From the data collected, students reported having good and positive thoughts about these tests, regardless of their performance. When asked what they thought about each test a common statement was "I think it's a good test." Below are just a few examples in which students explained why they thought certain tests were "good."

- One Mile Walk/Run

Ian: "I think it was a good test because it helps your legs." 
Fred: "I think it's good. They should have it. Because kids should be put to the max."

- Body Composition

Tom: "It was good "cause you know what your fat is."

Nancy: "I think it's good 'cause like if you're above 30 it means you have to lose some weight."

- Curl-Up

Sissy: "I liked it. It was fun. It was like a bet and it was just fun. I liked it a lot." Fred: "I feel that it's a good... it's good. Because it's part of the workouts of your body."

- Push-Ups

Fred: "I felt that it's a regular test and all P.E. teachers should do it. Because push-ups, they have always been part of physical activity.

- Backsaver Sit and Reach

Nancy: "I think it's a good test because you have to like force yourself to reach the number."

Tom: "You could tell how far you can flex. Yeah, it's pretty good." In brief, to be a "good test" student criteria centered around: (a) it was good for the body or part of a workout, (b) provided them with some knowledge or (c) it was fun.

It's interesting to note that when asked specifically about what they thought about the Trunk Lift test, 3 of the 6 participants made suggestions that this test was "too easy" and it should be made harder to "raise" the standard. Students gave the following reasons as to why they thought this test should be made more difficult. 
Nancy: "I thought maybe you should raise the ruler a little higher because it is very easy."

Fred: "Well, all the people I saw; they passed it, so I don't know if they should keep it... or raise the height of it."

Agreeing with the others about how easy the test was, Ian thought the test should be eliminated for children his age.

Ian: “I think it's really easy. I think not keep it because it's too easy. Keep it for third and second but not for fourth and fifth."

In summary, with the exception of the Trunk Lift test that the students thought was too "simple," these participants thought the Fitnessgram tests are "good tests" that should continue to be part of the yearly physical education curriculum.

\section{Final Conclusions}

This research study found that students who participated in the Fitnessgram physical fitness test did not acquire the basic knowledge of its health-related physical fitness components. This lack of understanding has been researched before; for example, the Laporte et al. (1993) study of over 1,000 Belgian University students. When investigating what students learned from their school physical education programs, they discovered that students felt they learned the most from technical/skill related components and learned the least in the cognitive/reflective area, which involves understanding, learning concepts, and knowing about physical education.

The second area of focus for this research was to determine a possible relationship between students' test scores and how much time they spend being physically active outside of school. There was no significant relationship found for four of the tests and a 
weak positive relationship for the two remaining tests. This finding is supported by research studies that have shown that even students who are not active at all may do well on certain tests simply because of favorable genetic factors (Welk \& Wood, 2000). A similar meta-analysis (Payne \& Morrow, 1993) analyzed 28 studies focusing on the impact of physical activity on aerobic performance in students. The results showed that physical activity (training) had little effect or ability to increase in aerobic capacity in prepubescent children. The findings of this research are similar in that there were no strong significant relationships and only two weak positive relationships found between children who pass or fail the Fitnessgram tests and how much time they spend being physically active outside of school.

Finally, the researcher asked students about their thoughts and feelings about the Fitnessgram testing experience. It was discovered that the children did have "knowledge of results" and that how they felt about their scores was directly related to how they had performed. Furthermore, students did report both physical and mental discomfort for some of the tests. Yet for others, they reported no physical or mental discomfort. Lastly, students described the Fitnessgram as a "good test" and one that "we should keep."

\section{Implications for Miami-Dade County Public Schools}

The intent of this research study was to examine children's knowledge and perceptions of the school physical fitness testing program, the Fitnessgram. This test battery was implemented in the M-DCPS physical education program for the 1998-99 school year as an assessment tool used to measure youth fitness levels. Many instructional hours are used training for and practicing for these tests. The actual test 
administration takes weeks to complete. With so much instructional time being spent on a single assessment device, it only makes sense that M-DCPS would want to know what children are learning from these hours of preparation, what they think about the experience, and whether the program goals and objectives are being realized.

The recurring goal included as part of the scope of the physical education curriculum is physical activity for a lifetime. This goal is emphasized at the national, state, and county levels and is demonstrated in objectives such as, exhibits a physically active lifestyle, maintains health enhancing levels of physical fitness, and participated in physical activity and develop fitness habits for life. Student motivation is a major contributor in accomplishing this goal.

Motivation is a key factor when encouraging children to adopt healthy active lifestyles. The motivational process for fitness begins with fun. All physical fitness activities should be enjoyable. When teaching fitness pain is not the name of the game. If the fitness activities are fun and the children experience success they will be intrinsically motivated to be physically active outside the school environment.

Children who participate in programs that are designed for maximum participation and that provide challenges appropriate to skill levels develop confidence in themselves as they develop competence in the skills of physical education. This combination of competence and confidence motivates children to adopt lifestyles that include moderate to vigorous activity on a regular basis. (Graham, Holt/Hale, \& Parker, 2001, p. 36)

Wall and Murray (1990) describe a similar motivational process in their "positive learning environment" spiral that follows this sequence: "I try, I'm reinforced, I try to improve, I practice, I improve, I'm more skilled and physically fit, I like physical education, I like myself, I continue to try" (p. 22). 
Students are motivated and more interested in learning and advancing to higher performance levels when they know what the goal is and get feedback concerning their progress toward the goal. The Fitnessgram computerized reporting system was created with this in mind. Utilizing the Fitnessgram software a teacher or student can input the student's fitness scores and create a personalized Fitnessgram computer report. Included in this report is specific feedback about the students current fitness levels in relation to the HFZ and suggestions for out of school activities that will help the student maintain or improve their level of fitness. From these reports students know their personal fitness goals and are given specific feedback on how to achieve those goals. To further motivate students to pursue their fitness goals at home the Activitygram, as part of the Fitnessgram, was created.

Students are asked to report on their physical activities for a two to three day period. From this information the Activitygram computer report is generated that provides individualized information about a students normal levels of physical activity. The report shows what types of activity a student does and how often. Most importantly, the report offers feedback about at home activities that can be practiced to improve certain health-related components of fitness. The Activitygram also recognizes children who establish regular physical activity behavior. Both theory and practical experience make it obvious that the beat way to encourage lifetime health and fitness is to recognize children who establish regular physical activity behavior. The Fitnessgram consists mainly of a comprehensive health-related fitness assessment, a computerized Fitnessgram reporting system, and a behavioral oriented recognition system (Activitygram). While the M-DCPS has fully implemented the assessment part of the program the other two areas, 
reporting system and recognition system has not been implemented. As a result, students are receiving a fragmented program. Without the full implementation of the Fitnessgram program students are not being supplied with the necessary knowledge, feedback, or recognition essential to be active for life.

Healthy active living is the goal. M-DCPS adopted the Fitnessgram program to direct physical education activities and experiences to help students achieve this goal. However, while M-DCPS has fully implemented the accountability part of the Fitnessgram, other areas of the Fitnessgram program (that could help children more fully reach the goal) have not been implemented and the $\mathrm{CBC}$ has not been updated to reflect the Fitnessgram program. Both of these concerns are discussed in the next two sections as recommendations for M-DCPS.

\section{Recommendations for Miami-Dade County Public Schools}

The results presented in Chapter IV of this paper are not completely positive as to what students' knowledge and perceptions are of the Fitnessgram physical fitness testing program. Although, these results and insights are only representative of a small number of children, it is likely that they are not unique to just those who participated in the study. It becomes apparent that concerns surrounding this study's results should be further examined to make the physical fitness testing experience more meaningful and relevant to children. Two main recommendations surfaced, the district should both: (a) examine the $\mathrm{CBC}$, and (b) incorporate a more comprehensive Fitnessgram program. Each of these is discussed below. 
When analyzing how the Fitnessgram physical fitness testing program fits into the scope of the M-DCPS Competency Based Curriculum many discrepancies were found. The most obvious of these discrepancies were: (a) participation in health-related fitness assessment was listed as an objective for the Grades $\mathrm{K}-1$ and 2, but no fitness assessment objectives were listed in the CBC for third, fourth, and fifth grades; (b) some CBC objectives listed for third, fourth, and fifth grades included fitness activities that are no longer done because they have been replaced with other more appropriate fitness activities; and (c) in the fourth and fifth grade CBC's there are objectives and competencies that refer to fitness percentile charts and percentile scores that were used for the President's Challenge physical fitness tests that haven't been used in M-DCPS for the past 5 years. Each of these discrepancies will now be discussed.

$C B C$ health-related fitness assessment for grades $K-1$ and 2 . The M-DCPS office of Life Skills and Physical Education requires schools to administer the Fitnessgram physical fitness test to students in grades 4 through 12 . In most cases, this means the elementary schools will test the fourth and fifth grade students. Occasionally, this means fourth, fifth, and sixth grade students are tested at the elementary level. Yet, even with these guidelines, there is no mention of participating in any type of fitness assessment in the fourth and fifth grade sections of the CBC. The only student objective stated in the $\mathrm{CBC}$ for fourth grade that is remotely about fitness assessment states, "Explain the importance of fitness testing when setting personal fitness goals." The fifth grade curriculum does not mention fitness assessment at all. But, for grades $\mathrm{K}-2$ there is an objective that reads "Participates in health-related fitness assessment." Graham, 
Holt/Hale and Parker (2001, p. 47) state, "Younger children can take the test as an educational experience, but the characteristics of young children do not promote maximum effort and extended concentration on a subject that is of more interest to the teacher then to them."

Performance standards for aerobic capacity test items for children under 10 years of age are not available. In the Cooper Institute for Aerobics Research Fitnessgram Test Administration Manual, the authors emphasize, "While standards are provided for other test items for primary grade children, you are strongly encouraged not to emphasize performance level and test results" (Meredith \& Welk, 1999, p. 9). With this in mind, as well as the requirements imposed by M-DCPS, it only makes sense that the aforementioned objective be eliminated from the $\mathrm{K}-2 \mathrm{CBC}$ and be placed in a more appropriate sequence of instruction, such as in the fourth and fifth grade section of the CBC.

Outdated fitness objectives as part of the $C B C$. In the $\mathrm{CBC}$ third, fourth, and fifth grade sections there are stated objectives that are directly related to the old President's Challenge physical fitness tests, which M-DCPS stopped administering 5 years ago. These objectives include fitness activities such as sit-ups, pull-ups, and a shuttle run. While these activities are age appropriate and beneficial in helping improve fitness, they have been replaced with more current but similar activities. For example, M-DCPS does not administer the sit up test anymore. Instead, currently as part of the Fitnessgram M-DCPS administers the Curl-Up test. There are only slight differences between the two but they are different. The differences are important because of the strict procedures that must be followed when administering this test. M-DCPS used to also administer, as part 
of the President's Challenge, the Pull-Up test. That has since been replaced with the Push-Up test of the Fitnessgram. Lastly, the CBC offers an objective about yet another "old" test-the shuttle run, "Perform shuttle run while demonstrating proper running techniques."

The three fitness activities, sit-ups, pull-ups, and the shuttle run do provide students with appropriate fitness tasks; however they have been replaced with more recently promoted activities. Problems arise because: (a) These activities are performed as part of the Fitnessgram testing program, which as mentioned earlier, encompasses much of the instructional time in physical education; and (b) The new fitness tasks are not mentioned in the Physical Education CBC. There is no mention of curl-ups or pushups in the fourth and fifth grade sections of the CBC. Within the field of physical education it is currently thought that it is necessary for children to be able to perform these tests which means there should be objectives included in the $\mathrm{CBC}$ that state this.

CBC objectives and competencies of percentiles. In the third, fourth and fifth grade sections of the $\mathrm{CBC}$, there are objectives stated that focus on percentile charts and percentile scores. For example, "Using the percentile charts, read the percentile for each fitness test" and "Show the correct procedure for averaging fitness percentile scores." M-DCPS has not used percentiles in evaluating fitness for over 5 years because the Fitnessgram, along with its criterion standards, or standards for a Healthy Fitness Zone (HFZ), replaced those percentiles along with the related test - the "President's Challenge." The objectives that refer to percentile charts and scores should be eliminated from the $\mathrm{CBC}$. More appropriate objectives centering around understanding the new (HFZ) charts should be incorporated into the curriculum. 
Conclusion. The researcher discovered many discrepancies in the scope of the physical education curriculum in M-DCPS. Physical fitness testing takes up an exorbitant amount of instructional time. Considering this, the M-DCPS CBC should include the appropriate fitness objectives in the appropriate sequence of instruction. Even the District Supervisor of Physical Education for M-DCPS writes about the Fitnessgram, “... the need to make health-related fitness testing an integral part of our annual curriculum becomes more apparent" (M-DCPS, Fitnessgram 1997, p. i). The most obvious problem has a clear solution. Update the physical education curriculum aligning the $\mathrm{CBC}$ to better reflect the current subject matter expertise concerning goals and objectives; thus enabling children to connect physical activity today to a physically fit adulthood.

\section{Incorporating a More Comprehensive Fitnessgram Program}

The Fitnessgram was created and intended to be used as a comprehensive healthrelated fitness program and computerized reporting system. M-DCPS provided physical education teachers with a short (approximately 30 pages) Fitnessgram pamphlet that includes reporting sheets, test administration, standards, class score sheets, and sample motivation/recognition awards. However, teachers received no Fitnessgram software. One of the primary goals of the original Fitnessgram program was to provide children, parents, and teachers with personal information regarding each student's current fitness levels. This is done by a computerized reporting system that M-DCPS physical education teachers never received. While student's personal test scores are available to parents and students it is impossible to personalize this information without the Fitnessgram computer software. 
The Fitnessgram provides the means of creating data bases in which students' test scores are recorded. Once the scores have been recorded personalized reports can be generated and accessed by teachers, students, and parents. In addition to fitness scores, these personalized reports include the relationship of a student's scores to the Healthy Fitness Zone criteria and information on how to improve or maintain current fitness levels. From this data students can chart their own progress and set personal fitness goals. Additionally, teachers may utilize this software as a means of evaluating their school's fitness program by producing statistical reports. These teacher reports contain group summary information such as means, standard deviations, range of scores, and percentage of students reaching the Healthy Fitness Zone criteria. The Fitnessgram software also includes the Activitygram in which students input information about their daily activities for a 2-3 day period. From this information an individualized "Activitygram" is created which specifically describes at home activities that enhance the health-related components of fitness. The Activitygram's primary function is to teach children about physical activity, “... the task of reflecting on their activity habits will provide children with a valuable educational experience" (Meredith \& Welk, 1999, p. 55). A clear connection between physical fitness activities performed at school and fitness activities at home can be made utilizing the Activitygram. This "transfer of learning" is essential to students becoming more physically active.

The benefits of providing students with the information produced by the Fitnessgram software are many. From this information students may: (a) self assess their fitness levels, (b) learn how to interpret assessment results, (c) plan personal fitness programs, (d) set personal fitness goals, and (e) motivate themselves to be active on their 
own. All of these benefits are also goals of a quality physical education program and may be reached if the Fitnessgram software is implemented and made available for students' use.

By not providing teachers and students with this software many previously mentioned program goals may not be attained to the degree they could be met if the software were available. In order to provide children with the comprehensive Fitnessgram program and to make the physical fitness testing experience more meaningful and relevant, teachers should be supplied with the necessary material to accomplish the program goals and objectives.

\section{Recommendations for Further Research}

While conducting this research, the researcher found related areas that would be worthwhile to explore further. One aspect of the research showed that children lacked certain knowledge related to physical fitness. It would be interesting to investigate whether certain teaching methods produced better student understanding of fitness components. This is important because if we could identify the specific teaching methods or teacher behaviors that result in improved student learning then teachers could incorporate them into their own personal teaching styles.

In addition, it would be beneficial to the field of physical education to further expand the literature on student knowledge exploration concerning a possible relationship between fitness scores and FCAT scores-or of fitness scores and overall academic progress. If an empirically supported connection could be shown, this would be a major breakthrough for physical education. Many academic teachers, students, parents, and administrators do not understand the contribution physical education makes to an 
individual's growth and as a result, physical education is often considered less important than other subjects, such as math and reading. But if additional research could establish such a connection, others may then see that physical education is a meaningful and integral part of the total school curriculum; more than just "recess" and "play time." Another area of focus for this research project dealt with what children think and feel about the Fitnessgram physical fitness tests. This qualitative section of the research proved to be very interesting. The students interviewed provided vivid insight into how they perceive the tests. One of the interviewees (Ellie) was slightly overweight. She contributed many insights into how she felt about the fitness testing experience. For example, when discussing the Push-Up test during the interview Ellie provided the following information.

Researcher: "How do you feel about that score?"

Ellie: "Bad."

Researcher: "OK. Can you be more specific than bad?"

Ellie: "Bad because I felt like... I felt like I was the only one that didn't pass that test, even though I know some of my other friends didn't pass it, I guess."

Researcher: "How did you feel physically when you were trying to push to push your body up off the mat?"

Ellie: “Um... I felt like I was going to break my arms because I couldn't push up and down more than once or three times."

Researcher: "How else did you feel during that test?"

Ellie: "Miserable." 
It would be beneficial to conduct a study into what overweight children think and feel about fitness testing and how it affects their activity levels outside of school. "The overwhelming odds are that a fat child will stay fat" (Pangrazi, 2001, p. 141). We need to explore ways to reverse these odds. "To physical educators, students' attitudes and perceptions in physical education class are deemed important because they may be related to participation in activity outside of class, either during free time or later in life" (Silverman \& Ennis, 1996, p. 68). For the overweight child activity outside of class or at home is a necessary element to weight loss and weight control. Many obese children do not engage in sufficient activity at school and at home to burn the calories ingested. The result is calories being stored as fat and the child gaining more weight. Insights into their perceptions about fitness may provide teachers with the information necessary to bridge the gap between exercise habits at home and at school.

Another area of interest may focus on what teachers think about the Fitnessgram physical fitness program. Working in the field, the researcher has been exposed to many different views from colleagues about what they think about the test. For example, some teachers have expressed concern that they think it is a waste of time whereas others feel it's a worthwhile educational experience for children. The effects of this diversity of views could be studied by sending out teacher questionnaires throughout M-DCPS to answer whether teachers' perspectives of the test affect student outcome. Teachers are a potent force in a student's development of positive and negative attitudes towards participation in fitness activities. Moreover, teachers' beliefs about program activities can be transmitted to children and affect their participation in fitness testing. This is an 
important area of study because students' fitness participation may prove to improve with improved teacher attitudes.

\section{Summary}

The demands placed on the public education system by society have extended to the field of physical education. At all levels, national, state, and county, the scope of the curriculum has expanded to include many goals, objectives, and assessment standards in order to provide students with the knowledge and skills necessary to develop healthy active lifestyles. To assist students in reaching this goal, M-DCPS incompletely implemented the Fitnessgram physical fitness-testing program. However, the results of this research suggest that from the partial implementation of the Fitnessgram students are not gaining the necessary knowledge of the health components and transfer of activity to out of school is limited. If the only goal of physical fitness was to get children fit then the Fitnessgram as implemented by M-DCPS may be appropriate. However, the ultimate goal of physical fitness is to encourage students to live active and healthy lifestyles. To help children attain this goal teachers must be supplied with all necessary Fitnessgram materials and the $\mathrm{CBC}$ should be updated and correctly reflect program goals and objectives in the area of physical fitness. Only then can we provide our students with a more meaningful and beneficial physical fitness testing program that encourages fitness and physical activity for a lifetime. 


\section{REFERENCES}

Alan Guttmacher Institute. (1994). Sex and America's teenagers. New York: Author.

American Heart Association. (1995). Heart and stroke facts: 1996 statistics supplement. Dallas: Author.

Anderson, E. A., Zhang, J. J., Rudisill, M. E., \& Gaa, J. (1997). Validity and reliability of a timed curl-up test: Development of a parallel form for the fitnessgram abdominal strength test. Research Quarterly for Exercise and Sport, 68 (Suppl.), A-51.

Appiah, K. (2003). Thinking it through: An introduction to contemporary philosophy. New York: Oxford University Press.

Arnett, D., McGovern, P., Jacobs, D., Shahar, E., Duval, S., Blackburn, H., et al. (2002). Fifteen-Year trends in cardiovascular risk factors 1980-1982 through 1995-1997. American Journal of Epidemiology, 156, 929-935.

At-Risk and delinquent youth: Multiple federal programs raise efficiency questions. (1996, March 6). (GAO/HEHS No. 96-34). General Accounting Office. Washington, DC: Health, Education, and Human Services Division. Retrieved September 2003 from HEHS website.

Bar-Or, O. (1987). A commentary to children and fitness: A public health perspective. Research Quarterly, 58, 304-307.

Bar-Or, O., \& Baranowski, T. (1994). Physical activity, adiposity, and obesity in adolescents. Pediatric Exercise Science, 6, 348-360.

Berlin, J.A., \& Colditz, G.A. (1990). A meta-analysis of physical activity in the prevention of coronary heart disease. American Journal of Epidemeology, 132, 612-628.

Beunen, G. (1989). Biological age in pediatric exercise research. In O. Bar-Or (Ed.), Advances in Pediatric Sport Sciences Vol. III (pp. 1-25). Champaign, IL: Human Kinetics.

Beyer, L. E., \& Liston, D. P. (1996). Curriculum in conflict: Social visions, educational agendas, and progressive school reform. New York: Teachers College Press.

Blair, S. N., \& Connelly, J. C. (1996). How much physical activity should we do? The case for moderate amounts and intensities of physical activity. Research Quarterly for Exercise and Sport, 67, 193-205. 
Blair, S. N., Kohl, H. W., Paffenbarger, R. S., Clark, D. G., Cooper, K. H., \& Gibbons, L. W. (1989). Physical fitness and all-cause mortality: A prospective study of healthy men and women. Journal of the American Medical Association, $17,2395-2401$.

Bode, B. (1931). Education at the crossroads. In American education: its men, ideas, and institutions. Series 2, Vol. 8 Progressive education (pp.543-544). New York: Arno Press.

Bryman, A., \& Duncan, C. (1997). Quantitative data analysis with SPSS for Windows. New York: Routledge.

Burt, V., Cutler, J., Higgins, M., Horan, M., Labarthe, D., Whelton, P., et al. (1995). Trends in prevalence, awareness, treatment, and control of hypertension in the adult U.S. population. Hypertension, 26, 60-67.

Carruthers, P. (1986). Introducing persons theories and arguments in the philosophy of mind. Albany, NY: State University of New York Press.

Cates, W. (1999). Estimates of the incidence and prevalence of sexually transmitted diseases in the United States. Sexually Transmitted Diseases, 26 (Suppl 4), S2-S7.

Centers for Disease Control and Prevention. (2000). Tracking the hidden epidemic trends in STDs in the United States 2000. Washington, DC: US Department of Health and Human Services.

Centers for Disease Control. (2002). Trends in sexual risk behaviors among high school students - United States, 1991-2001. Morbidity and Mortality Weekly Report, 51, 856-859. Retrieved August 30, 2003 from http://www.cdc.gov/mmwr/preview/mmwrhtml/mm5138a2.htm

Centers for Disease Control. (1996). Physical activity and health: A report of the surgeon general. Retrieved February 26, 2003 from http://www.cdc.gov/nccdphp/sgr/ataglan.htm

Chisholm, R. (1957). Perceiving: A philosophical study. Ithaca, NY: Cornell University Press.

Cohen, M. (2002). 101 philosophy problems ( $2^{\text {nd }}$ ed.). New York: Routledge Taylor \& Francis.

Combs, A. (1962). A perceptual view of the adequate personality. In Arthur W. Combs, (Ed.), ASCD 1962 yearbook: Perceiving, behaving, becoming (pp. 5064). Alexandria, VA: Association for Supervision and Curriculum Development. 
Cooper Institute for Aerobics Research. (1992). The Prudential Fitnessgram Test Administration Manual. Dallas: Author.

Cooper, R., Cutler, J., Desvigne-Nickens, P., Fortmann, S., Friedman, L., Havlik, R., et al. (2000). Trends and disparities in coronary heart disease, stroke, and other cardiovascular diseases in the United States. Circulation. Retrieved March 2003 from http://circ.ahajournals.org/cgi/content/full/102/25/3137

Corbin, C. B., \& Fletcher, P. (1968). Diet and activity patterns of obese and non obese elementary school children. Research Quarterly, 39, 922-928.

Dade County Public Schools. (1988). Physical fitness testing program. School Board of Dade County, Florida.

Dewey, J. (1899). The school and society. Chicago: University of Chicago Press.

Dewey, J. (1902). The child and the curriculum. Chicago: University of Chicago.

Dietz, W. H. Jr., \& Gortmaker, S. L. (1985). Do we fatten our children at the television set? Obesity and television viewing in children and adolescents. Pediatrics, 75, 807-812.

Doolittle, T. L., \& Bigbee, R. (1968). The twelve-minute run-walk: A test of cardiorespiratory fitness of adolescent boys. Research Quarterly, 39, 491-495.

Drug and alcohol abuse: Billions spent annually for treatment and prevention activities (GAO/HEHS No. 97-12). (1996, October 8). United States General Accounting Office Report to Congressional Requesters: Substance Abuse Funding.

Durlak, J. (1995). School-Based prevention programs for children and adolescents. Thousands Oaks, CA: Sage.

Dyson, B. P. (1995). Students' voices in two alternative elementary physical education programs. Journal of Teaching in Physical Education, 14, 394-407.

Eisner, E. W. (1994). The educational: Imagination on the design and evaluation of school programs $\left(3^{\text {rd }}\right.$ ed.). New York: Macmillan College Publishing.

Eisner, E., \& Vallance, E. (Eds.) (1974). Conflicting conceptions of curriculum. Berkeley, CA.: McCutchan.

Ennett, S. T., Tobler, N. S., Ringwalt, C. L., \& Flewelling, R. L. (1994). How effective is drug abuse resistance education? A meta-analysis of Project DARE outcome evaluations. American Journal of Public Health, 84, 1394-1401. 
Expert panel on detection, evaluation and treatment of high blood cholesterol in adults. (1994). National cholesterol education program: Second report of the expert panel on detection, evaluation, and treatment of high blood cholesterol in adults (Adult Treatment Panel II). Circulation, 89, 1329-1445.

Florida State Board of Education. (1996). Sunshine State Standards. Tallahassee, FL: Board of Education.

Fowler, F. J. (1993). Survey research methods (2 ${ }^{\text {nd }}$ ed.). Newbury Park, CA: Sage.

Frederick, O. I., \& Farquear, L. (1937). Areas of human activity. Journal of Educational Research, 30, 672-679.

Fry, P. L. (1999). From fat to fit. World and I, 14, 330-335.

Gay, L.R. (1987). Educational research competencies for analysis and application $\left(3^{\text {rd }}\right.$ ed.). Columbus, $\mathrm{OH}$ : Merrill.

Glass, W. (1973, May/June). Coronary heart disease sessions prove vitally interesting. California AHPER Journal, 7.

Glasser, W. (1976). Positive addiction. New York: Harper \& Row.

Going, S., \& Williams, D. (1989). Understanding fitness standards. Journal of Physical Education, Recreation and Dance, 60(6), 34-38.

Goodlad, J. I. (1984). A place called school: Prospectus for the future. New York: McGraw-Hill.

Goodlad, J., \& Su, Z. (1992). Organization of the curriculum. In P. Jackson (Ed.), Handbook of research on curriculum (pp. 327-344). New York: Macmillan.

Graham, G., Holt/Hale, S. A., \& Parker, M. (1993). Children moving: A reflective approach to teaching physical education $\left(3^{\text {rd }}\right.$ ed.). Mountain View, CA: Mayfield.

Graham, G., Holt/Hale, S. A., \& Parker, M. (2001). Children moving: A reflective approach to teaching physical education $\left(5^{\text {th }}\right.$ ed.). Mountain View, CA: Mayfield.

Graham, G., Holt/Hale, S. A., and Parker, M. (2004). Children moving: A reflective approach to teaching physical education $\left(6^{\text {th }}\right.$ ed.). New York: McGraw-Hill.

Gross, R. E. (1978). Seven new cardinal principles. Phi Delta Kappan, 60, 291-293. 
Groves, D. (1981). Is childhood obesity related to T.V. addiction? (Part 2 of 2).

The Physician and Sportsmedicine, 16(1), 117-122.

Haas, J. (1994, November). 2001: A school odyssey. Cardinal principles for the twenty-first century. National Association of Secondary School Principals Bulletin, 78(565), 47-59.

Hardy, C., \& Mawer, M. (Eds.). (1999). Learning and teaching in physical education. Philadelphia, PA.: Falmer Press.

Harris, N. (1996). Children, sex education, and the law. London: National Children's Bureau Enterprises.

Haskell, W. L. (1988). Physical activity and the diseases of a technologically advanced society. In the American Academy of Physical Education Papers No. 21 (pp. 73 -87). Physical Activity in Early and Modern Populations.

He, J., \& Whelton, P.K. (1997). Epidemeology and prevention of hypertension. Medical Clinic, North America, 81, 1077-1097.

He, J., Whelton, P.K., Appel, L.J., Charleston, J., \& Klag, M.J. (2000). Long-term effects of weight loss and dietary sodium reduction on incidence of hypertension. Hypertension 2000, 35, 544-549.

Hedgepeth, E., \& Helmich, J. (1996). Teaching about sexuality and HIV. New York: New York University Press.

Heyward, V. H. (1998). Advanced fitness assessment \& exercise prescription ( ${ }^{\text {rd }}$ ed.). Champaign, IL: Burgess Publishing.

Hinson, C. (1995). Fitness for children. Champaign, IL: Human Kinetics.

Holtzman, D., Greene, B. Z., Ingraham, G. C., Daily, L. A., Demchuk, D. G., \& Kolbe, L. J. (1992). HIV education and health education in the United States: A national survey of local school district policies and practices. Journal of School Health, 62, 421-427.

Hopple, C. \& Graham, G. (1995). What children think, feel, and know about physical fitness testing. Journal of Teaching in Physical Education, 14, 408-417.

Horner, C., \& Westacott, E. (2000). Thinking through philosophy: An introduction. Cambridge, England: Cambridge University Press.

House of Representatives. (2002). Extension of funding for abstinence education. H.R.

Doc. No. 107-462 (2002). 
Hovell, M., Sallis, J., Kolody, B., \& McKenzie, T. (1999). Children's physical activity choices: A developmental analysis of gender, intensity levels, and time. Pediatric Exercise Science, 11, 158-168.

Hubert, H.B., Feinleib, M., McNamara, P.M., \&Castelli, W.P. (1983). Obesity as an independent risk factor for cardiovascular disease: A 26-year follow-up of participants in the Framingham Heart Study. Circulation, 67, 968-977.

Hui, S.C., \& Yuen, P. Y. (2000). Validity of the modified back-saver sit-and-reach test: A comparison with other protocols. Medicine and Science in Sports and Exercise, 32, 1655.

Hui, S.C., Yuen, P. Y., Morrow, J. R., Jr., \& Jackson, A. W. (1999). Comparison of the criterion-related validity of sit-and-reach tests with and without limb length adjustments in Asian adults. Research Quarterly for Exercise and Sport, 70, 401406.

Institute of Medicine. (1997). The hidden epidemic: Confronting sexually transmitted diseases. Washington, DC: National Academy Press.

Iverson, D. C., Fielding, J. E., Crow, R. S., \& Christianson, G. M. (1985). The promotion of physical activity in the United States population: The status of programs in medical, worksite, community, and school settings. Public Health Reports, 100, 212-224.

Jackson, A. S., \& Pollock, M. L. (1978). Generalized equations for predicting body density of man. British Journal of Nutrition, 40, 497-504.

Jackson, A. S., Pollock, M. L., \& Ward, A. (1980). Generalized equations for predicting body density of women. Medicine and Science in Sports and Exercise, 12, 175-182.

Jackson, A. W., Morrow, J. R., Jr., Jensen, R. L., Jones, N. A., \& Schultes, S. S. (1996). Reliability of the Prudential fitnessgram trunk life in young adults. Research Quarterly for Exercise and Sport, 67, 115-117.

Jemmott, J. B., III, Jemmott, L. S., \& Fong, G. T. (1992). Reductions in HIV risk associated sexual behaviors among black male adolescents: Effects of an AIDS prevention intervention. American Journal of Public Health, 82, 372-377.

Johnson, B.L., \& Nelson, J. (1986). Practical measurements for evaluation in physical education. New York: Macmillan.

Kennedy, J., \& Bush, A. (1985). An introduction to the design and analysis of experiments in behavioral research. Lanham, MD: University Press of America. 
Kimiecik, J. C., \& Horn, T. S. (1998). Parental beliefs and children's moderate to vigorous physical activity. Research Quarterly for Exercise and Sport, 69, 163175.

Kimm, S. Y. S., \& Kwiterovich, P. O. (1995). Childhood prevention of adult chronic diseases: Rationale and strategies. In L. W. Y. Cheun \& J. B. Richmond (Eds.), Child health, nutrition, and physical activity (pp. 249-273). Champaign, IL: Human Kinetics Publishers.

Kirby, D., Short, L., Collins, J., Rugg, D., Kolbe, L., Howard, L., et al. (1994). Schoolbased programs to reduce sexual risk behaviors: A review of effectiveness. Public Health Reports, 109, 339-360.

Kliebard, H. (1992). The struggle for the American curriculum 1893-1958. New York: Routledge \& Kegan Paul.

Kriska, A.M., Blair, S.N., \& Pereira, M.A. (1994). The potential role of physical activity in the prevention of non-insulin dependent diabetes mellitus: The epidemiological evidence. Exercise and sport sciences reviews, 22, 121-143.

Laporte, W., Musch, E., \& Vermeesch, M. (1993). Perceived learning results of physical education lessons in secondary schools by the learner: A report. In Proceedings of the ICHPER $36^{\text {th }}$ World Congress, Yokohama, Japan (pp. 437444). Tokyo, Japan: Tokyo Gakagei University Press.

Laws, C., \& Fisher, R. (1999). Pupils' interpretations of physical education. In C. Hardy, \& M. Mawer (Eds.), Learning and teaching in physical education (pp. 23-37). Philadelphia, PA.: Falmer Press.

Leiter, L.A., Abbott, D., Campbell, N.R., Mendelson, R., Ogilvie,R. I., \& Chockalingam, A. (1999). Lifestyle modifications to prevent and control hypertension: Recommendations on obesity and weight loss. Canadian Medical Association Journal, 160 (Suppl. 9), S7-12.

Lewis, A. J. (1979, February). Educational basics to serve citizens in the future. FASCD Journal, 1, 2-8.

Luepker, R. V. (1999). How physically active are American children and what can we do about it? International Journal of Obesity and Related Metabolic Disorders, 23(Suppl. 2), S12 - 17.

Maier, T. W. (2001, August 27). School giving P.E. short shift. Insight on the News. Retrieved July 25, 2003 from http://www.findarticles.com 
Manross, M. (1994). What children think, feel and know about the overhand throw. Unpublished master's thesis, Virginia Polytechnic Institute and State University, Blacksburg.

Manson, J.E., Nathan, D.M., Krolewski, A.S., Stampfer, M.J., Willett, W.C., \& Hennekens, C.H. (1992). A prospective study of exercise and incidence of diabetes among U.S. male physicians. Journal of the American Medical Association, 268, 63-67.

Manson, J.E., Rimm, E.B., Stampfer, M.J., Rosner, B., Hennekens, C.H., Speizer, F.E., et al. (1991). Physical activity incidence of non-insulin dependent diabetes mellitus in women. Lancet, 338, 774-778.

McGinnis, J. M. (Ed.) (1987). The national children and youth study II. Journal of Physical Education, Recreation, and Dance, 58(9), 50.

McGinnis, J. M., Kanner, L., \& Degraw, C. (1991). Physical education's role in achieving national health objectives. Research Quarterly for Exercise and Sport, 62(2), 138-142.

Meredith, M. (1988). Activity or fitness: Is the process or the product more important for public health? Quest, 40, 180-186.

Meredith, M. D., \& Welk, G. J. (1999). Fitnessgram: Test administration manual. Dallas, TX: The Cooper Institute for Aerobics Research.

Miami-Dade County Public Schools. (n.d.) Competency-Based Curriculum: Physical Education. Miami, FL: Author.

Miami-Dade County Public Schools. (1988). Physical fitness testing program. Miami-Dade County Public Schools, Division of Life Skills.

Miami-Dade County Public Schools. (1997). Physical fitness testing program: Fitnessgram. School Board of Miami-Dade County, FL.

Mobidity Mortality Weekly Report. (1998). Incidence of initiation of cigarette Smoking - United States, 1965-1996, 47, 837-40.

Mokdad, A.H., Serdula, M.K., Dietz, W.H., Bowman, B., Marks, J., \& Koplan, J. (1999). The spread of the obesity epidemic in the United States, 1991-1998. Journal of the American Medical Association, 282, 1519-22.

National Association for Sport and Physical Education. (1992). Outcomes of quality physical education programs. Reston, VA.: American Association for Health, Physical Education, Recreation, and Dance. 
National Association for Sport and Physical Education. (1995). Moving into the future: National standards for physical education. St. Louis, MO.: Mosby.

National Heart, Lung and Blood Institute. (1998, October). Morbidity and mortality: 1998 chartbook on cardiovascular, lung, and blood diseases. Bethesda, MD: Public Health Services, National Institutes of Health, National Heart, Lung, and Blood Institute.

National Institute of Health. (1995). Physical activity and cardiovascular health: NIH consensus statement. Kensington, MD: NIH Consensus Program Information Center.

National Institute Of Health Consensus Development Panel. (1985). Health implications of obesity: National Institute of Health consensus development conference statement. Annals of Internal Medicine, 103, 1073-1077.

Oliva, P. (1992). Developing the curriculum ( $3^{\text {rd }}$ ed.). New York: Harper Collins.

Oliva, P. (1997). Developing the curriculum ( $4^{\text {th }}$ ed.). New York: Addison Wesley Longman.

Olsen, E. (1990, May). “A” is too active. American Health, 73-80.

Pangrazi, R. (1998). Dynamic physical education for elementary school children $\left(12^{\text {th }}\right.$ ed.). Needham Heights, MA: Allyn \& Bacon.

Pangrazi, R. (2001). Dynamic physical education for elementary school children $\left(13^{\text {th }}\right.$ ed.). Needham Heights, MA: Allyn \& Bacon.

Pangrazi, R. P., \& Dauer, V. P. (1995). Dynamic physical education for elementary school children ( $11^{\text {th }}$ ed.). Needham Heights, MA: Allyn \& Bacon.

Pate, R. (1983). A new definition of youth fitness. Physicians and Sportsmedicine, 11(4), 80.

Pate, R. (1991). Health-related measures of children's physical fitness. Journal of School Health, 61, 231-233.

Pate, R. R., Dowda, M., \& Ross, J. G. (1990). Association between physical activity and physical fitness in American children. American Journal of Diseases on Children, 144, 1123-1129.

Pate, R. R., \& Ross, J. G. (1987). Factors associated with health-related fitness. Journal of Physical Education, Recreation, and Dance, 58(9), 93-96. 
Patterson, P., Rethwisch, N., \& Wiksten, D. (1997). Reliability of the trunk lift in high school boys and girls. Measurement in Physical Education and Exercise Science, 1, 145-151.

Patton, M. (1990). Qualitative evaluation and research methods $\left(2^{\text {nd }}\right.$ ed.). Newbury Park, CA.: Sage.

Payne, V. G., \& Morrow, Jr., J. R. (1993). Exercise and VO2max in children: A Meta-analysis. Research Quarterly for Exercise and Sport, 64, 305-313.

Physical Activity and Health: A Report of the Surgeon General. (1996). Atlanta, GA: U.S. Department of Health and Human Services, Centers for Disease Control and Prevention.

Pinar, W., Reynolds, W., Slattery, P., \& Taubman, P. (1995). Understanding curriculum. New York, N.Y.: Peter Lang.

Popham, J., \& Baker, E. L. (1970). Establishing instructional goals. Englewood Cliffs, NJ: Prentice-Hall.

President's Council on Physical Fitness and Sports, 96(2) [Newsletter]. (1996, Summer/Fall). Washington, DC: Department of Health and Human Services

Raithel-Simmons, K. (1988). Are American children really unfit? (Part 1 of 2). The Physician and Sportsmedicine, 16(10), 146-154.

Rattliffe, T., Imwold, C., \& Conkell, C. (1994). Children's views of their third grade physical education class. The Physical Educator, 51, 106-111.

Reiff, G. G., Dixon, W. R., Jacoby, D., Ye, X. Y., Spain, C. G., \& Hunsicker, P. A. (1987). The President's council on physical fitness and sports 1985 national school population fitness survey. Washington, DC: U.S. Department of Health and Human Services.

Riopel, D. A., Boerth, R. C., Coates, T. J., Hennekens, C. H., Miller, W. W., Weidman, W. H. (1986).Coronary risk factor modification in children: Exercise. Circulation, 74, 1189A-1191A.

Robertson, L. D., \& Magnusdottir, H. (1987). Evaluation of criteria associated with abdominal fitness testing. Research Quarterly for Exercise and Sport, 58, 355-359.

Rose, K. (1968). To keep people in health. Journal of the American College Health Association, 22, 80. 
Rosenthal, L. (n.d.). A+ Plan for Education: Florida's Blueprint for Improving Schools. Retrieved November 3, 2003 from http://www.greatschools.net

Ross, J. G., Pate, R. R., Caspersen, C. J., Damberg, C. L., \& Svilar, M. (1987). Home and community in children's exercise habits. Journal of Physical Education, Recreation, and Dance, 58(9), 85-92.

Rowland, T. W. (1999). Adolescence: A "risk factor" for physical inactivity. Research Digest, 3(6), 1-8.

Safrit, M. J. (1986). Introduction to measurement in physical education and exercise science. St. Louis, MO: The C. V. Mosby Company.

Safrit, M. J., \& Wood, T. M. (1995). Introduction to measurement in physical education and exercise science ( $3^{\text {rd }}$ ed.). St. Louis, MO: The C. V. Mosby Company.

Saint Romain, B. \& Mahar, M. T. (2001). Norm-referenced and criterion referenced reliability of the push-up and modified pull-up. Measurement in Physical Education and Exercise Science, 5, 67-80.

Sallis, J. F. (1987). A commentary on children and fitness: A public health perspective. Research Quarterly for Exercise and Sports, 58, 326-330.

Sallis, J. F., \& McKenzie, T. L. (1991). Physical education's role in public health. Research Quarterly for Exercise and Sport, 62, 124-137.

Sandmaier, M. (1997). Healthy heart handbook for women. U.S. Department of Health and Human Services. NIH Publication No. 98-2720.

Schinke, S. P., Botvin, G. J., \& Orlandi, M. A. (1991). Substance abuse in children and adolescents: Evaluation and intervention. Newbury Park, CA: Sage.

School performance plan. (2003). Miami-Dade County Public Schools: Redland Elementary School.

Schubert, W. (1986). Curriculum perspective, paradigm, and possibility. New York: Macmillan.

Sempos, C.T., Cleeman, J.I., Carroll, M.D., Johnson, C. L., Bachorik, P. S., \& Gordon, D. J., et al. (1993). Prevalence of high blood cholesterol among U.S. adults: An update based on guidelines from the second report of the national cholesterol education program adult treatment panel. Journal of the American Medical Association, 269, 3009-3014. 
Shephard, R. (1995). Physical activity, health and well-being at different life stages. Research Quarterly for Exercise and Sport, 66, 298-302.

Silverman, S., \& Ennis, C. (1996). Student learning in physical education applying research to enhance instruction. Champaign, IL: Human Kinetics.

Slaughter, M. H., Lohman, T. G., Boileau, R. A., Horswill, C. A., Stillman, R. J., Van Loan, M. D., et al. (1988). Skinfold equations for estimation of body fatness in children and youth. Human Biology, 60, 709-723.

Solso, R. L. (1991). Cognitive psychology ( $3^{\text {rd }}$ ed.). Needham Heights, MA: Allyn \& Bacon.

SPSS 10.0 for Windows. (1998). [Computer Software]. Chicago: SPSS Inc.

Stevens, J. (1990). Intermediate Statistics A Modern Approach. Hillsdale, NJ: Lawrence Erlbaum Associates.

Stucky-Ropp, R. C., \& DiLorenzo, T. M. (1993). Determinates of exercise in children. Preventative Medicine, 22, 880-889.

Sunshine State Standards. (2003). A service of the college of education at Florida Gulf Coast University. Retrieved November 3, 2003 from http://sunshinestatestandards.net/

Taba, H. (1962). Curriculum development: Theory and practice. New York: Harcourt Brace Jovanovich.

Tanner, D. \& Tanner, L. N. (1975). Curriculum development Theory into Practice. New York: Macmillan.

Tanner, D. \& Tanner, L. N. (1980). Curriculum development Theory into Practice $\left(^{\text {nd }}\right.$ ed.). New York: Macmillan.

Teichman, J. \& White, G. (Eds.) (1995). An introduction to modern European philosophy. New York: St. Martin's Press.

The president's council on physical fitness and sports. (1996-97). 1996-97:

The President's Challenge Physical Fitness Program Packet. Washington, DC: Author

The president's council on physical fitness and sports. (1997). Physical Activity \& Sport in the Lives of Girls. Under The Direction of The Center For Research On Girls \& Women In Sports, University of Minnesota. 
Tyler, R. (1949). Basic principles of curriculum and instruction. Chicago: University of Chicago Press.

United States Department of Health and Human Services. (1996). Physical activity and health: A report of the surgeon general. Atlanta, GA.: U.S. Department of Health and Human Services, Centers for Disease Control and Prevention, National Center for Chronic Disease Prevention and Health Promotion.

United States Department of Health and Human Services. (2000). Healthy people 2010: Leading health indicators. Retrieved March 3, 2003 from healthypeople.gov/document

United States Department of Health and Human Services. (2000). Healthy people 2010: Understanding and improving health. Washington, DC: Government Printing Office.

United States General Accounting Office. (2000). District of Columbia: Adolescent AIDS Prevention Program (GAO/HEHS Report No. 00-194 R.D.C. Adolescent AIDS Prevention Program). Washington, DC: Department of Health, Education, and Human Services.

United States Public Health Services. (1990). Healthy People 2000: National Health Promotion and Disease Objectives. Washington, DC: Government Printing Office.

Wall, J., \& Murray, N. (1990). Children and movement. Denver, CO: Wm. C. Brown.

Walter, H. J., \& Vaughan, R. D. (1993). AIDS risk reduction among multiethnic sample of urban high school students. Journal of American Medical Association, $270,725-730$.

Welk, G. J. \& Wood, K. (2000). Physical activity assessments in physical education: A practical review of instruments and their use in the curriculum, Journal of Physical Education, Recreation, and Dance, 71(1), 30-40.

Whitehead, A. (1929). The aims of education. New York: Macmillan.

Wiles, J., \& Bondi, J. C. (1984). Curriculum development: A guide to practice. Columbus, OH.: Charles E. Merrill.

Williams, D. P., Going, S. B., Lohman, T. G., Harsha, D. W., Webber, L. S., \& Bereson, G. S. (1992). Body fatness and the risk of elevated blood pressure, total cholesterol and serum lipoprotein rations in children and youth. American Journal of Public Health, 82, 358-363. 
Wilmore, J. H., \& McNamara, J.J. (1974). Prevalence of coronary disease risk factors in boys, 8 to 12 years of age. Journal of Pediatrics, 84, 527-533.

Your Heart Your Life: A Lay Educators Manual. (1999). National Institute Of Health. National Heart, Lung, and Blood Institute. Office of Prevention, Education, and Control (NIH Publication No. 99-3674). Washington, DC: Department of Health and Human Services. 


\section{APPENDICES}


Appendix A

Physically Educated Person 


\section{A PHYSICALLY EDUCATED PERSON:}

\section{HAS learned skills necessary to perform a variety of physical activities}

1. ... moves using concepts of body awareness space awareness, effort, and relationships.

2. ... demonstrates competence in a variety of manipulative, locomotor, and nonlocomotor skills.

3. ... demonstrates competence in combinations of manipulative, locomotor, and nonlocomotor skills performed individually and with others.

4. ... demonstrates competence in many different forms of physical activity.

5. ... demonstrates proficiency in a few forms of physical activity.

6. ... has leamed how to learn new skills.

\section{IS physically fit}

7. ... assesses, achieves, and maintains physical fitness.

8. ... designs safe, personal fitness programs in accordance with principles of training and conditioning.

\section{DOES participates regularly in physical activity}

9. ... participates in health enhancing physical activity at least three times a week.

10. ... selects and regularly participates in lifetime physical activities.

\section{KNOWS the implications of and the benefits from involvement in physical activities}

11. ... identifies the benefits, cost, and obligations associated with regular participation in physical activity.

12. ... recognizes the risk and safety factors associated with regular participation in physical activity

13. ... applies concepts and principles to the development of motor skills.

14. ... understands that wellness involves more than being physically fit.

15. ... knows the rules, strategies, and appropriate behaviors for selected physical activities.

16. ... recognizes that participation in physical activity can lead to multi-cultural and international understanding.

17. ... understanding that physical activity provides the opportunity for enjoyment, selfexpression, and communication.

\section{VALUES physical activity and its contributions to a healthful lifestyle}

18. ... appreciates the relationships with others that result from participation in physical activity.

19. ... respects the role that regular physical activity plays in the pursuit of life-long health and well-being.

20. ... cherishes the feeling that result from regular participation in physical activity.

(Pangrazi, 1998, p. 6) 
Appendix B

Sunshine State Standards

For Physical Education 


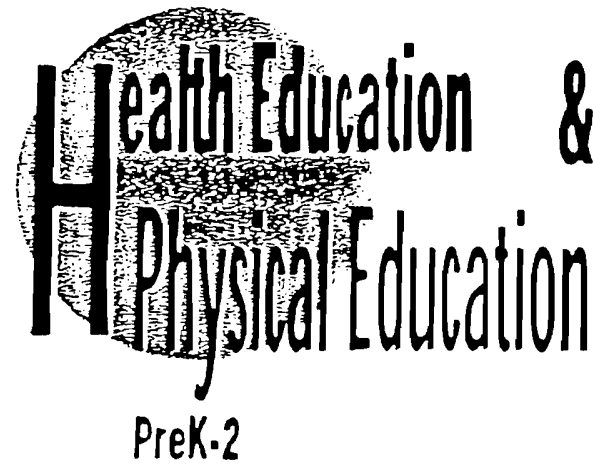

\section{Physical Education}

\section{Physical [ ducation Literacy}

\section{Standard 1:}

The slodest demeasliales compeleacy in many moverneat lermes and pofficiency in a lew lories of plysiol aciviny. (or (1.1)

3. combines shapes, levels, directions, pathways, and ranges into simple sequences.

2. kicks stationary and rolled balls with strong force while maintaining balance.

3. adapts movement to changing environmental conditions.

4. chases, flees, and dodges to avoid or catch others and maneuver around obstades.

5. consistently strikes lightweight objects with body parts and with lightweighl implements.

6. knows ways to manage own body weight in a variety of situations (e.g., hanging and dimbing and balancing in symmetrical and asymmetrical shapes on a variety of body parts on mats or apparatus).

7. demonstrates basic locomotor skills (e.g., hop, walk, run jump, leap, gallop, skip, and slide).

8. uses an overthand throwing pattern with accuracy.

9. knows various techniques for catching thrown objects.

\section{SLandard 2:}

The student appres concepts and principles of human movemem 10 the development of molor sto and the learing of new dits. (PLC.1.1)

1. knows how 10 absorb force by establishing a base of support to receive the force of the oncoming object.

2. knows ways to establish bases of support using various body parts and fundamental prinoples of balance.
3. knows various techniques for landing safely.

4. uses concepts of space and movement to design and practice sequences that show the use of al three types of pathways (i.e, straight, aig-zag, and curved).

5. uses movement control to run, hop, and skip in different ways in a large group without bumping into others or falling.

6. knows the characteristics of a mature throw.

\section{Slandard 3:}

The guden andyre the lenefito of regeta pricipan

in physical activily. PLL3.1)

1. identifies changes in the body during physical activity.

2. knows that the heart is a musde that will become stronger as a result of physical activity.

3. understands that physical activity produces feelings of pleasure.

4. knows ways in which physical activity promotes muscular strength.

\section{Responsible Physical Activity \\ Behaviors}

\section{Slandard 1:}

The sudem actieves and maimains a meath entuaning level of phyical finess. (R.R.1.1)

3. knows how to move each joint through a functional range of motion

2. underslands the changes that ocour in respiration during vigorous physical activity.

3. knows various warm-up and cool-dmm exeroses.

4. participates in health-related fitmess assessment.

\section{Slandard 2}

The studed demonst ales lesponsita persend and sacial behavior in physial activily. PL.2.1)

1. understands the importance of being aware of one's surroundings and acting in a safe manner while participating in physical activity settings.

2. follows directions given by instructor or group leader.

3. understands the difference between compliance and noncompliance with game rules and fair play.

4. identifies appropriate behaviors for participating with others in physical activity settings. 
Advocate and Promote Physically

Active Lifestyles

\section{Standard 1:}

The student understands how paricipating in physical adivity promoles indusion and an understanding of the abrities and altural diversiny of people. (PE.C.1.1)

1. knows the importance of demonstrating consideration of others in physical activity settings.

2. knows games to play with students who have disabilities.

\section{Standard 2:}

The studern understands that physical activity provides the opporiunity for enjoymeat, challenge, selfexpression, and communiotion. (P.C.2.1)

1. identifies the feelings resulting from challenges, successes, and failures in physical activity.

2. knows various ways to use the body and movement activities to communicate ideas and feelings (e.g., creative movement).

3. recognizes the benefits that accompany cooperation and sharing. 


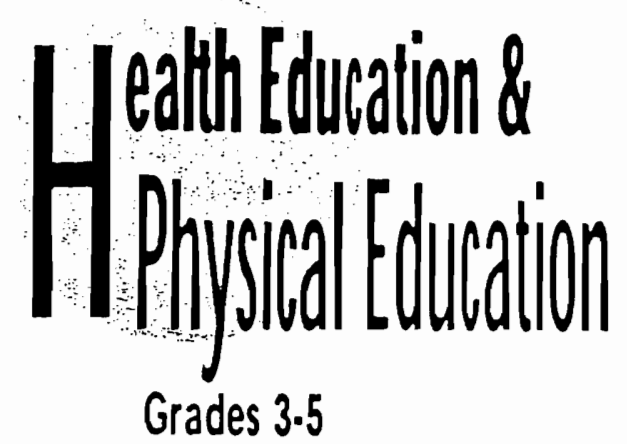

Physical Education

\section{Physical Educalion Literacy}

\section{Standard 1:}

The sludent demonstrales competency in many movement forms and proficiency in a few lorms of physical acivity. (PLA12)

1. knows various techniques for throwing or catching different objects.

2. knows how to design and modify sequences that show changes in direction and speed.

3. knows how to demonstrate functional patterns of striking, dribbling, volleying, throwing, and catching in dynamic situations.

4. understands that games consist of people, boundaries, equipment, purpose, and rules which all interrelate during game play.

5. knows how to create, explore, and devise game strategies.

\section{Slandard 2:}

The studeal applies concepts and principles of human movement to the development of molor stils and the learning of new shits. (PLA2.2)

1. recognizes the proper techniques of performing an overhand throw.

2. understands and applies basic movement concepts (e.g., space awareness, body awareness, and transfer of weight) to games, dance, and gymnastics.

3. knows the reasons that appropriate practice improves performance.

\section{Standard 3:}

The sudeat analyes the benefits of regula participation

in physical activity. (PLA32)
1. describes healthtul benefits that result from regular participation in vigorous physical activity.

2. understands how a healthy body contributes to positive self-concepts.

3. knows the upportunities in the school and community for regular participation in physical activity.

4. selects and participates regularly in physical activities for the purpose of improving skill and health.

\section{Responsible Physical Activity Behaviors}

\section{Standard 1:}

The student achieves and maintains a heakh-enhancing level of physical fitness. (PC.B.1.2)

1. knows how to maintain continuous aerobic activity for a specified period of time in order to improve endurance.

2. knows activities that promote a faster heart rate.

3. knows how proper stretching increases flexibility and understands why flexibility is important.

4. knows how exercise helps control obesity.

5. understands that correct body position and proper use of muscles are necessary to improve strength and flexibility.

\section{Standard 2:}

The studenl demonstrales responsiole personal and social behavior in physical adivity. (PE.B.2.2)

1. knows potential risks associated with physical activities.

2. applies and follows rules while playing sports and games.

3. knows the importance of seeking out, participating with, and showing respect for people of like and different physical abilities.

\section{Advocate and Promote Physically Active Lifestyles}

\section{Standard 1:}

The studem underslands how participaling in physical activity promotes inckusion and an understanding of the abities and antu al diversity of people. (PE.C.1.2)

1. recognizes the differences and similarities in the physical activity choices of others.

2. knows how to perform games and/or dances from a variety of cultures. 


\section{Standard 2:}

The studemt understands that physical activity provides the opportunity for enjoyment, challenge, selfexpression, and communication. (PE.C.2.2)

1. identifies physical activities that contribute to personal feelings of joy.

2. knows the positive benefits of exercising at home.

3. designs and performs games, gymnastics, and dance sequences that allow for group creativity and discussion. 
Appendix C

Miami-Dade County Public School

Competency Based Curriculum

Physical Fitness Objectives

For Physical Education 


\section{PHYSICALEDUCATION GRADE K-1}

\begin{tabular}{|c|c|c|}
\hline COMPONENT & OBJECTIVES & COMPETENCY \\
\hline IV Physical Fitness & 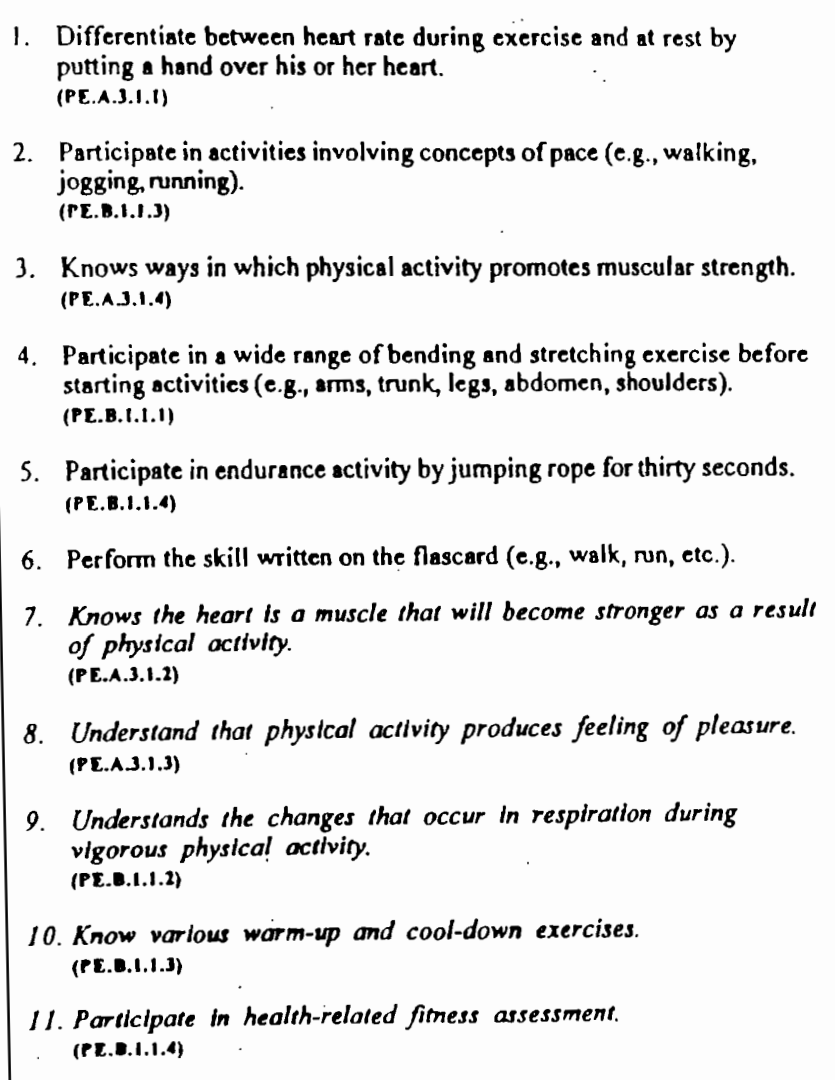 & 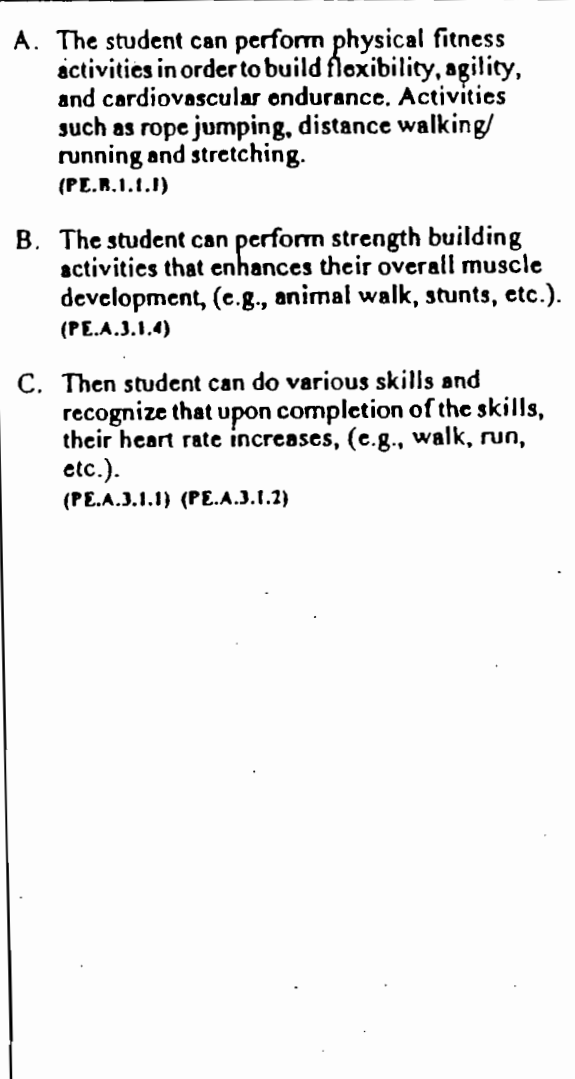 \\
\hline
\end{tabular}




\section{PHYSICALEDUCATION}

GRADE 2

\begin{tabular}{|c|c|c|}
\hline COMPONENT & OBJECTIVES & COMPETENCY \\
\hline IV Physical fitness & $\begin{array}{l}\text { 1. Locate his/her pulse in various locations (e.g., neck, wrist). } \\
\text { 2. Demonstrate correct sustained stretching techniques. } \\
\text { 3. Identify which body parts are developed through activities (e.g., } \\
\text { cardiovascular, flexibility, and strengthening exercises). } \\
\text { (PE.A.3.1.2) (PE.A.3.1.4) } \\
\text { 4. Demonstrate endurance by jumping rope continuously for one minute } \\
\text { and walking/running a half-mile in five minutes. } \\
\text { 5. Perform a modified pull-up (e.g., reclining, partner pull-up). } \\
\text { 6. Participate in abdominal strengthening activities (e.g., curl-ups, sit- } \\
\text { ups). } \\
\text { 7. Bring in a collage of healthy foods. } \\
\text { 8. Iden(ifies changes in the body during physical activity. } \\
\text { (PE.A.3.1.1) } \\
\text { 9. Understands that physical activity produces feelings of pleasure. } \\
\text { (PE.A.3.1.3) } \\
\text { 10. Knows how to move each joint through a functional range of } \\
\text { motion. } \\
\text { (PE.B.1.1.1) } \\
\text { 11. Understands the changes that occur in respiration during } \\
\text { vigorous physical activity. } \\
\text { (PE.B.1.1.2) } \\
\text { 12. Knows various warm-up and cool-down exercises. } \\
\text { (PE.B.1.1.3) } \\
\text { 13. Porticipate in healih-relared firness assessment. } \\
\text { (PE.B.1.1.4) }\end{array}$ & $\begin{array}{l}\text { A. The student can perform physical fitness } \\
\text { activities (e.g., rope jumping, half mile run/ } \\
\text { walk, stretching, arm hand and rope climbing, } \\
\text { etc.) in order to build flexibility, agility, } \\
\text { cardiovascular endurance and upper body } \\
\text { strength. } \\
\text { (PE.B.1.1.1) } \\
\text { B. The student can understand how exercise } \\
\text { and nutrition affects the body. } \\
\text { (PE.A.J.1.1) (PE.A.3.1.2) (PE.A.J.1.J) (PE.A.3.1.4) }\end{array}$ \\
\hline
\end{tabular}




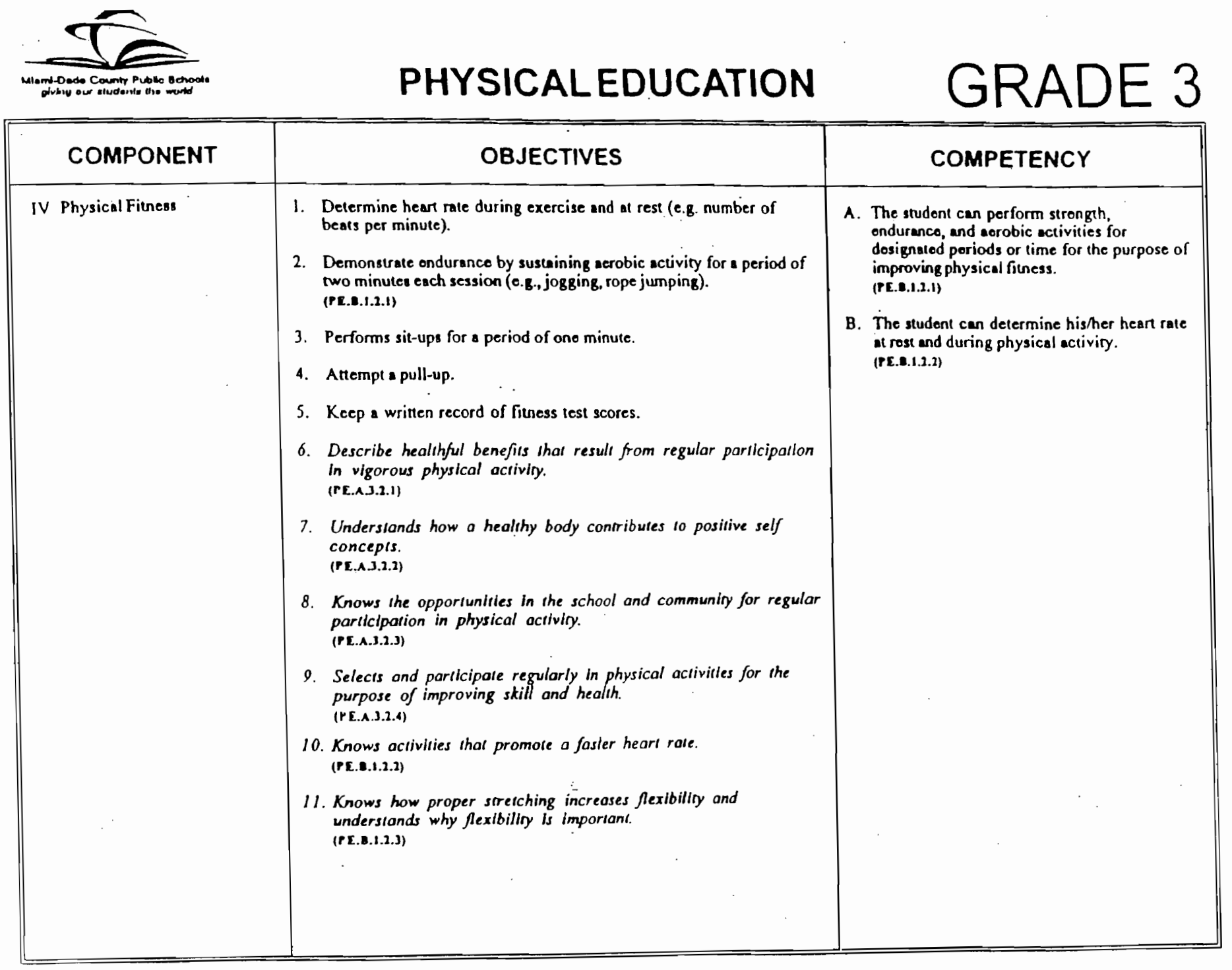




\section{PHYSICALEDUCATION}

GRADE 3

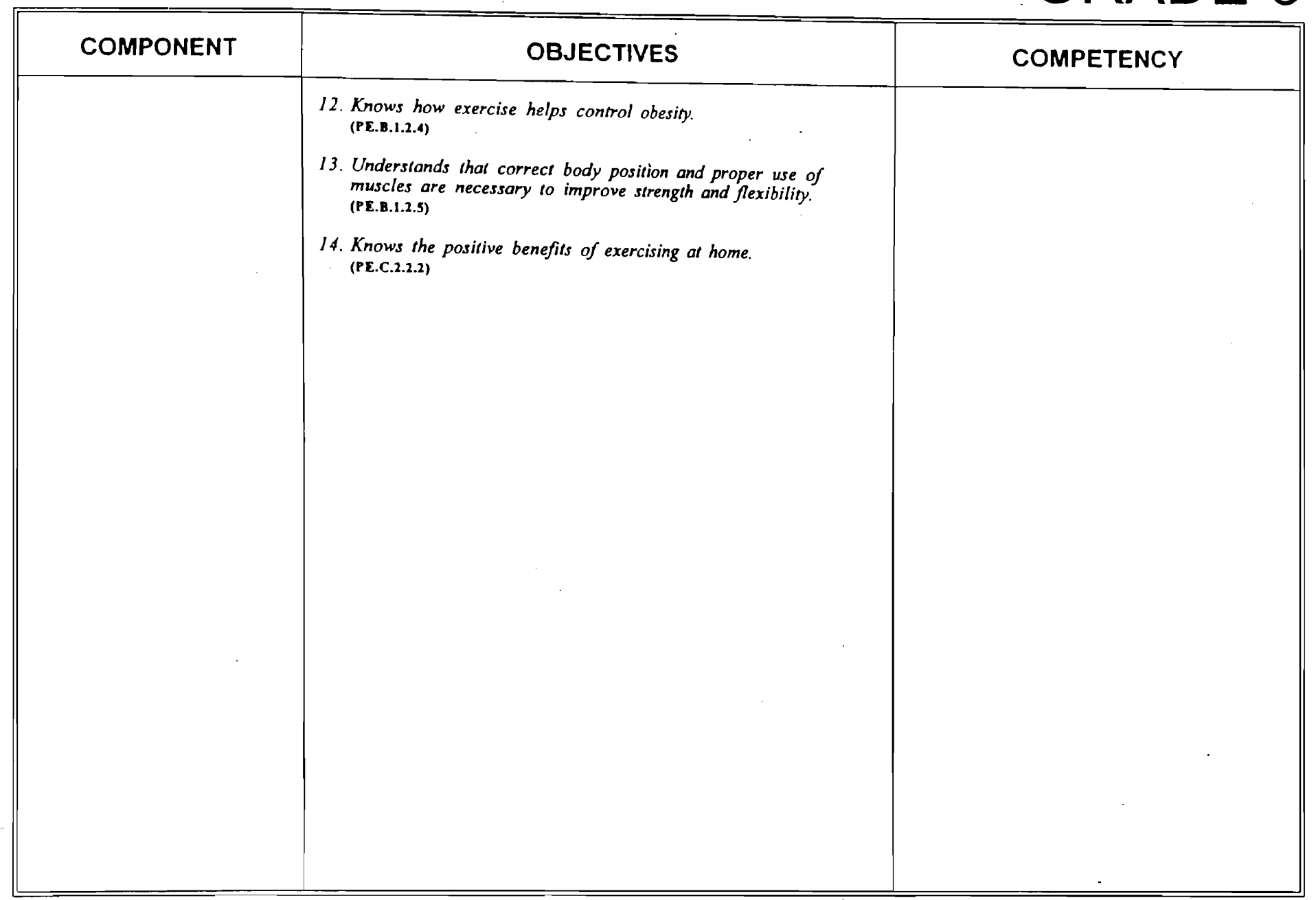




\section{PHYSICALEDUCATION}

\section{GRADE 4}

\begin{tabular}{|c|c|c|}
\hline COMPONENT & OBJECTIVES & COMPETENCY \\
\hline IV Physical Fitness & $\begin{array}{l}\text { 1. Participate in physical activity and develop fitness habits for life. } \\
\text { (PE.A.3.2.4) } \\
\text { 2. Explain the importance of fitness testing when setting personal fitness } \\
\text { goals. } \\
\text { 3. Walk/run one mile. } \\
\text { 4. Perform sit-ups for one minute. } \\
\text { 5. Perform the sit and reach test. } \\
\text { 6. Perform a pull-up. } \\
\text { 7. Perform shuttle run while demonstrating proper running techniques. } \\
\text { 8. Using the percentile charts, read the percentiles for each fitness test. } \\
\text { 9. Describe healthful benefits that result from regular participation } \\
\text { in vigorous physical activity. } \\
\text { (PE.A.3.2.1) } \\
\text { 10. Understands how a healthy body contributes to a positive self- } \\
\text { concept. } \\
\text { (PE.A.3.2.2) } \\
\text { 11. Knows the opportunities in the school and community for regular } \\
\text { participation in physical activity. } \\
\text { (PE.A.3.2.3) } \\
\text { 12. Knows how to maintain continuos aerobic activity for a specified } \\
\text { period of time in order to improve endurance. } \\
\text { (PE.B.1.2.1) } \\
\text { 13. Knows activities that promote a faster heart rate. } \\
\text { (PE.B.1.2.2) }\end{array}$ & $\begin{array}{l}\text { A. The student can recognize that time and } \\
\text { effort are prerequisites for skill improvement } \\
\text { and fitness. } \\
\text { B. The student can perform different fitness } \\
\text { activities and determine a percentile score. } \\
\text { (PE.B.1.2.1) (PE.B.t.2.2) } \\
\text { C. The student can maintain continuous aerobic } \\
\text { activity for a specific period of time and } \\
\text { understand the positive benefits. } \\
\text { (PE.B.1.2.1) (PE.C.2.2.2) }\end{array}$ \\
\hline
\end{tabular}




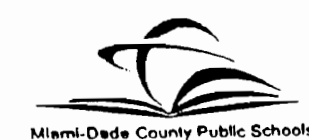

PHYSICALEDUCATION

GRADE 4

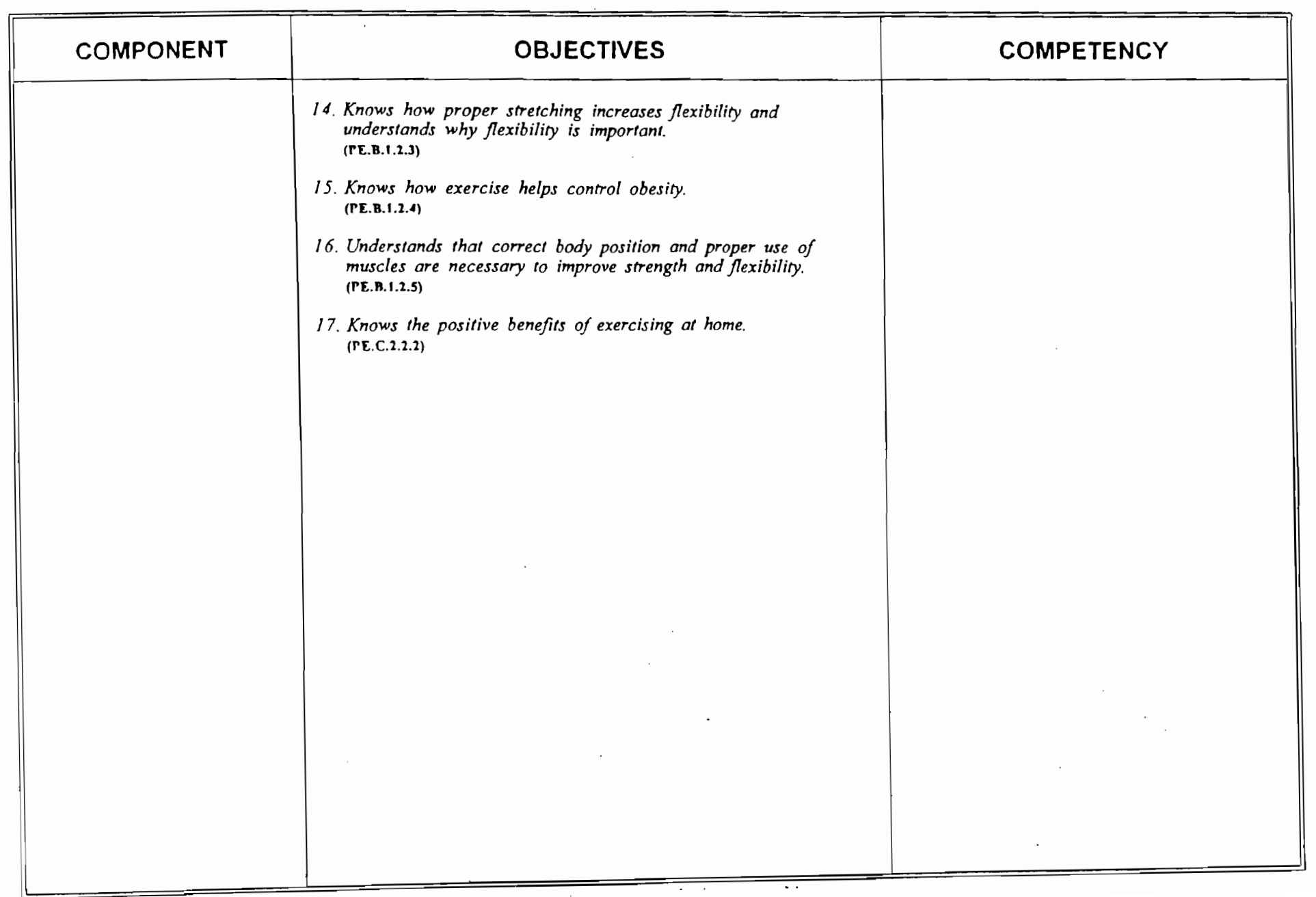




\section{PHYSICALEDUCATION GRADE 5}

\begin{tabular}{|c|c|c|}
\hline COMPONENT & OBJECTIVES & COMPETENCY \\
\hline IV Physical Fitness & 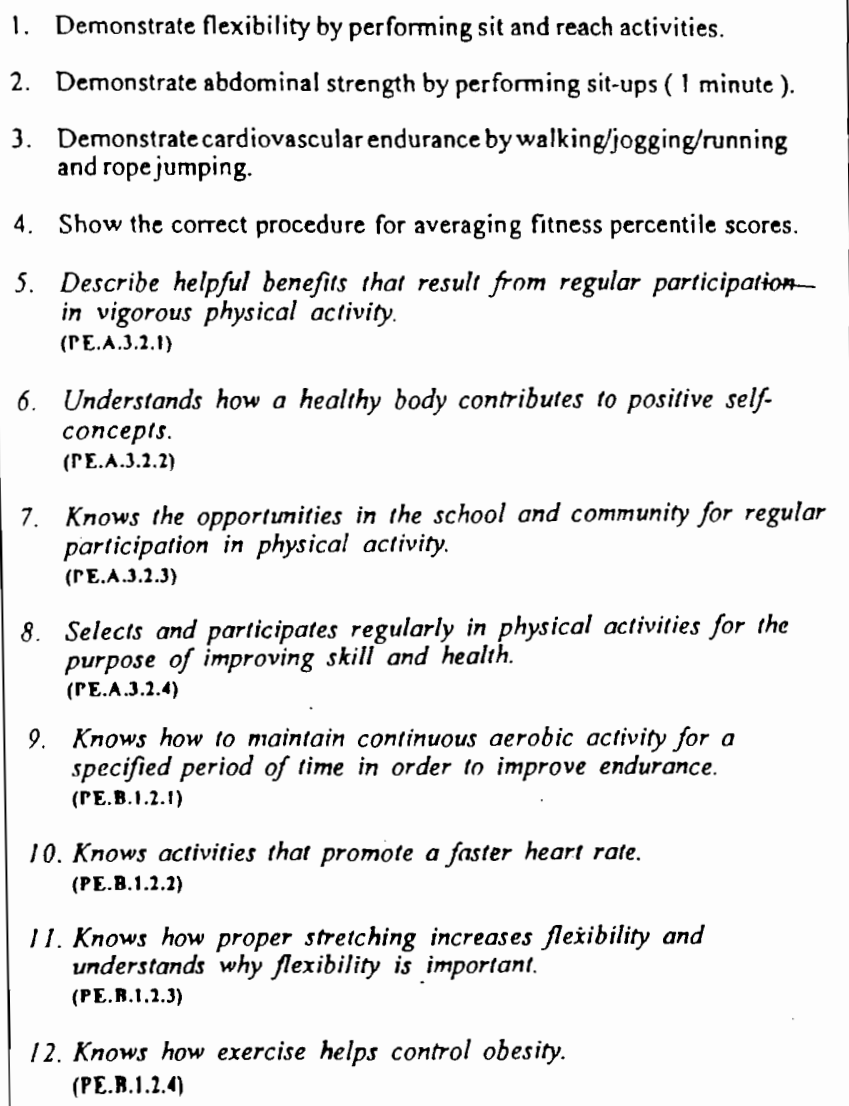 & $\begin{array}{l}\text { A. The student can perform physical fitness } \\
\text { activities which are essential for physical } \\
\text { fitness improvement, cardio-respiratory } \\
\text { endurance, strength, flexibility and agility } \\
\text { (e.g., jump a short roper for sixty seconds, } \\
\text { run/walk a mile in twelve minutes, do } 40 \text { sit- } \\
\text { ups in one minute, stretching exercises, etc.). } \\
\text { (rE.R.1.2.1) (PE.R.1.3.2) (rE.n.1.2.3) } \\
\text { B. The student can determine his/her levels of } \\
\text { fitness by reading the National percentile } \\
\text { Chart. } \\
\text { C. Can maintain continuous aerobic activity for } \\
\text { a specific period of time and understand the } \\
\text { positive benefits. }\end{array}$ \\
\hline
\end{tabular}




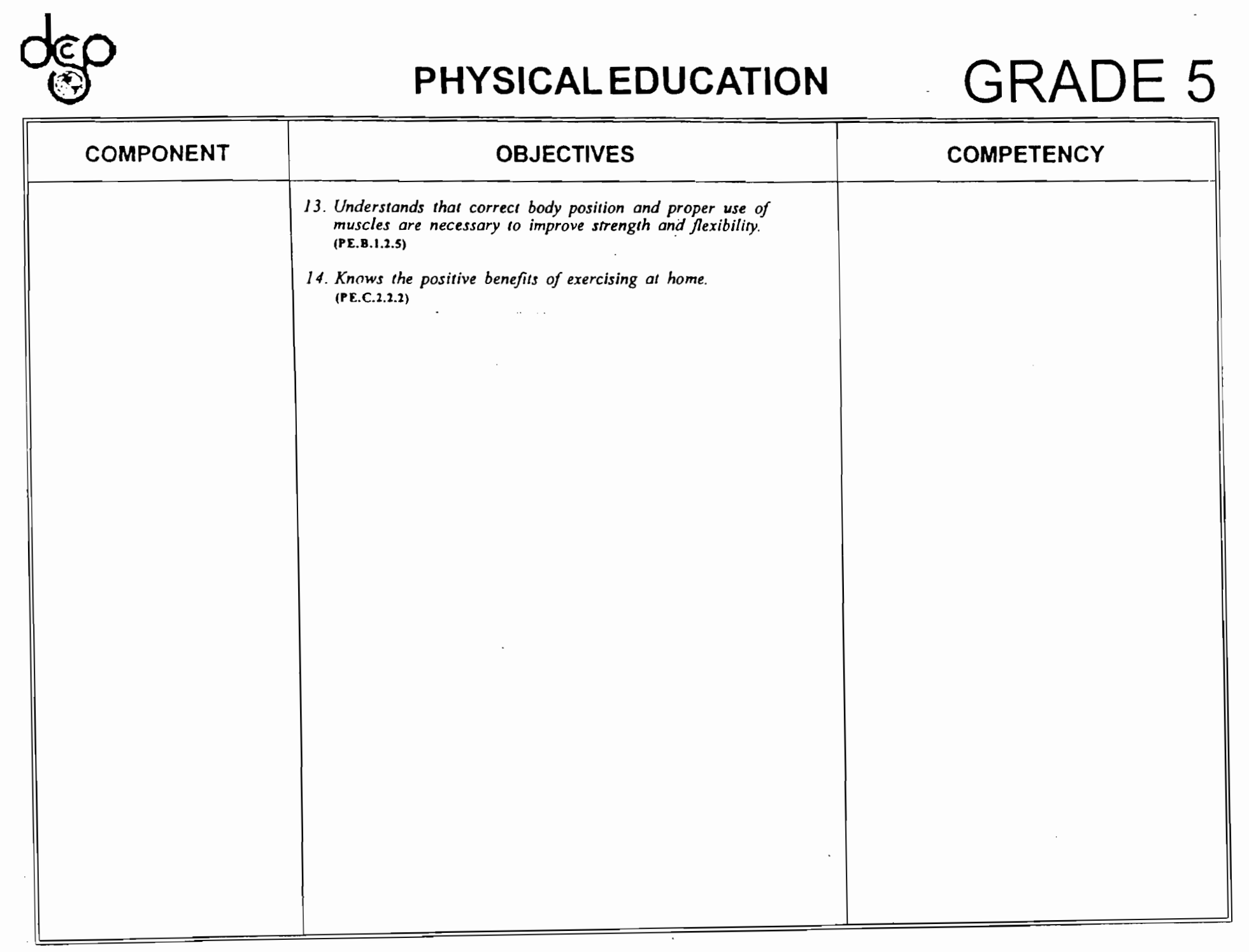


Appendix D

Miami-Dade County Public School

Fitnessgram Test Administration 


\section{TEST ADMIMISTRATION}

\section{One Mile Walk/Run}

\section{a.Objective:}

To measure aerobic capacity by walking and/or running a mile distance at the fastest pace possible. If a student cannot run the total distance, walking is permitted.

\section{b. EquipmentFacilities:}

A nat running course, stopwatch, pencil, and scoresheets are required. The course may be a track or any other measured area.

\section{c. Test Instructions:}

Before administering this test, teachers must properly condition students for the stress it places upon the body. By gradually increasing the distances run over a period of time and using interval training, which can be used for conditioning purposes as well as introducing the concept of pace, students may be conditioned for testing. Consideration must be given to a training period that utilizes gradual progression in intensity, and recognizes potential problems with local heat and humidity. In addition, students with known medical problems which contraindicate vigorous exercise should be allowed to walk the mile test.

Students begin on the signal "Ready, Start." As they cross the finish line elapsed time should be called to the participants (or their partners).

\section{d. Scoring:}

The one mile walk/nun is scored in minutes and seconds.

\section{Body Composition}

a. Objective:

To measure the triceps and calf skinfold thicknesses for calculation of percent of body fatness.

b. EquipmenUFacilities:

A skinfold caliper is necessary to perform this measurement. Cost of calipers range from $\$ 5-\$ 200$. An accurate low-cost model can be purchased from local physical education supply vendors. 


\section{Body Composition}

\section{c. Test Instructions:}

The triceps and calf skinfolds have been chosen for the FITNESSGRAM because they are easily measured and are highly correlated with total body fat. The tricep skinfold is measured on the back of the arm over the triceps muscle of the right arm midway between the elbow and the acromion process of the scapula. The skinfold sight should be vertical. Pinching the fold slightly above the midpoint will ensure that the fold is measured right on the midpoint. The calf skinfold is measured on the inside of the right leg at the level of the maximal calf girth. The right foot is placed flat on an elevaled surface with the knee flexed at a 90 degree angle. The vertical skinfold should be grasped just above the level of maximal girth and the measurement made below the grasp of maximal girth.

\section{d. Scoring:}

The skinfold measure is registered on the dial of the caliper. Each measurement should be taken three times with the recorded score being the median(middle) of the three scores.
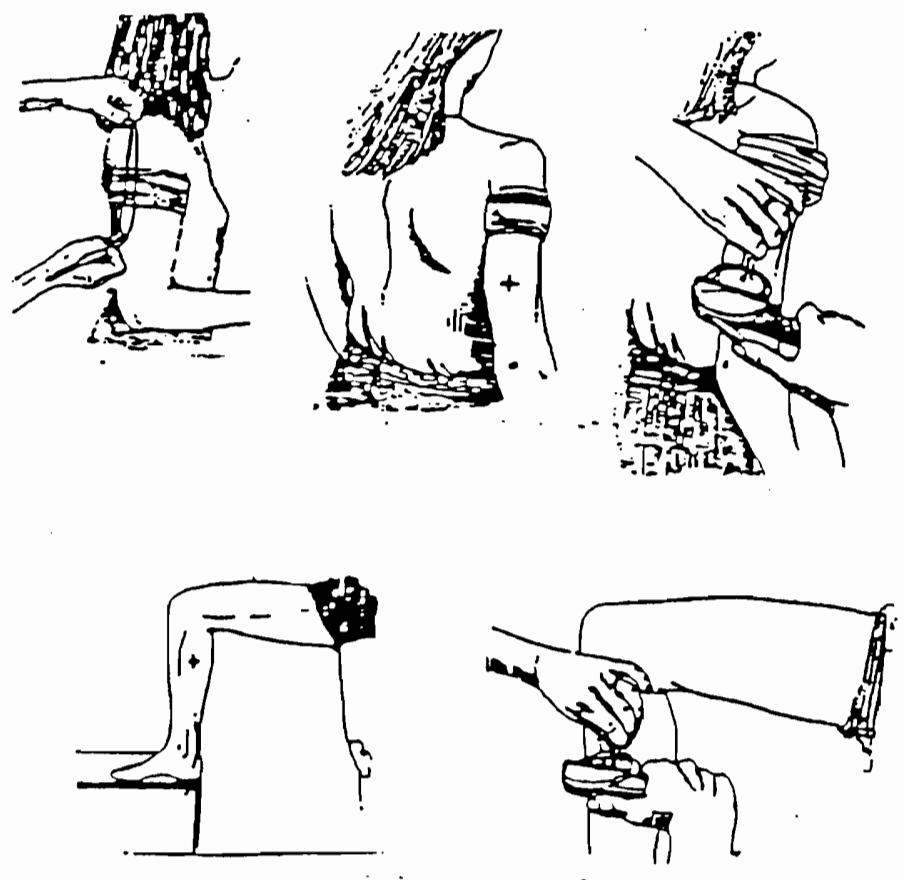


\section{The Curl-up}

a. Objective:

To evaluate abdominal muscular stength and endurance by completing as many cur]-ups as possible up 10 a maximum of 75 at a specified pace.

b. Equipment/Facilities:

Gym mats and a cardboard measuring strip for every two students are needed. The strip should be approximately $30 " \times 4.5^{\prime \prime}$. (See diagram)

c. Test lnstructions:

Allow students 10 form groups of three. One will perform the curl-ups, another will place hands under the head of student doing curl-ups and count, the third will secure the measuring strip so that it does not move.

The student being tested lies in a supine position on the mat, knees bent at an angle of approximately 140 degrees, feet flat on tbe floor, legs slightly apar, arms straight and parallel to the trunk with palms of hands resting on the mat. The fingers are stretched out and the head is in contact with the partner's hand, resting on the mat. Afler the student has assumed the correct position on the mat, place measuring strip under the knees on the mat so that fingerips are just resting on the edge of the measuring strip. The third student in each group should stand astride the one being tested securing the ends of the measuring strip with the feet.

Keeping the heels in contact with the mat, the student curls up slowly sliding fingers across the measuring card until fingerips reach the other side, then curl back down unil the head touches the partner's hand. Movement should be slow and controlled 10 the specified cadence which is about 20 curl-ups per minute. The teacher should call a cadence or use a pre-recorded cadence. The student continues without pausing until be/sbe can no longer continue or bas completed a maximum Dumber of 75 curl-ups.

\section{d. Scoring:}

The score is the number of correctly performed curl-ups. Count should be made when the student's head returns to contact the parner's hand on the mat. Do not count a curl-up if the feet completely leave the floor at any time during the movement.

\section{SEE NEXT PAGE FOR JLLUSTRATJONS OF PROPER CURL-UP PROCEDURES}



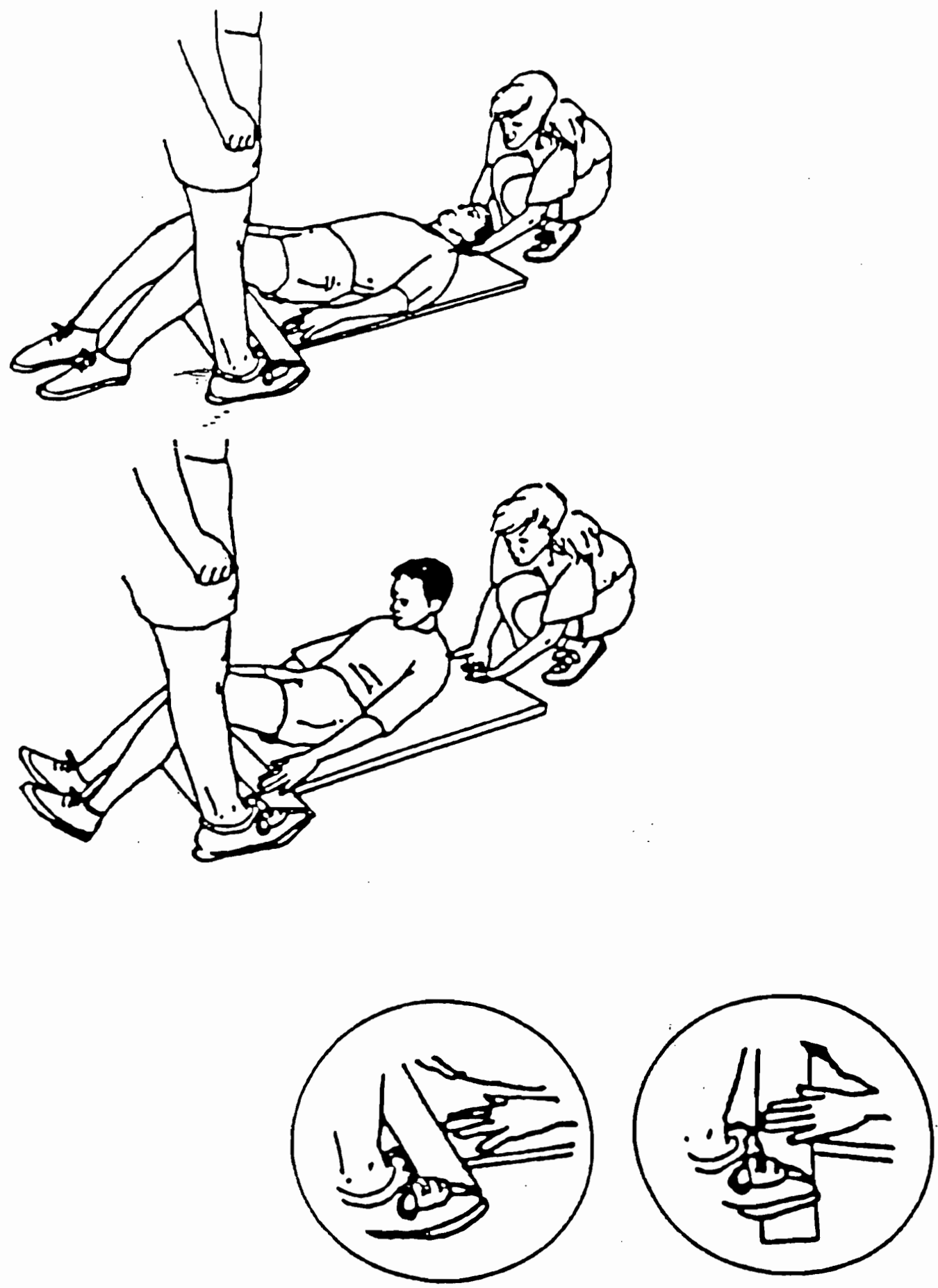
aber. 


\section{Trunk Lift}

\section{a. Objective:}

Trunk extensor strength and flexibility is being included in the FITNESSGRAM because of its relationship to low back health, especially proper vertibral alignment. It is important that attention is given to performance technique during this test. The movement should be performed in a slow and controlled manner.

The objective is to lift the upper body 12 inches off the floor using the muscles of the back and hold the position to allow for the measurement.

\section{b. Equipment/Facilities:}

Gym mats and a measuring stick with colored tape marking the 6 inch and the 12 inch mark.

\section{c. Test Instructions:}

The student being tested lies face down on the mat. Toes are pointed and bands are placed under the thighs. Have the student find and look at a spot on the floor that is close to the nose. During the movement, the student's focus should not move from that spot. The student lifts the upper body off the floor, in a very slow and controlled manner, to a maximum height of 12 inches. The position is held long enough to allow tester to place the ruler on the floor in front of the student and determine the distance of the student's chin from the floor. The ruler should be placed at least an inch to the front of the student's chin and not directly under the chin. Once the measurement has been made the student returns to starting position in a controlled manner. Allow two trials recording the highest score.

\section{d. Scoring:}

The score is recorded to the nearest inch. Distances above 12" should be recorded as $12^{\prime \prime}$.

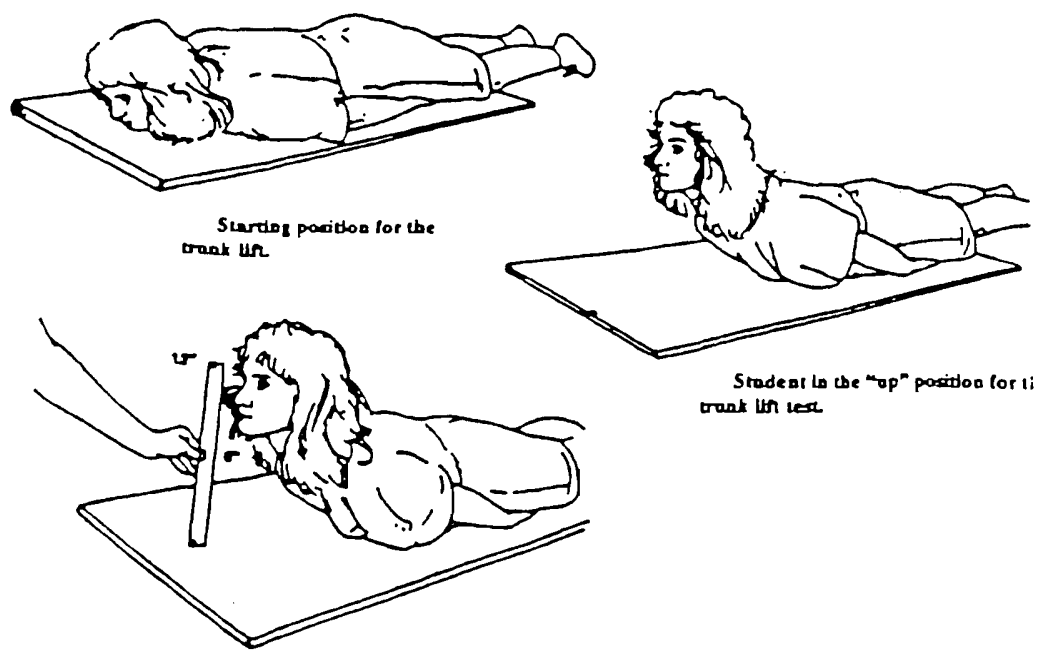

Measarement of trank Uh. 


\section{Pusb-up}

a. Objective:

The push-up to an elbow angle of 90 degrees is the recommended test for the upper body strength and endurance. The objective is to complete as many push-ups as possible at a rhythmic pace.

\section{b. Equipmen U/Facilities:}

The only equipment necessary is an audio tape with the recorded cadence or a teacher set cadence of 20 push-ups per minute.

\section{c. Test Instructions:}

The students should be paired; one will perform the test while the other counts pushups and watches to see that the student being tested bends the elbow to 90 degrees with the upper arm parallel to the floor.

The student being tested lies face down on the mat with the hands placed under the shoulders, fingers stretched out, legs straight, parallel and slightly apart, and toes tucked under. The student pushes up off the mat with the ams until arms are straight, keeping legs and back straight. The back should be kept in a straight line from bead to toes throughout the test. The student then lowers the body until the elbows bend at 90 degrees and the upper arms are parallel to the floor. This movement is repeated as many times as possible. Students are stopped when the second form correction is made. Corrected push-ups do not count toward the student's score.

\section{d. Scoring:}

The score is the number of push-ups completed successfully.

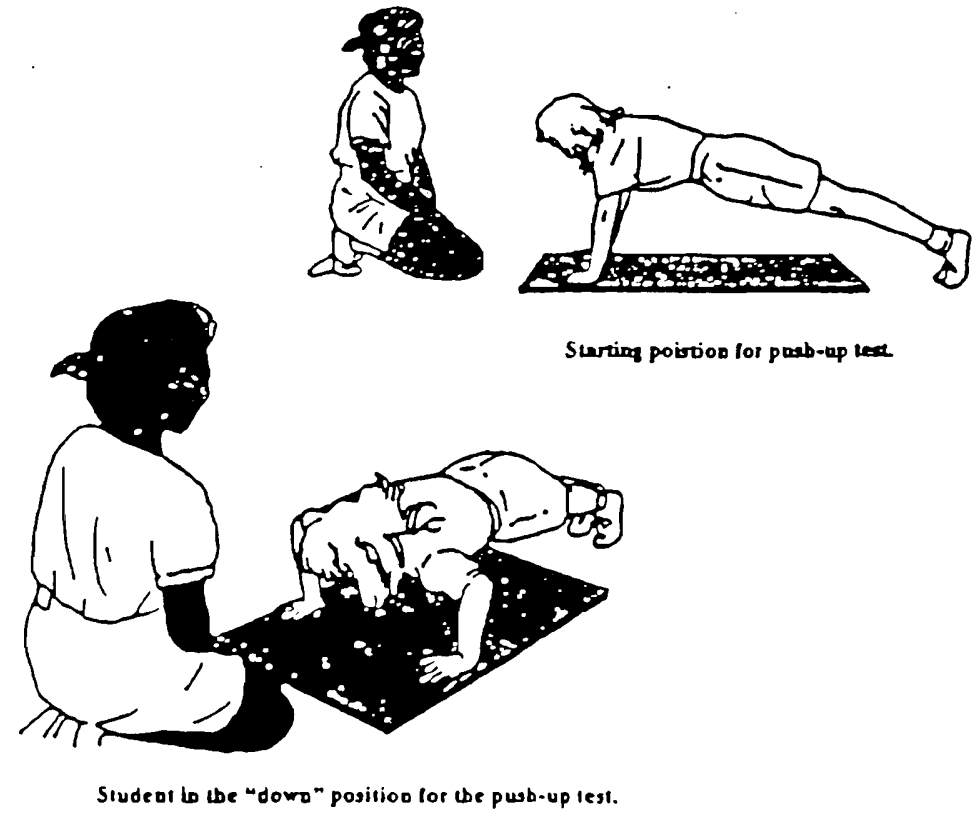




\section{Backsaver Sit and Reacb}

a. Objective:

To evaluate the flexibility of the lower back and hamstring muscles. The backsaver sit and reach is very similar to the traditional sit and reach except that it is performed on one side at a time. The measurement is performed on one side at at time so that students are not encouraged to hyperextend. The objective is to be able to reach a specified distance on the right and left sides of the body.

\section{b. Equipment/Facilities:}

Sit and Reach box or any other sturdy box measuring approximately 12 inches high. If using a self constructed box, place a measuring scale on top of the box with the 9 inch mark even with the near edge of the box. The zero end of the ruler is nearest the student.

\section{c. Test Instructions:}

The student removes his/her shoes and sits down at the test apparatus. One leg is fully extended with the foot flat against the end of the box. The other knee is bent with the sole of the foot flat on the floor and 2-3 inches to the side of the straight knee. The arms are extended forward over the measuring scale with the hands placed one on top of the other. With palms down, the student reaches directly forward with both hands along the scale four times and holds the position of the fourth reach for at least one second. After measuring one side the student switches the position of the legs and reaches again.

\section{d. Scoring:}

Record the number of inches on each side to the last whole inch reached to a maximum score of 12". The FITNESSGRAM will report this as a "pass" or "fail" depending on the distance reached as it compares to the appropriate standard.
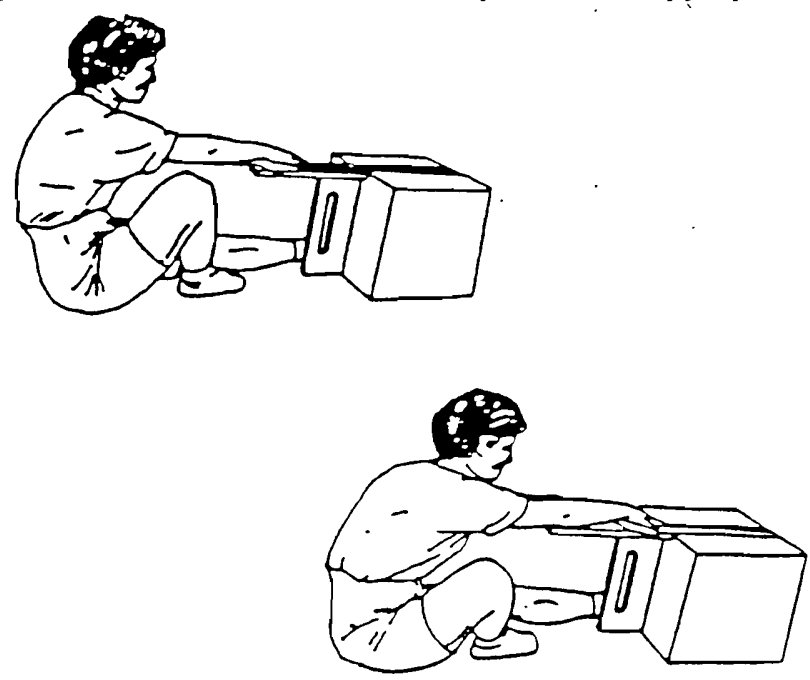
THE PRUDENTIAL FITNESSGRAM

STANDARDS FOR HEALTHY FITNESS ZONE*

BOYS

\begin{tabular}{|c|c|c|c|c|c|c|c|c|c|c|c|}
\hline AGE & \multicolumn{2}{|c|}{$\underset{\substack{\text { ONE MILE } \\
\text { misec }}}{ }$} & \multicolumn{2}{|c|}{$\begin{array}{c}\text { PERCENT } \\
\text { FAT }\end{array}$} & \multicolumn{2}{|c|}{$\begin{array}{c}\text { CURL- } \\
\text { UP } \\
\# \\
\text { completed }\end{array}$} & \multicolumn{2}{|c|}{$\begin{array}{l}\text { TRUNK } \\
\text { LIFT } \\
\text { incbes }\end{array}$} & \multicolumn{2}{|c|}{$\begin{array}{l}\text { PUSH-UP } \\
\# \text { completed }\end{array}$} & $\begin{array}{c}\text { BACKSAVER } \\
\text { SIT\&REACH* } \\
\text { mebes }\end{array}$ \\
\hline 5 & \multirow{5}{*}{\multicolumn{2}{|c|}{$\begin{array}{l}\text { Time Standards } \\
\text { Not } \\
\text { Recommended. }\end{array}$}} & 25 & 10 & 2 & 10 & 6 & 12 & 3 & 8 & 8 \\
\hline 6 & & & 25 & 10 & 2 & 10 & 6 & 12 & 3 & 8 & 8 \\
\hline 7 & & & 25 & 10 & 4 & 14 & 6 & 12 & 4 & 10 & 8 \\
\hline 8 & & & 25 & 10 & 6 & 20 & 6 & 12 & 5 & 13 & 8 \\
\hline 9 & & & 25 & 10 & 9 & 24 & 6 & 12 & 6 & 15 & 8 \\
\hline 10 & $11: 30$ & $9: 00$ & 25 & 10 & 12 & 24 & 9 & 12 & 7 & 20 & 8 \\
\hline 11 & $11: 00$ & $8: 30$ & 25 & 10 & 15 & 28 & 9 & 12 & 8 & 20 & 8 \\
\hline 12 & $10: 30$ & $8: 00$ & 25 & 10 & 18 & 36 & 9 & 12 & 10 & 20 & 8 \\
\hline 13 & $10: 00$ & $7: 30$ & 25 & 10 & 21 & 40 & 9 & 12 & 12 & 25 & 8 \\
\hline 14 & $9: 30$ & $7: 00$ & 25 & 10 & 24 & 45 & 9 & 12 & 14 & 30 & 8 \\
\hline 15 & $9: 00$ & $7: 00$ & 25 & 10 & 24 & 47 & 9 & 12 & 16 & 35 & 8. \\
\hline 16 & $8: 30$ & $7: 00$ & 25 & 10 & 24 & 47 & 9 & 12 & 18 & 35 & 8 \\
\hline 17 & $8: 30$ & $7: 00$ & 25 & 10 & 24 & 47 & 9 & 12 & 18 & 35 & 8 \\
\hline $17+$ & $8: 30$ & $7: 00$ & 25 & 10 & 24 & 47 & 9 & 12 & 18 & 35 & 8 \\
\hline
\end{tabular}

* Number on lefi is lower end of HFZ; number on right is upper end of HFZ.

* Test scored Pass/Fail; must reach this distance 10 pass. 
THE PRUDENTIAL FITNESSGRAM

STANDARDS FOR HEALTHY FJTNESS ZONE*

GIRLS

\begin{tabular}{|c|c|c|c|c|c|c|c|c|c|c|c|}
\hline$\overline{A G E}$ & \multicolumn{2}{|c|}{$\begin{array}{l}\text { ONE MRE } \\
\mathrm{min} / \mathrm{sec}\end{array}$} & \multicolumn{2}{|c|}{$\begin{array}{c}\text { PERCENT } \\
\text { FAT }\end{array}$} & \multicolumn{2}{|c|}{$\begin{array}{c}\text { CURL } \\
\text { UP } \\
\hbar \\
\text { completed }\end{array}$} & \multicolumn{2}{|c|}{$\begin{array}{l}\text { TRUNK } \\
\text { LIFT } \\
\text { idches }\end{array}$} & \multicolumn{2}{|c|}{$\begin{array}{l}\text { PUSB-UP } \\
\text { \# completed }\end{array}$} & \multirow{2}{*}{$\begin{array}{c}\begin{array}{c}\text { BACKSAVER } \\
\text { SIT\&REACH* } \\
\text { incbes }\end{array} \\
9\end{array}$} \\
\hline 5 & \multirow{5}{*}{\multicolumn{2}{|c|}{$\begin{array}{c}\text { Time } \\
\text { Standards Not } \\
\text { Recommended }\end{array}$}} & 32 & 17 & 2 & 10 & 6 & 12 & 3 & 8 & \\
\hline 6 & & & 32 & 17 & 2 & 10 & 6 & 12 & 3 & 8 & 9 \\
\hline 7 & & & 321 & 17 & 4 & 14 & 6 & 12 & 4 & 10 & 9 \\
\hline 8 & & & 32 & 17 & 6 & 20 & 6 & 12 & 5 & 13 & 9 \\
\hline 9 & & & 32 & 17 & 9 & 22 & 6 & 12 & 6 & 15 & 9 \\
\hline 10 & $12: 30$ & $9: 30$ & 32 & 17 & 12 & 26 & 9 & 12 & 7 & 15 & 9 \\
\hline 11 & $12: 00$ & $9: 00$ & 32 & 17 & 15 & 29 & 9 & 12 & 7 & 15 & 10 \\
\hline 12 & $12: 00$ & $9: 00$ & 32 & 17 & 18 & 32 & 9 & 12 & 7 & 15 & 10 \\
\hline 13 & $11: 30$ & $9: 00$ & 32 & 17 & 18 & 32 & 9 & 12 & 7 & 15 & 10 \\
\hline 14 & $11: 00$ & $8: 30$ & 32 & 17 & 18 & 32 & 9 & 12 & 7 & 15 & 10 \\
\hline 15 & $10: 30$ & $8: 00$ & 32 & 17 & 18 & 35 & 9 & 12 & 7 & 15 & 12 \\
\hline 16 & $10: 00$ & $8: 00$ & 32 & 17 & 18 & 35 & 9 & 12 & 7 & 15 & 12 \\
\hline 17 & $10: 00$ & $8: 00$ & 32 & 17 & 18 & 35 & 9 & 12 & 7 & 15 & 12 \\
\hline $17+$ & $10: 00$ & $8: 00$ & 32 & 17 & 18 & 35 & 9 & 12 & 7 & 15 & 12 \\
\hline
\end{tabular}

* Number on lefi is lower end of HFZ; number on right is upper end of HFZ.

- "Test is scored Pass/Fail; must reach this distance to pass. 


\section{Explanation of Healtby Fitness Zone Standards}

The Healthy Fimess Zone Standards were set to accommodate the differences in variability of body type among children. (ie. bone stucture, growth and development, maturation, heredity, etc.). The FITNESSGRAM standards were established based upon research conducted by the Cooper Aerobics Institute and suppored by the Centers for Disease Control. These standards represent an acceptable level of fitness required to both maintain a healthy lifestyle and reduce preventable diseases resuiung from a sedentary. lifestyle

With regard 10 aerobic fitness level, research has shown a significant decrease in risk of all-cause morality from getring out of the lower $20 \%$ of the population. Risk levels continue to decrease as fitness levels increase but not as dramatically as getting out of the bothom $20 \%$. Aerobic capacity standards were set to equal getting out of the lower $20 \%$ of the population.

Body fal percentages were also set by following the recommendations of current research. Children with body fat levels above $25 \%$ for boys and $30-35 \%$ for girls, are more likely to exhibit elevated cholesterol levels and hyperension.

All students should strive 10 achieve a score that places them inside the Healthy Fitness Zone. Performance above the Healthy Fimess Zone should be recognized appropriately but should not be the goal for all students. Teachers and students should work together to set realistic and individual performance goals. 
Appendix E

F.I.U. Project Approval 


\section{FLORIDA INTERNATIONAL UNIVERSITY}

October 12, 1999

Mrs. Jacqueline Becker-Busha 21260 SW $246^{\text {th }}$ Street

Homestead, FL 33031

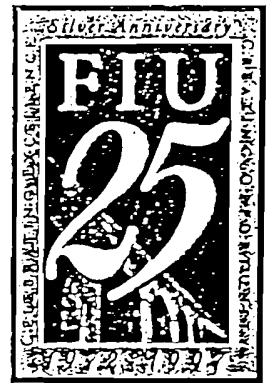

Re: Approval of Research Involving Human Subjects

Dear. Mrs. Becker-Busha:

Your Application for Approval of Research Involving Human Subjects bas been reviewed. We are pleased to inform you that your proposed study "Student and Teacher Perceptions of the School Physical Fitness Testing Program: The Fitnessgram " mezts the criteria set forth for an Expedited Review, Category \#9. Please keep the University Research Council apprised of any changes in your proposed methodology that may effect the buman subjects who will be participating in your research study.

Congratulations on your approval and good luck with your research study.

Paul A. Rendulic, Ed.D.

University Research Council Member

CC: Dr. Bernard Gerstman

University Research Council Chairperson 
Appendix F

Informed Consent

English and Spanish Versions 


\section{Informed Consent \\ Student Perceptions of the \\ School Physical Fitness Testing Program: The Fitnessgram}

I agree to allow my child to be a participant in the research project, $\underline{\text { Student }}$ Perceptions of the School Physical Fitness Testing Program: The Fitnessgram. It will be conducted at Redland Elementary School during the period of December, 1999 through May, 2000. Mrs. Jacqueline Becker-Busha is the principal investigator.

I understand that the purpose of this research is to examine $5^{\text {th }}$ grade students' perceptions and experience with the M-DCPS Physical Fitness Testing Program-the Fitnessgram, as well as, related physical fitness activities. I understand there will be approximately 178 students at Redland Elementary School participating in this study.

I understand that the research procedures will be as follows: 1) After completing each of the five Fitnessgram subtests (as required by M-DCPS), students will be asked to complete a questionnaire during their regularly scheduled physical education class. Each questionnaire will take approximately 5 to 10 minutes to complete. 2) A small number of students will be interviewed individually regarding their involvement. The interview will be audio recorded. During these interviews, students will be asked to elaborate on the answers they provided on the questionnaires. I understand that the tape recordings will be secured in the researcher's home office, and they will be available only to the researcher, a transcriptionist, and Dr. Judith Slater of Florida International University. All tape recordings will be erased upon completion of the study. I understand these interviews will be conducted during regular school hours for approximately 15 to 20 minutes. 3) I understand that the students' physical fitness test scores will be analyzed. I understand total participation time for my child will be approximately two hours over the course of six months.

I understand that there are no known risks or benefits involved in my child's participation in this research project. My child's performance will be kept strictly confidential. All scores, questionnaires, and interview responses will be identified only by a code number or pseudonym. My child's performance will not be revealed to anyone without my permission. 
I understand that I may withdraw my consent and have my child discontinue participation in this research project at any time with no negative consequences. If I choose to withdraw my child from the study, all recordings, transcripts and questionnaire responses will be erased or destroyed. I have been given the right to ask questions concerning the research procedure, and my questions have been answered to my satisfaction.

I understand that if I desire further information concerning this research project, I should contact either Mrs. Becker-Busha at Redland Elementary School, phone \# (305) 247-8141 or Dr. Slater at Florida International University, phone \# (305) 348-3214. I have been offered a copy of this informed consent form.

I have read and I understand the above.

Student Name

Parent signature-I grant permission

Date

Parent signature-I refuse permission

Date

I have explained in detail the research procedure to the parent and I have offered him/her a copy of this informed consent form.

Principal Investigator's signature

Date 
Informe de Consentimiento

Percepciones de estudiantes

sobre el programa escolar de ejercicios físicos de

las Escuelas Públicas del Condado de Miami-Dade (M-DCPS)

Yo permito que mi hijo/hija participe en un proyecto de investigación sobre las percepciones de estudiantes y profesores con respecto a un programa de ejercicios físicos. Este proyecto, llamado Percepciones de estudiantes $y$ profesores sobre el programa escolar de ejercicios físicos, será conducido en la escuela elementaria de Redland durante el periodo de diciembre 1999 hasta mayo del 2000. La señora Becker-Busha es la investigadora principal.

Yo entiendo que el propósito de este estudio es examinar como los estudiantes de quinto grado reaccionan al programa, también sus percepciones sobre este examen y algunas actividades físicas relacionadas. Habrán 178 estudiantes de quinto grado de dicha escuela que tomarán parte en el estudio.

Yo comprendo que los procedimientos serán los siguientes:

1.) Durante las horas de clases, después de completar cada uno de los cinco sub-exámenes (como requerido por M-DCPS), los estudiantes deberán llenar un cuestionario que demorará de 5 a 10 minutos para completar;

2.) Un pequeño numero de estudiantes serán entrevistados referente a su participación en el estudio y la conversación será gravada. Durante estas entrevistas, se les pedirán que elaboren más a fondo sus respuestas al cuestionario. También entiendo que las gravaciones se mantendrán seguras en la casa de la Investigadora Principal y estarán disponibles solamente para la Investigadora Principal, la transcripcionista y la doctora J. Slater. Todas la gravaciones serán borradas al final del estudio. Yo comprendo que estas entrevistas, de 15 a 20 minutos de duración, serán conducidas individualmente y solamente durante las horas regular de escuela.

3.) Los resultados de los exámenes serán analizados. Entiendo que el tiempo total de participación será aproximadamente dos horas, sobre un curso de seis meses. 
Yo comprendo que no hay ni riezgo ni beneficio alguno al participante de este experimento. Se me ha dicho que las repuestas se mantendrán estrictamente confidenciales. Todas las notas, cuestionarios, entrevistas y participación individual serán identificadas por un código numérico solamente y la identidad de mi hijo/hija no será revelada sin mi permiso. Para el propósito de reportar los resultados de este estudio, un nombre ficticio se usará para proteger la identidad de mi hijo/hija. Entiendo también que puedo retirar mi consentimiento y descontinuar la participación de mi hijo/hija sin resultado adverso. Si decido retirar mi hijo/hija del estudio, toda gravación, transcriptos y cuestionarios serán destruidos o borrados. Me han dado el derecho de hacer preguntar acerca de este estudio y me preguntas han sido contestadas satisfactoriamente.

Yo entiendo que si yo deseo más información sobre este proyecto, puedo comunicarme con la señora Becker-Busha a la escuela elemental de Redland, teléfono (305) 247-8141, dirección 24501 SW 162 Ave. Homestead o la Dr. Judith Slater de la Universidad Internacional de la Florida, teléfono (305) 3483214. Me han ofrecido una copia de este informe de consentimiento. Este documento está a mi alcance con sólo pedirlo a la escuela elemental de Redland.

Yo leí y entiendo lo antes mencionado.

Nombre del Estudiante

Firma del Padre - doy permiso 
Yo he explicado en detalle el proyecto de investigación al cual los padres han consentido la participacion de su hijo/hija. Yo he ofrecido una copia de este informe de consentimiento.

Firma de la Investigadora Principal 
Appendix G

Student Questionnaires 


\section{Questionnaire \\ Fitnessgram: One Mile Walk/Run}

Introduction: During the past two months we have been practicing and preparing for the One-Mile Walk/Run physical fitness subtest. Just this week you took this subtest. Please take a few minutes to fill in the answers to these questions, which are directly related to the One-Mile Walk/Run subtest. Remember, there are no wrong answers.

\section{Directions: Circle the answer of your response and fill in the blanks where indicated.}

1. Why do the physical education teachers have you take the One-Mile Walk/Run test?
A. to measure muscular strength
B. to measure body fatness
C. to measure cardiorespiratory endurance
D. to measure muscular endurance
E. to measure flexibility

2. What activities have you done during your daily physical education class time that would help you do well on this test?

Activities:

3. Do you participate in any physical activities outside of school that would help you with the One-Mile Walk/Run?

Yes No

4. If yes, what activities? 
- Only answer this next question if you answered yes to the above question.

5. How much time do you spend participating in these out of school activities during a one-week period?
A. 0 minutes-15 minutes
B. 16 minutes-30 minutes
C. 31 minutes- 60 minutes
D. More than 60 minutes

6. In general, how much time do you spend outside of school, exercising or just being active during a one week period? minutes 


\section{Questionnaire}

\section{Fitnessgram: Body Composition}

Introduction: During the past months we have been involved in a variety of activities which are specifically intended to help you reach a satisfactory level of body composition. Just this week your physical education teacher measured and calculated your individual percent of body fatness. Please take a few minutes to fill in the answers to these questions, which are directly related to the Body Composition subtest. Remember, there are no wrong answers.

\section{Directions: Circle the answer of your response and fill in the blanks where indicated.}

1. Why do the physical education teacher's measure/calculate your Body Composition?
A. to measure muscular strength
B. to measure body fatness
C. to measure cardiorespiratory endurance
D. to measure muscular endurance
E. to measure flexibility

2. What activities have you done during your daily physical education class time that would help you do well on this test?

Activities:

3. Do you participate in any physical activities outside of school that would help you with the Body Composition test?

Yes No 
4. If yes, what activities?

- Only answer this next question if you answered yes to the above question.

5. How much time do you spend participating in these out of school activities during a one week period?
A. 0 minutes- 15 minutes
B. 16 minutes-30 minutes
C. 31 minutes -60 minutes
D. More than 60 minutes

6. In general, how much time do you spend outside of school, exercising or just being active during a one week period? minutes 
Questionnaire

Fitnessgram: Curl-Up

Introduction: During the past two months we have been practicing and preparing for the Curl-Up physical fitness subtest. Just this week you took this subtest. Please take a few minutes to fill in the answers to these questions, which are directly related to the Curl-Up subtest. Remember, there are no wrong answers.

\section{Directions: Circie the answer of your response aud fill in the bianks where indicated.}

1. Why do the physical education teachers have you take the Curl-Up test?
A. to measure muscular strength
B. to measure body fatness
C. to measure cardiorespiratory endurance
D. to measure muscular endurance
E. to measure flexibility

2. What activities have you done during your daily physical education class time that would help you do well on this test?

Activities:

3. Do you participate in any physical activities outside of school that would help you with the Curl-Up test?

Yes No

4. If yes, what activities? 
- Only answer this next question if you answered yes to the above question.

5. How much time do you spend participating in these out of school activities during a one-week period?
A. 0 minutes -15 minutes
B. 16 minutes-30 minutes
C. 31 minutes-60 minutes
D. More than 60 minutes

6. In general, how much time do you spend outside of school, exercising or just being active during a one week period? minutes 
\#

\section{Questionnaire}

\section{Fitnessgram: Trunk Lift}

Introduction: During the past two months we have been practicing and preparing for the Trunk Lift physical fitness subtest. Just this week you took this subtest. Please take a few minutes to fill in the answers to these questions, which are directly related to the Trunk Lift subtest. Remember, there are no wrong answers.

\section{Directions: Circle the answer of your response and fill in the blanks where indicated.}

1. Why do the physical education teachers have you take the Trunk Lift test?
A. to measure muscular strength
B. to measure body fatness
C. to measure cardiorespiratory endurance
D. to measure muscular endurance
E. to measure flexibility

2. What activities have you done during your daily physical education class time that would help you do well on this test? Activities:

3. Do you participate in any physical activities outside of school that would help you with the Trunk Lift?

Yes No

4. If yes, what activities? 
- Only answer this next question if you answered yes to the above question.

5. How much time do you spend participating in these out of school activities during a one week period?
A. 0 minutes- 15 minutes
B. 16 minutes-30 minutes
C. 31 minutes- 60 minutes
D. More than 60 minutes

6. In general, how much time do you spend outside of school, exercising or just being active during a one week period? minute\$ 


\section{Questionnaire}

\section{Fitnessgram: Push-Up}

Introduction: During the past two months we have been practicing and preparing for the Push-Up physical fitness subtest. Just this week you took this subtest. Please take a few minutes to fill in the answers to these questions, which are directly related to the Push-Up subtest. Remember, there are no wrong answers.

\section{Directions: Circle the answer of your respense and fill in the blanks where indicated.}

1. Why do the physical education teachers have you take the Push-Up test?
A. to measure muscular strength
B. to measure body fatness
C. to measure cardiorespiratory endurance
D. to measure muscular endurance
E. to measure flexibility

2. What activities have you done during your daily physical education class time that would help you do well on this test?

Activities:

3. Do you participate in any physical activities outside of school that would help you with the Push-Up test?

Yes No

4. If yes, what activities? 
- Only answer this next question if you answered yes to the above question.

5. How much time do you spend participating in these out of school activities during a one week period?

A. 0 minutes- 15 minutes

B. 16 minutes- 30 minutes

C. 31 minutes-60 minutes

D. More than 60 minutes

6. In general, how much time do you spend outside of school, exercising or just being active during a one week period? minutes 


\section{Questionnaire}

\section{Fitnessgram: Backsaver Sit and Reach}

Introduction: During the past two months we have been practicing and preparing for the Backsaver Sit and Reach physical fitness subtest. Just this week you took this subtest. Please take a few minutes to fill in the answers to these questions, which are directly related to the Backsaver Sit and Reach subtest. Remember, there are no wrong answers.

\section{Directions: Circle the answer of your response and fill in the blanks where} indicated.

1. Why do the physical education teachers have you take the Backsaver Sit and Reach test?
A. to measure muscular strength
B. to measure body fatness
C. to measure cardiorespiratory endurance
D. to measure muscular endurance
E. to measure flexibility

2. What activities have you done during your daily physical education class time that would help you do well on this test?

Activities:

3. Do you participate in any physical activities outside of school that would help you with the Backsaver Sit and Reach?

Yes No 
4. If yes, what activities?

- Only answer this next question if you answered yes to the above question.

5. How much time do you spend participating in these out of school activities during a one week period?
A. 0 minutes- 15 minutes
B. 16 minutes-30 minutes
C. 31 minutes-60 minutes
D. More than 60 minutes

6. In general, how much time do you spend outside of school, exercising or just being active during a one week period? minutes 
Appendix $\mathrm{H}$

Healthy Fitness Zone 
THE PRUDENTIAL FITNESSGRAM

STANDARDS FOR HEALTHY FITNESS ZONE*

BOYS

\begin{tabular}{|c|c|c|c|c|c|c|c|c|c|c|c|}
\hline AGE & \multicolumn{2}{|c|}{$\begin{array}{c}\text { ONE MILE } \\
\mathrm{min} / \mathrm{sec}\end{array}$} & \multicolumn{2}{|c|}{$\begin{array}{l}\text { PERCENT } \\
\text { FAT }\end{array}$} & \multicolumn{2}{|c|}{$\begin{array}{c}\text { CURI } \\
\text { UP } \\
* \\
\text { completed }\end{array}$} & \multicolumn{2}{|c|}{$\begin{array}{l}\text { TRUNK } \\
\text { LIFT } \\
\text { inches }\end{array}$} & \multicolumn{2}{|c|}{$\begin{array}{l}\text { PUSH-UP } \\
\text { \# completed }\end{array}$} & $\begin{array}{c}\text { BACKSAVER } \\
\text { SIT\&REACB } \& \text { inches }\end{array}$ \\
\hline 5 & \multirow{5}{*}{\multicolumn{2}{|c|}{$\begin{array}{c}\text { Time Standards } \\
\text { Not } \\
\text { Recommended. }\end{array}$}} & 25 & 10 & 2 & 10 & 6 & 12 & 3 & 8 & 8 \\
\hline 6 & & & 25 & 10 & 2 & 10 & 6 & 12 & 3 & 8 & 8 \\
\hline 7 & & & 25 & 10 & 4 & 14 & 6 & 12 & 4 & 10 & 8 \\
\hline 8 & & & 25 & 10 & 6 & 20 & 6 & 12 & 5 & 13 & 8. \\
\hline 9 & & & 25 & 10 & 9 & 24 & 6 & 12 & 6 & 15 & 8 \\
\hline 10 & $11: 30$ & 9:00 & 25 & 10 & 12 & 24 & 9 & 12 & 7 & 20 & 8 \\
\hline 11 & $11: 00$ & $8: 30$ & 25 & 10 & 15 & 28 & 9 & 12 & 8 & 20 & 8 \\
\hline 12 & $10: 30$ & $8: 00$ & 25 & 10 & 18 & 36 & 9 & 12 & 10 & 20 & 8 \\
\hline 13 & $10: 00$ & $7: 30$ & 25 & 10 & 21 & 40 & 9 & 12 & 12 & 25 & 8 \\
\hline 14 & $9: 30$ & $7: 00$ & 25 & 10 & 24 & 45 & 9 & 12 & 14 & 30 & 8 \\
\hline 15 & $9: 00$ & $7: 00$ & 25 & 10 & 24 & 47 & 9 & 12 & 16 & 35 & 8. \\
\hline 16 & $8: 30$ & $7: 00$ & 25 & 10 & 24 & 47 & 9 & 12 & 18 & 35 & 8 \\
\hline 17 & $8: 30$ & $7: 00$ & 25 & 10 & 24 & 47 & 9 & 12 & 18 & 35 & 8 \\
\hline $17+$ & $8: 30$ & $7: 00$ & 25 & 10 & 24 & 47 & 9 & 12 & 18 & 35 & 8 \\
\hline
\end{tabular}

- Number on lefi is lower end of HFZ; number on right is upper end of HFZ.

* Test scored Pass/Fail; must reach this distance to pass. 
THE PRUDENTIAL FITNESSGRAM

STANDARDS FOR HEALTHY FITNESS ZONE*

GIRLS

\begin{tabular}{|c|c|c|c|c|c|c|c|c|c|c|c|}
\hline$\overline{A G E}$ & \multicolumn{2}{|c|}{$\underset{\mathrm{m}}{\mathrm{ON} / \mathrm{sec}}$} & \multicolumn{2}{|c|}{$\begin{array}{c}\text { PERCENT } \\
\text { FAT }\end{array}$} & \multicolumn{2}{|c|}{$\begin{array}{c}\text { CURI } \\
\text { UP } \\
\sharp \\
\text { completed }\end{array}$} & \multicolumn{2}{|c|}{$\begin{array}{l}\text { TRUNK } \\
\text { LIFT } \\
\text { inches }\end{array}$} & \multicolumn{2}{|c|}{$\begin{array}{l}\text { PUSH-UP } \\
\text { \# completed }\end{array}$} & \multirow{2}{*}{$\begin{array}{c}\begin{array}{c}\text { BACKSAVER } \\
\text { SIT\&REACH** } \\
\text { incbes }\end{array} \\
9\end{array}$} \\
\hline 5 & \multirow{5}{*}{\multicolumn{2}{|c|}{$\begin{array}{c}\text { Time } \\
\text { Standards Not } \\
\text { Recommended }\end{array}$}} & 32 & 17 & 2 & 10 & 6 & 12 & 3 & 8 & \\
\hline 6 & & & 32 & 17 & 2 & 10 & 6 & 12 & 3 & 8 & 9 \\
\hline 7 & & & 32 & 17 & 4 & 14 & 6 & 12 & 4 & 10 & 9 \\
\hline 8 & & & 32 & 17 & 6 & 20 & 6 & 12 & 5 & 13 & 9 \\
\hline 9 & & & 32 & 17 & 9 & 22 & 6 & 12 & 6 & 15 & 9 \\
\hline 10 & $12: 30$ & $9: 30$ & 32 & 17 & 12 & 26 & 9 & 12 & 7 & 15 & 9 \\
\hline 11 & $12: 00$ & $9: 00$ & 32 & 17 & 15 & 29 & 9 & 12 & 7 & 15 & 10 \\
\hline 12 & $12: 00$ & $9: 00$ & 32 & 17 & 18 & 32 & 9 & 12 & 7 & 15 & 10 \\
\hline 13 & $11: 30$ & $9: 00$ & 32 & 17 & 18 & 32 & 9 & 12 & 7 & 15 & 10 \\
\hline 14 & $11: 00$ & $8: 30$ & 32 & 17 & 18 & 32 & 9 & 12 & 7 & 15 & 10 \\
\hline 15 & $10: 30$ & $8: 00$ & 32 & 17 & 18 & 35 & 9 & 12 & 7 & 15 & 12 \\
\hline 16 & $10: 00$ & $8: 00$ & 32 & 17 & 18 & 35 & 9 & 12 & 7 & 15 & 12 \\
\hline 17 & $10: 00$ & $8: 00$ & 32 & 17 & 18 & 35 & 9 & 12 & 7 & 15 & 12 \\
\hline $17+$ & $10: 00$ & $8: 00$ & 32 & 17 & 18 & 35 & 9 & 12 & 7 & 15 & 12 \\
\hline
\end{tabular}

- Number on lefi is lower end of HFZ; number on right is upper end of HFZ.

- Test is scored Pass/Fail; must reach this distance to pass. 


\section{Explapation of Healtby Findess Zone Standards}

The Healthy Fimess Zone Standards were set to accommodate the differences in variability of body type among children. (ie. bone structure, growth and development, maturation, heredity, etc.). The FITNESSGRAM standards were established based upon research conducted by the Cooper Aerobics lnstitute and supponed by the Centers for Disease Control. These standards represent an acceptable level of fitmess required to both maintain a healthy lifestyle and reduce preventable diseases resulting from a secentary.liteste

With regard to aerobic finess level, research has shown a significant dectease in risk of all-cause monality from gening out of the lower $20 \%$ of the population. Risk levels continue to decrease as futsess levels increase but not as dramatically as getting out of the bottom $20 \%$. Aerobic capacity standards were set to equal getring out of the lower $20 \%$ of the population.

Body fat percentages were also set by following the recommendations of curent research. Children with body fat levels above $25 \%$ for boys and $30-35 \%$ for girls, are more likely to exhibit elevated cholesterol levels and hyperiension.

All students should strive to achieve a score that places them inside the Healthy Fitness Zone. Performance above the Healthy Fitness Zone should be recognized appropriately but should not be the goal for all students. Teachers and students should work together to set realistic and individual performance goals. 
Appendix I

Student Interview Guide 


\section{Student Interview Guide}

Introduction: Your parents have given consent for you to participate in this study. But just because they gave consent doesn't mean that you must participate. It's important to me that you also agree to participate. Do you feel o.k. about participating and answering a few questions? Do you remember the questionnaires that you filled out after each fitness test during your physical education time? Well, that is what were going to talk about today. It's important that you be open and honest with your answers. Remember, I'm not here to grade you. However, I am very interested in the experiences you've had during physical education.

One Mile Walk/Run

1. How did you do on the One Mile Walk/Run test?

2. Do you know what your score was?

3. How did you feel about your score?

4. How did you feel during the test both physically and mentally?

5. What do you think about the One Mile Walk/Run test? 
Body Composition

1. How did you do on the Body Composition test?

2. Do you know what your score was?

3. How did you feel about your score?

4. How did you feel during the test both physically and mentally?

5. What do you think about the Body Composition test? 


\section{Curl-Up}

1. How did you do on the Curl-Up test?

2. Do you know what your score was?

3. How did you feel about your score?

4. How did you feel during the test both physically and mentally?

5. What do you think about the Curl-Up test? 
1. How did you do on the Trunk Lift test?

2. Do you know what your score was?

3. How did you feel about your score?

4. How did you feel during the test both physically and mentally?

5. What do you think about the Trunk Lift test? 


\section{Push-Up}

1. How did you do on the Push-Up test?

2. Do you know what your score was?

3. How did you feel about your score?

4. How did you feel during the test both physically and mentally?

5. What do you think about the Push-Up test? 


\section{Backsaver Sit and Reach}

1. How did you do on the Backsaver Sit and Reach test?

2. Do you know what your score was?

3. How did you feel about your score?

4. How did you feel during the test both physically and mentally?

5. What do you think about the Backsaver Sit and Reach test?

* Out of all six tests: One Mile Walk/Run, Body Composition, Backsaver Sit and Reach, Push-Up, Trunk Lift, and Curl-Up, which was your favorite? Why? Which was your least favorite? Why? 
Appendix J

Audiotaped Student Interview

Transcription Sample 
Introduction: Now your parents, now when you see me writing down on this sheet, I'm writing down your answers. And what I can't write as fast as what you talk, so what I don't get written down I go back and I listen to the tape and then I fill in the words that I missed. Your parents have given consent for you to participate in this study. But just because they gave consent doesn't mean that you must participate. It's important to me that you also agree to participate. Do you feel okay about answering a few questions?

Yes.

Do you remember the questionnaires that you filled out after each physical fitness test during your PE time?

Not all of them.

Okay, but you remember doing that?

Um. . um

Okay. That's what we're going to talk about today. It's important to me that you be open and honest with your answers. And remember, I'm not here to grade you. This is not a test. However, I am very interested in the experiences that you've had during physical education time. If you let us know some of the things that were not so good or some of the things that were great, then it helps us be better teachers. Okay? So that's what we're looking for. Now when I. ask you a question you can't shake your head, because then we can't get that on tape, so you have to make sure that verbally you tell me the answers.

One Mile Walk/Run

1. Now remember the One Mile Run Test? That's when you had to go around the track five-and-a-half times.

Um. . um.

How did you do on that test?

Bad.

Bad?

2. Do you know what your score was?

No.

Did you pass it or fail it?

Fail

3. Okay, how do you feel about failing it? 
Okay, I guess.

You felt okay about failing it? Did that make you feel bad because you failed it?

It. . .

It's okay. Think about it.

I felt bad a little.

Okay. And that's okay, honey.

S3 - Page Two

4. Now do you remember when you were out there running? I know it was a while ago, but try to think back to the day that you were out there and you're running. You run. . you do the track every day, so think about your body physically. When you were out there having to run five-and-ahalf laps, how did your body feel? Did you any pain anywhere or did you feel in your legs, in yout heart, in your arms? How did your body feel physically?

Bad, it burt, like on my side, on the side of my ribs.

See that's exactly... you're giving me some great answers. This is what I want to find out and know. Now did it hurt any place else?

No.

Okay. Now mentally, when you had this pain in your body and you knew you still had to go, however many more times that you had to go once you started feeling the pain, what were you thinking when you were out there?

I wasn't going to pass the test.

How did this make you feel?

Bad.

5. Now in general what do you think about that test?

I don't like it.

Okay. Why don't you like it?

Because you bave to run like five-and-a-balf-Laps and it burts most of the time when you're on your third lap.

Good answer. You've given me some very good information.

S3 - Page Three

Okay now those questions that you just answered, they are the same questions, but about the different tests. Okay?

Okgy:

So now we're going to talk about the Body Composition. That's when you came into the office and I did the pinch here and I did the pinch at your triceps muscle. 
Body Composition

1. How did you do on that test?

Um. . bad

Okay.

2. Do you know what your score was?

Fail

3. Okay, and how do you feel about that score?

Bad

How did it make you feel?

Bad

4. Okay, now when you came into the office and when I administered the test, did it hurt physically? Did you feel anything?

Yes.

Well, how did it feel?

It bur like you were taking your nails and pinching me.

I wasn't pinching you.

I know.

I know. That's a good answer, though.

Now what were you thinking when you were standing outside the door and you knew your turn was coming up? What mentally were you thinking about this?

I thought I vasn't going to pass.

How did that make you feel?

Bad.

5. Okay, now what do you think about that test? I't's a good test, it's a bad test.

It's a good test to see like how much fat you have. To see if you're like in good shape or not.

Okay, so even though you didn't pass it, you still think that it's a good test.

Um. .. um.

So you think. . um. . okay, that's a good answer.

S3-Page Four

Okay now Backsaver Sit and Reach. That was the one where we, yeah that's that one, where we had the box, you bend one leg and you reach as far as you can on the box. 


\section{Backsaver Sit and Reach}

1. How did you do on that test?

I don't remember.

Okay. Let me remind you.

I think I passed.

2. Um. . backsaver. . . you sure did pass. That's good. So you know your score was

Pass.

Pass. Okay, and how do you feel about a passing score?

Hmmm. . good.

3. So that score made you feel?

Good

Okay.

4. Now when you took that test physically how did you feel? Did you feel any pain or any stretching?

I felt like my spinal cord was going to burst.

Did you feel any other pain? So you felt pain in the back?

And when I put my legs against the thing, my legs burt because I bad to keep them down while I stretched.

It was your legs that hurt?

And my spinal cord

Okay. Now what were you thinking when you felt this pain in your back and you knew you had to reach and you were trying so hard to pass the test. What were you thinking?

I thought I was going to pass it.

So you did have a good feeling that you were going to pass it?

L'b. bub. . . because I was so close.

5. Good test, bad test, keep it, ditch it? What do you think about the test?

I like that test because it sees bow far you can stretch and it belps your spinal cord like move, bave more flexibility.

Great! Okay good. We have a couple more to go. We got three more tests to do.

\section{S3 - Page Five}

The push-up test. 


\section{Push-Up}

1. How'd you do on the Push-Up test?

Bad.

2. Do you know what your score was?

Fail

Fail.

3. And how do you feel about that score?

Bad

Okay, can you be more specific than bad?

Um. .. I thought like there was going to be. . um. . Like I wasn't. . bad because I felt like. .. I felt like I was the only one that didn't pass that test, even though I know some of my other friends didn't pass it, I guess.

I know. You're not the only one, Sweetie. That's a really hard test.

4. Um, now how did you feel physically when you were trying to push your body up off the mat?

Um. . I felt like I was going to break my arms because I couldn't push up and down more than once or three times. This has stopped turning.

When we stop talking it stops turning. It has like a sensor to it. If it hears...if it hears, picks up some sounds, it starts recording it Okay, mentally what were you thinking when you were trying so hard to push your body up?

Like I was going to burn or something.

Okay, but what were you thinking? That's physically you felt pain in your arms and then what were you thinking? I got to keep going, I have to try? Or?

I had to try.

How else did you feel during that test?

Miserable.

Okay. Couldn't wait for it to be over. So you felt miserable. How else?

That's it.

Okay.

5. Now what do you think about that test?

I think you should keep it to see how many times a person can actually lift themselves up just by using their arms and muscles.

So even though you didn't pass it, you still think that that's a good test? Um, buh.

Okay. Do you have any other thoughts about that test? 
No.

\section{S3 - Page Six}

Okay. Two more to go. The Trunk Lift was the one where you had to lay on your belly and lift up and we had the ruler in front

\section{Trunk Lift}

1. How did you do on that test?

Good I think I passed that one also.

2. Okay so you know what your score was? Uh. . you think you passed it

3. So how do you feel about the passing score?

Good since I always do that 'cause I passed last year, so I thought I could probably pass this year so I stanted practicing right when they announced it.

Okay good. Okay great!

4. Now think about that test, you were laying on the mat, you had to lift yourself up trying to get past that ruler, how did your body feel physically?

I didn't have any pain in my body, because I bad been doing it more than bradically.

Since you'd been doing it what?

More than bradically.

More than sporadically?

Sporadically. More than once in a while.

Oh, okay. I don't know that word. Girl, I'm gonna have to add that to my spelling list. I think it's sporadically. We'll have to look that up. Okay now what were you thinking mentally?

That I was going to pass the test.

Okay. Was that a good feeling or?

Um, hub. .. I had a good feeling about that.

5. Okay, now what do you think about that test?

Um. . that you should keep it because it. . um. . . tests bow much someone can lift their upper part of the body.

Okay good!

\section{S3 - Page Seven}

The last one the Curl-Up test, that's the sit-up test where you had to knees bent on the mat, hands on the mat, you had to slide your arms past the line on the edge of the mat. 


\section{Curl-Up}

1. I think I passed that one. I'm not sure.

Okay, I'll look at your score. Um. . curl up was 22 . you passed that one.

2. So how did you do on that test?

Passed.

Okay, but how'd you do? Good, bad, great?

Great!

Do you know what your score was?

Passed.

3. Okay, how do you feel about your score?

I feel good about it because I didn't know' I could actually do so many sit-ups. Now that m'

Stepmom has a machine for sit-ups, it's like. . you put your bead down on it and you push it and it makes sit-ups, so I can do more on it.

4. Okay now when you were taking that test physically how did your body feel?

Comfortable, okay. Since I was laying on a mat, not on the concrete or the grass.

Okay, did you feel any pain in your body?

Un, bub... no.

Okay, now what were you thinking when you were taking this test? Happy thoughts, bad thoughts?

Happy thoughts. I knew I was going to pass it.

Okay good.

5. Now what do you think about that test?

You should keep it because it tests bow many sit-ups one person can actually do, instead of just asking them and baving them lying to you saying they can do a million when they can't even do two.

Okay. Now do you have a favorite test and a least favorite test? Which of the tests did you like the most?

I liked the Trunk Lift.

Why'd you like that one?

Because it makes me feel comfortable, like, I know that I can lift nJ' upper part of the body bigher than I can usually lift the Lower part of my body, like a bandstand.

Which one do you like the least?

The Mile Run.

S3 - Page Eight

Why do you like that the least? 
Because you bave to run five-and-a-balf laps and sometimes most of my classmates complain if you soy to do two.

Why do you think they complain? Like, say to do two. Why do they complaint?

Because they're lavy most of the time.

Okay, any other last thoughts about any of these tests?

No.

You gave me some good answers. Very nice answers. I love these answers. This is going to help me a lot on my paper. You've probably been the most expressive in your answers. All right Veronica, thank you, Sweetie. 
VITA

JACQUELINE BECKER - BUSHA

May 11,1964

1985

1988

1990

1990 - Present

$1988-1995$

1995

1996 - Present

2003
Born, Coral Gables, Florida

A.A.

Miami-Dade Community College

Miami, Florida

B.S., Physical Education

Graduation with High Honors

Florida International University

Miami, Florida

M. S., Physical Education

Florida International University

Miami, Florida

Adjunct Instructor

Florida International University

Department of Health, Physical Education, and

Recreation

Miami, Florida

Physical Education Teacher

Bel-Aire Elementary School

Miami, Florida

Teacher of the Year

Bel-Aire Elementary School

Miami, Florida

Physical Education Teacher

Redland Elementary School

Homestead, Florida

Teacher of the Year

Redland Elementary School

Homestead, Florida 